\title{
WestVirginiaUniversity
}

THE RESEARCH REPOSITORY @ WVU

Graduate Theses, Dissertations, and Problem Reports

2000

\section{Voltage collapse prediction for interconnected power systems}

Amer S. Al-Hinai

West Virginia University

Follow this and additional works at: https://researchrepository.wvu.edu/etd

\section{Recommended Citation}

Al-Hinai, Amer S., "Voltage collapse prediction for interconnected power systems" (2000). Graduate Theses, Dissertations, and Problem Reports. 1065.

https://researchrepository.wvu.edu/etd/1065

This Thesis is protected by copyright and/or related rights. It has been brought to you by the The Research Repository @ WVU with permission from the rights-holder(s). You are free to use this Thesis in any way that is permitted by the copyright and related rights legislation that applies to your use. For other uses you must obtain permission from the rights-holder(s) directly, unless additional rights are indicated by a Creative Commons license in the record and/ or on the work itself. This Thesis has been accepted for inclusion in WVU Graduate Theses, Dissertations, and Problem Reports collection by an authorized administrator of The Research Repository @ WVU. For more information, please contact researchrepository@mail.wvu.edu. 


\title{
VOLTAGE COLLAPSE PREDICTION FOR INTERCONNECTED POWER SYSTEMS
}

\author{
Amer AL-Hinai \\ Thesis submitted to College of Engineering \\ and Mineral Resources at West Virginia University \\ in partial fulfillment of the requirements for \\ the degree of \\ Master of Science \\ In \\ Electrical Engineering \\ Muhammad A. Choudhry, Ph.D., Chair \\ Ali Feliachi, Ph.D. \\ Ronald L. Klein, Ph. D.
}

Morgantown, West Virginia

2000

Keywords: Power Systems, Voltage Collapse, Modal Analysis, Q-V Curve, Load Characteristics and Induction Machine Load. 


\title{
ABSTRACT \\ VOLTAGE COLLAPSE PREDICTION FOR INTERCONNECTED POWER SYSTEMS
}

\begin{abstract}
Amer AL-Hinai
A steady state analysis is applied to study the voltage collapse problem. The modal analysis method is used to investigate the stability of the power system. Q-V curves are used to confirm the obtained results by modal analysis method and to predict the stability margin or distance to voltage collapse based on reactive power load demand. The load characteristics are considered in this research. Different voltage dependent loads are proposed in order to be used instead of the constant load model. The effect of induction machine load is considered in this study. The load is connected to several selected buses.

The analysis is performed for three well-known system; Western System Coordinating Council (WSCC) 3-Machines 9-Bus system, IEEE 14 Bus system and IEEE 30 Bus system. The modal analysis technique is performed for all systems using the constant load model, the voltage dependent load models and induction machine load model. Then, the most critical mode is identified for each system. After that, the weakest buses, which contribute the most to the critical mode, are identified using the participation factor. The Q-V curves are generated at specific buses in order to check the results obtained by the modal analysis technique and to estimate the stability margin or distance to voltage collapse at those buses.
\end{abstract}




\section{ACKNOWLEDGEMENTS}

First I would like to express my sincere appreciation to my research advisor Prof. Muhammad Choudhary for his support and guidance of this research. I would like also to thank Prof. Ali Feliachi for his advice and direction. My thanks are extended to Prof. Ronald Kline for his suggestion and advice. My special thanks are expressed to Dr. Khaled Elithiy (Sultan Qaboos University) for helpful advice, encouragements and discussions.

Thanks are also to Sultan Qaboos University for giving me full financial support throughout my education.

Special thanks to my wife for her support, help and patience while we are away from our home

country, Oman. Finally, I would like to thank my mother, my brothers, and my sister for their help and encouragements. 


\section{DEDICATION}

To my mother,

To my brothers and my sister,

To my wife. 


\section{TABLE OF CONTENTS}

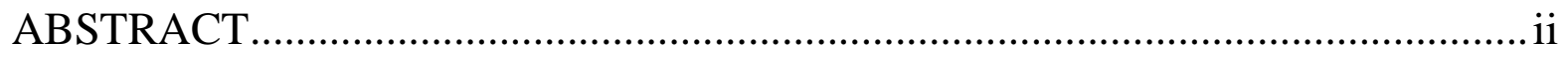

ACKNOWLEDGEMENTS..........................................................................ii

DEDICATION .................................................................................. iv

TABLE OF CONTENTS ......................................................................

LIST OF FIGURES ............................................................................ viii

LIST OF TABLES ..........................................................................

CHAPTER 1

\section{INTRODUCTION}

1.1 Introduction and Background ............................................................... 1

1.2 Scope of Thesis................................................................................ 3

\section{CHAPTER 2}

\section{LITERATURE REVIEW}

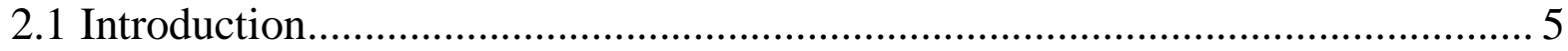

2.2 Dynamic and Steady State Analysis ......................................................... 7

2.3 Methods of Voltage Stability Analysis.................................................... 9

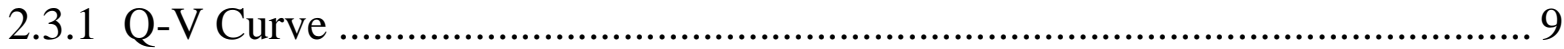

2.3.2 P-V curve .................................................................................... 10

2.3.3 Multiple Power Flow Solutions ........................................................ 11

2.3.4 Minimum Singular Value Decomposition. ......................................... 12

2.3.5 Modal or Eigenvalue Analysis Method.............................................. 12

2.4 Power Flow Problem ............................................................................. 13

\section{CHAPTER 3}

\section{METHOD OF ANALYSIS}

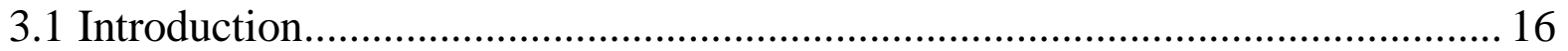

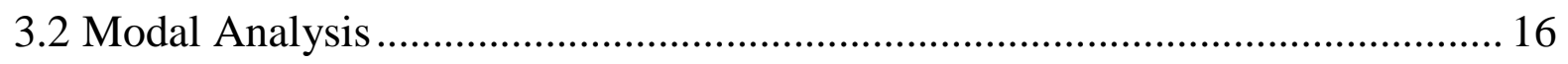

3.3 Identification of the Weak Load Buses ..................................................... 20 


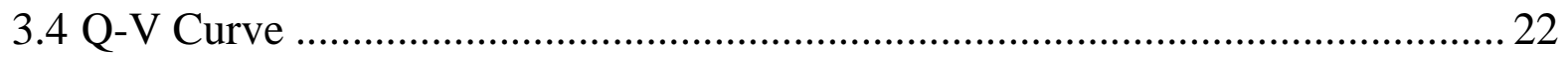

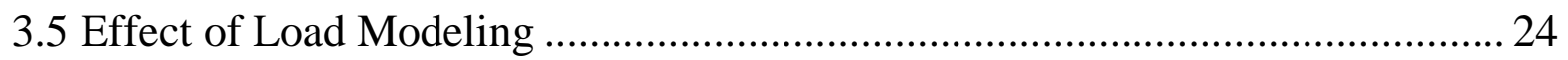

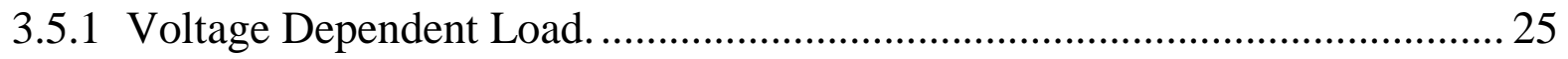

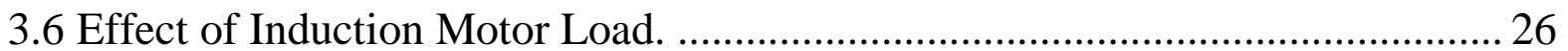

CHAPTER 4

RESULTS AND DISCUSSION

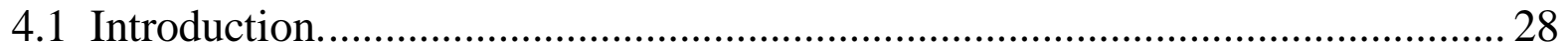

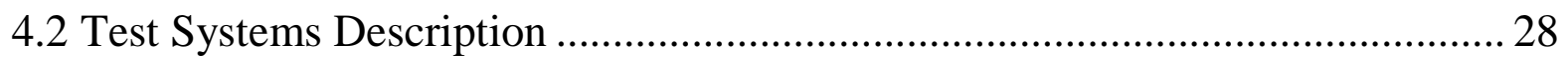

4.3 Analysis with Constant Impedance Load........................................................... 30

4.3.1 Western System Coordinating Council (WSCC) 3-Machines 9-Bus system. 30

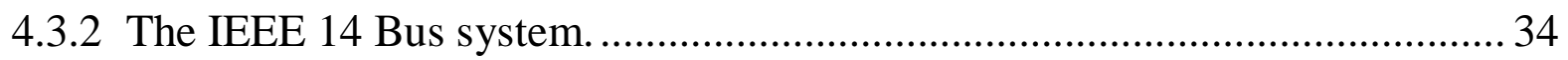

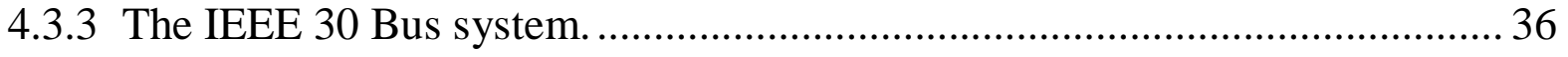

4.4 Analysis Considering Load Characteristics. ...................................................... 40

4.4.1 Western System Coordinating Council (WSCC) 3-Machines 9-Bus system. 40

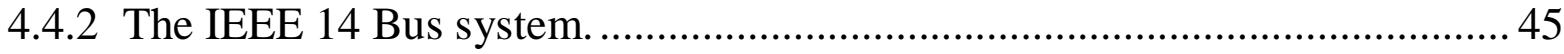

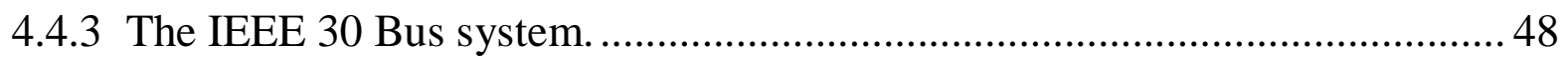

4.5 Analysis Considering Effect of Induction Machine Load.................................. 52

4.5.1 Western System Coordinating Council (WSCC) 3-Machines 9-Bus system. 53

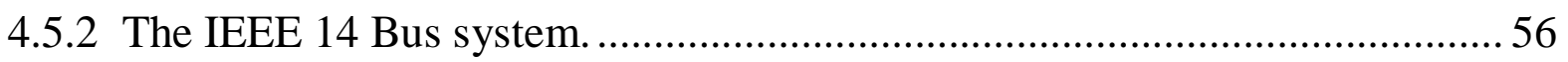

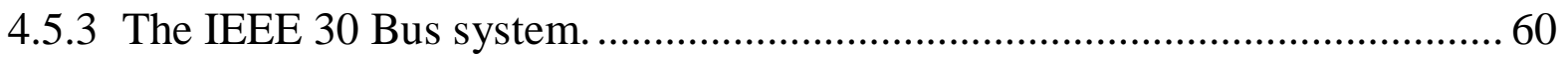

CHAPTER 5

CONCLUSION \& RECOMMENDATIONS

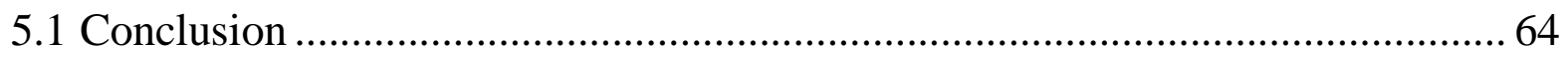

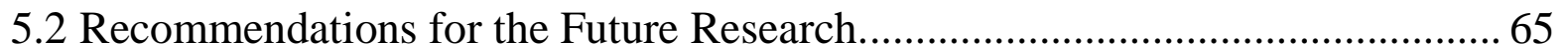

REFERENCES

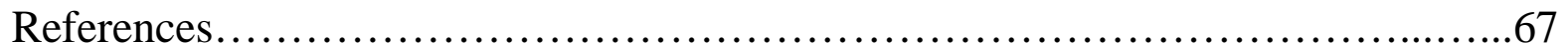




\section{APPENDIX A}

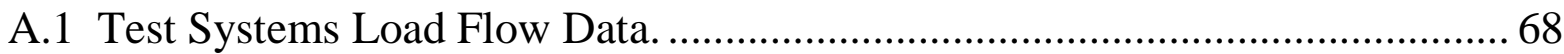

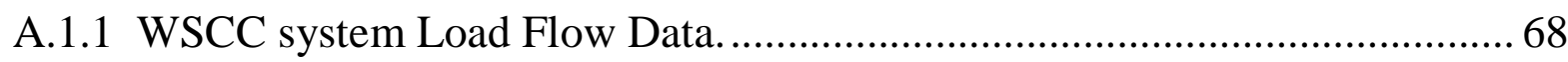

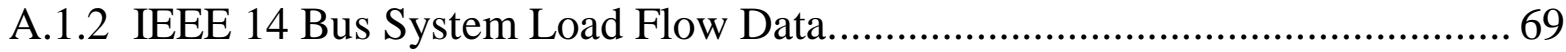

A.1.3 IEEE 30 Bus System Load Flow Data........................................................... 70

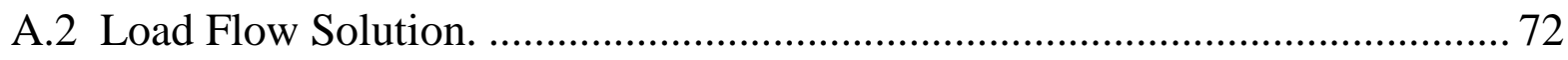

A.2.1 WSCC system Load Flow Solution with Constant Load Model..................... 72

A.2.2 IEEE 14 Bus System Load Flow Solution with Constant Load Model. ........ 73

A.2.3 IEEE 30 Bus System Load Flow Solution with Constant Load Model. ........ 74 APPENDIX B

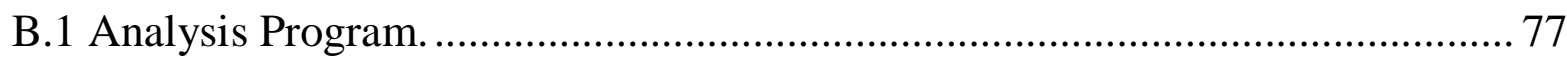

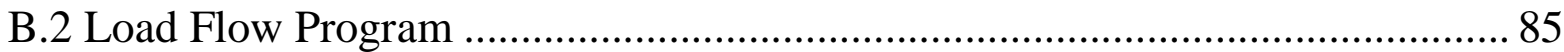




\section{LIST OF FIGURES}

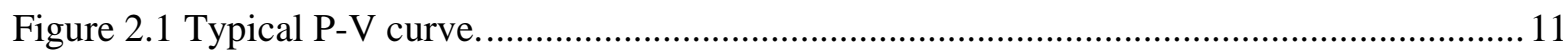

Figure 3.1 Algorithm for the voltage stability analysis............................................................ 21

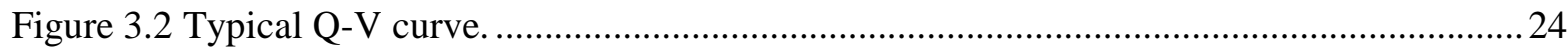

Figure 4.1 Western System Coordinating Council (WSCC) 3-Machines 9-Bus system...............29

Figure 4.2 Single line diagram of the IEEE 14 Bus System. ...................................................29

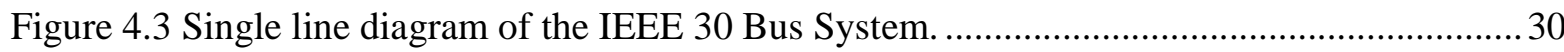

Figure 4.4 Voltage profiles of all buses of the WSCC 3-Machines 9-Bus system........................ 31

Figure 4.5 The participating factor of all buses for most critical mode for the WSCC 3-Machines

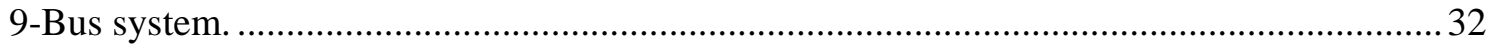

Figure 4.6 The Q-V curves at buses 5, 8 and 6 for the WSCC 3-Machines 9-Bus system. ...........33

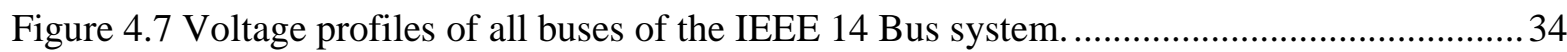

Figure 4.8 The participating factor of all buses for most critical mode for the IEEE 14 Bus system.

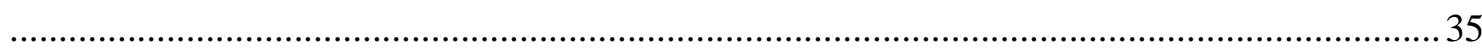

Figure 4.9 The Q-V curves at buses 9, 10 and 14 for the IEEE 14 Bus system. ..........................36

Figure 4.10 Voltage profiles of all buses of the IEEE 30 Bus system.........................................37

Figure 4.11 The participating factor of all buses for most critical mode for the IEEE 30 Bus

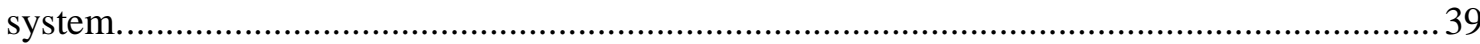

Figure 4.12 The Q-V curves at buses 30, 29 and 26 for the IEEE 30 Bus system. ......................39

Figure 4.13 Voltage profiles of all buses of the WSCC 3-Machines 9-Bus system at different load models.

Figure 4.14 The participating factor of all buses for most critical modes for the WSCC 3-Machines

9-Bus system at different load models.

Figure 4.15 The Q-V curves at bus 5 for the WSCC 3-Machines 9-Bus system at different load models.

Figure 4.16 The Q-V curves at bus 6 for the WSCC 3-Machines 9-Bus system at different load models.

Figure 4.17 The Q-V curves at bus 5 for the WSCC 3-Machines 9-Bus system at different load models (Unstable system).

Figure 4.18 The Q-V curves at bus 6 for the WSCC 3-Machines 9-Bus system at different load models (Unstable system). 
Figure 4.19 Voltage profiles of all buses of the IEEE 14 Bus system at different load's models...46 Figure 4.20 The participating factor of all buses for most critical modes for the IEEE 14 Bus system at different load's models .47

Figure 4.21 The Q-V curves at bus 14 for the IEEE 14 Bus system at different load's models...... 47 Figure 4.22 The Q-V curves at bus 14 for the IEEE 14 Bus system at different load models (Unstable system) 48

Figure 4.23 Voltage profiles of all buses of the IEEE 30 Bus system at different types of load models. 50

Figure 4.24 The participating factor of all buses for most critical modes for the IEEE 30 Bus at different types of load models. 50

Figure 4.25 The Q-V curves at bus 30 for the IEEE 30 Bus system at different types of load.......51

Figure 4.26 The Q-V curves at bus 30 for the IEEE 30 Bus system at different load's models (Unstable system) .52

Figure 4.27 Voltage profiles of all buses of the WSCC 3-Machines 9-Bus system including Induction machine load at bus \# 5 . 53

Figure 4.28 The participating factor of all buses for the most critical modes for the WSCC 3-

Machines 9-Bus system at different load models at bus \# 5. .54

Figure 4.29 The Q-V curves at bus 5 for the WSCC 3-Machines 9-Bus system at different load models at bus\# 5 . 55

Figure 4.30 The Q-V curves of bus \# 5 for the WSCC 3-Machines 9-Bus system at different induction machine load models (Unstable system). .56

Figure 4.31 Voltage profiles of all buses of the IEEE 14 Bus system including Induction machine load at bus \# 14.

Figure 4.32 The participating factor of all buses for most critical modes for the IEEE 14 Bus System at different load's models in bus \# 14. .58

Figure 4.33 The Q-V curves at bus \# 14 for the IEEE 14 Bus System at different load's models in bus \# 14. .59

Figure 4.34 The Q-V curves of bus \# 14 for the IEEE 14 Bus system at different induction machine load's models at bus \# 14 (Unstable system). .59

Figure 4.35 Voltage profiles of all buses of the IEEE 30 Bus system including Induction machine load at bus \# 30 . 
Figure 4.36 The participating factor of all buses for most critical modes for the IEEE 30 Bus

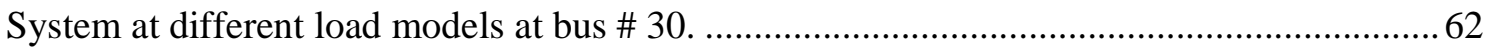

Figure 4.37 The Q-V curves at bus \# 30 for the IEEE 30 Bus System at different load's models in bus \# 30.

Figure 4.38 The Q-V curves of bus \# 30 for the IEEE 30 Bus system at different induction machine load models at bus \# 30 (Unstable system). 


\section{LIST OF TABLES}

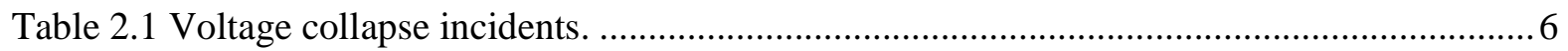

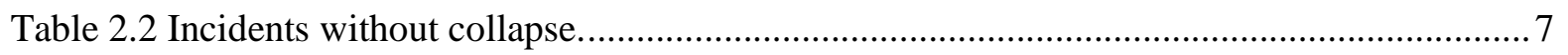

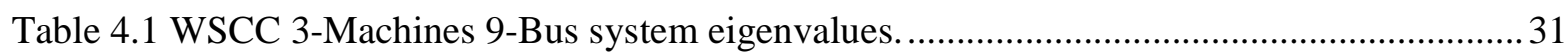

Table 4.2 Voltage and reactive power margins for the WSCC 3-Machines 9-Bus system from Q-V

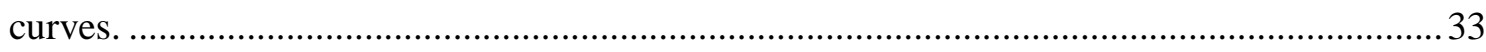

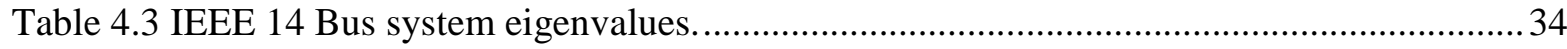

Table 4.4 Voltage and reactive power margins for the IEEE 14 Bus system from Q-V curves......36

Table 4.5 IEEE 30 Bus system eigenvalues sorted by ascending values.....................................38

Table 4.6 Voltage and reactive power margins for the IEEE 30 Bus system from Q-V curves...... 38

Table 4.7 WSCC 3-Machines 9-Bus system eigenvalues at different np and nq values................ 40

Table 4.8 Voltage and reactive power margins for the WSCC system from Q-V curves for bus \# 5.

Table 4.9 Voltage and reactive power margins for the WSCC system from Q-V curves for bus \# 6.

Table 4.10 IEEE 14 Bus system eigenvalues at different $\mathrm{np}$ and nq values. 45

Table 4.11 Voltage and reactive power margins for the IEEE 14 Bus system from Q-V curves for bus \# 14. 48

Table 4.12 IEEE 30 Bus system eigenvalues at different $n p$ and nq values. 49

Table 4.13 Voltage and reactive power margins for the IEEE 30 Bus system from Q-V curves for

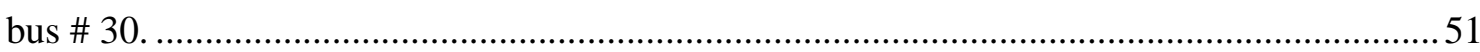

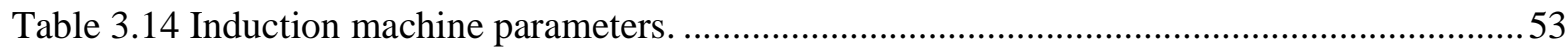

Table 4.15 WSCC 3-Machines 9-Bus system eigenvalues at different loads in bus \# 5................54

Table 4.16 Voltage and reactive power margins for the WSCC system from Q-V curves for bus\# 5. 55

Table 4.17 IEEE 14 Bus system eigenvalues at different loads at bus \# 14 .................................57

Table 4.18 Voltage and reactive power margins for the IEEE 14 Bus system from Q-V curves for

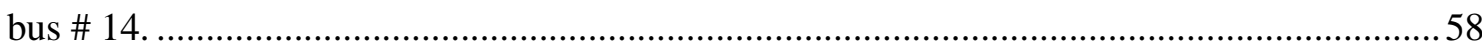

Table 4.19 IEEE 30 Bus system eigenvalues at different loads at bus \# 30 ................................. 61 
Table 4.20 Voltage and reactive power margins for the IEEE 30 Bus system from Q-V curves for

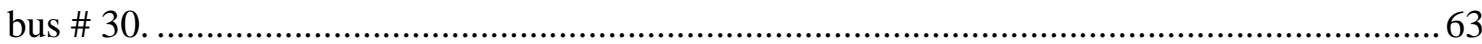




\section{CHAPTER 1}

\section{INTRODUCTION}

\subsection{Introduction and Background}

Voltage collapse problem has been one of the major problems facing the electric power utilities in many countries. The problem is also a main concern in power system operation and planning. It can be characterized by a continuous decrease of the system voltage. In the initial stage the decrease of the system voltage starts gradually and then decreases rapidly. The following can be considered the main contributing factors to the problem [22]:

1. Stressed power system; i.e. high active power loading in the system.

2. Inadequate reactive power resources.

3. Load characteristics at low voltage magnitudes and their difference from those traditionally used in stability studies.

4. Transformers tap changer responding to decreasing voltage magnitudes at the load buses.

5. Unexpected and or unwanted relay operation may occur during conditions with decreased voltage magnitudes.

This problem is a dynamic phenomenon and transient stability simulation may be used. However, such simulations do not readily provide sensitivity information or the degree of stability. They are also time consuming in terms of computers and engineering effort required for analysis of results. The problem regularly requires inspection of a wide range of system conditions and a large number of contingencies. For such application, the steady state analysis approach is much more suitable and can provide much insight into the voltage and reactive power loads problem [20] and [13]. 


\section{CHAPTER 1 INTRODUCTION}

So, there is a requirement to have an analytical method, which can predict the voltage collapse problem in a power system. As a result, considerable attention has been given to this problem by many power system researchers. A number of techniques have been proposed in the literature for the analysis of this problem [5].

The problem of reactive power and voltage control is well known and is considered by many researchers. It is known that to maintain an acceptable system voltage profile, a sufficient reactive support at appropriate locations must be found. Nevertheless, maintaining a good voltage profile does not automatically guarantee voltage stability. On the other hand, low voltage although frequently associated with voltage instability is not necessarily its cause [15] and [32].

In 1992 Geo, Morison and Kundur proposed the Modal analysis technique to predict the voltage collapse of a power system. The method basically computes the smallest eigenvalue and associated eigenvectors of the reduced Jacobian matrix of the power system based on the steady state system model. The eigenvalues are associated with a mode of voltage and reactive power variation. The system stability can be evaluated by checking the status of those eigenvalues. If all the eigenvalues are positive, then the system is considered to be voltage stable. On the other hand, the system is considered to be voltage unstable if only one of the eigenvalues is negative. A zero eigenvalue of the reduced Jacobian matrix means that the system is on the border of voltage instability. The potential voltage collapse situation of a stable system can be predicted through the evaluation of the minimum positive eigenvalues. The magnitude of each minimum eigenvalue provides a measure how close the system is to voltage collapse.

By using the participation factor, the weakest bus or node can be determined which is the greatest

contributing factor for a system to reach voltage collapse situation. This can provide insight into possible remedial action as well as contingencies, which may result in losing the system. 


\section{CHAPTER 1 INTRODUCTION}

Q-V curve is a general method used by many utilities to assess the voltage stability. It can be used to determine proximity to voltage collapse since it directly assesses shortage of reactive power. The curves mainly show the sensitivity and variation of bus voltage with respect to reactive power injection. Using the Q-V curves, the stability margin or distance to voltage collapse at a specific bus can be evaluated.

It is common in steady state analysis to represent the loads by a combination of constant impedance, constant current and constant power elements. However, it is found that voltage stability analysis is affected by considering the load characteristics. The importance of proper representation of loads in power system stability studies has been noticed clearly.

The induction machine is one of the most important loads in a power system especially in the industrial area. It has been found that, such load can influence the system voltage stability in a wide range. As a result, considerable attention has been taken by many power system researchers regarding this load.

\subsection{Scope of Thesis.}

In chapter 2, a literature review is presented, discussing the voltage collapse problem in an electric power system. Many voltage instability incidents have occurred around the world. Lists of incidents resulting in voltage collapse and not resulting in voltage collapse are presented. Then, a number of related published techniques have been discussed briefly.

In chapter 3 , the modal or eigenvalue analysis technique is discussed. The method is used to provide a relative measure of proximity to voltage instability. The load characteristics are also discussed in this chapter. A voltage dependent load model is proposed to be used for the analysis. In addition, the induction machine load model effect is considered. The model is derived from the steady state equivalent circuit of induction machine. The active and reactive powers consumed by the induction motor are function of the bus voltage and machine slip. 


\section{CHAPTER 1 INTRODUCTION}

In chapter 4, the research results are presented. First, the analysis is applied using the constant load model. Then, different voltage dependent load models are applied and the results analyzed. After that, the induction machine load model is connected to selected buses in the systems. The preceding analyses is applied with the new load model.

In chapter 5, the research conclusion is presented and the recommendations are made for further work. 


\section{CHAPTER 2}

\section{LITERATURE REVIEW}

\section{$2.1 \quad$ Introduction}

Recently, increased attention has been devoted to the voltage instability phenomenon in power systems. Voltage stability is concerned with the ability of a power system to maintain acceptable voltage level at all nodes in the system under normal and contingent conditions. A power system is said to have a situation of voltage instability when a disturbance causes a progressive and uncontrollable decrease in voltage level. The voltage instability progress is usually caused by a disturbance or change in operating conditions, which create increased demand for reactive power [9] and [30]. This increase in electric power demand makes the power system work close to their limit conditions such as high line current, low voltage level and relatively high power angle

differences which indicate the system is operating under heavy loading conditions. Such a situation may cause losing system stability, islanding or voltage collapse.

The main problem facing many utilities in maintaining adequate voltage level is economic. They are squeezing the maximum possible capacity for their bulk transmission network to avoid the cost of building new lines and generation facilities. When a bulk transmission network is operated close to the voltage instability limit, it becomes difficult to control the reactive power margin for that system. As a result the system stability becomes one of the major concerns and an appropriate way must be found to monitor the system and avoid system collapse [33].

One of the major reasons of voltage collapse is the heavy loading of the power system, which is comprised of long transmission lines. The system appears unable to supply the reactive power demand. Producing the demanded reactive power through synchronous generators, synchronous condensers or static capacitors, can overtake the problem [7]. Another solution is to build 
Table 2.1 Voltage collapse incidents.

\begin{tabular}{|c|c|c|}
\hline Date & Location & Duration \\
\hline 13April1986 & $\begin{array}{c}\text { Winnipeg, Canada } \\
\text { Nelson River HVDC link }\end{array}$ & 1 second \\
\hline 30Nov.1986 & SE Brazil, Paraguay & 2 seconds \\
\hline 17May1985 & South Florida & 4 seconds \\
\hline 22Aug.1987 & Western Tennessee & 10 seconds \\
\hline 27Dec.1983 & Sweden & 55 seconds \\
\hline 21May1983 & Northern California & 2 minutes \\
\hline 2Sep.1982 & Florida & $1-3$ minutes \\
\hline 26Nov.1982 & Florida & $1-3$ minutes \\
\hline 28Dec.1982 & Florida & $1-3$ minutes \\
\hline 30Dec.1982 & Florida & 1-3 minutes \\
\hline 22Sep.1977 & Jacksonville, Florida & Few minutes \\
\hline 4Aug.1982 & Belgium & 4.5 minutes \\
\hline 20May1986 & England & 5 minutes \\
\hline 12Jan.1987 & Western France & 6-7 minutes \\
\hline 9Dec.1965 & Brittany, France & Unknown \\
\hline 10Nov.1976 & Brittany, France & Unknown \\
\hline 23July1987 & Tokyo & 20 minutes \\
\hline 19Dec.1978 & France & 26 minutes \\
\hline 22Aug.1970 & Japan & 30 minutes \\
\hline 22Sep.1970 & New York State & Several hours \\
\hline 20July1987 & Illinois and Indiana & Hours \\
\hline 11June1984 & Northeast United States & Hours \\
\hline
\end{tabular}

transmission lines to the weakest nodes. Voltage collapse may occur due to a major disturbance in the system such as generators outage or lines outage. In such a situation a protection system and proper control may resolve the problem. 
Many voltage collapse incidents have occurred throughout the world as shown in Table 2.1 and Table $2.2[1]$.

Table 2.2 Incidents without collapse.

\begin{tabular}{|c|c|c|}
\hline Date & Location & Duration \\
\hline 17,20,21May1986 & $\begin{array}{l}\text { Miles City, Montana, USA } \\
\text { HVDC link }\end{array}$ & Transient, 1-2 second \\
\hline 11,30,31July1987 & Mississippi, USA & Transient, $1-2$ seconds \\
\hline 11July1989 & South Carolina, USA & Unknown \\
\hline 21May 1983 & North California, USA & Longer term, 2 minutes \\
\hline 10Aug.1981 & Longview, Wash., USA & Longer term, minutes \\
\hline 17Sept.1981 & Central Oregon, USA & Longer term, minutes \\
\hline 20May 1986 & England & Longer term, 5minutes \\
\hline 2Mar.1979 & Zealand, Denmark & Longer term, 15 minutes \\
\hline 3Feb.1990 & Western France & Longer term, minutes \\
\hline Nov.1990 & Western France & Longer term, minutes \\
\hline 22Sept.1970 & New York state, USA & $\begin{array}{l}\text { Longer term, minutes insecure } \\
\text { for hours }\end{array}$ \\
\hline 20July 1987 & Illinois and Indiana, USA & $\begin{array}{l}\text { Longer term, minutes insecure } \\
\text { for hours }\end{array}$ \\
\hline 11June1984 & Northeast USA & $\begin{array}{l}\text { Longer term, minutes insecure } \\
\text { for hours }\end{array}$ \\
\hline 5July1990 & $\begin{array}{c}\text { Baltimore, Washington D.C, } \\
\text { USA }\end{array}$ & $\begin{array}{l}\text { Longer term, minutes insecure } \\
\text { for hours }\end{array}$ \\
\hline
\end{tabular}

\subsection{Dynamic and Steady State Analysis}

Voltage stability analysis involves both steady state and dynamic aspects [21]. Researchers have used both approaches. The Steady State or Static Methods mainly depend on the steady state model in the analysis, such as power flow model or a linearized dynamic model described by the steady state operation. These methods can be divided into [1], [34] and [12]:

1. Load flow feasibility methods, which depend on the existence of an acceptable voltage profile across the network. This approach is concerned with the maximum power transfer 


\section{CHAPTER 2 LITERATURE REVIEW}

capability of the network or the existence of a solved load flow case. There are many criteria proposed under this approach. Some of these criteria are the following:

- The reactive power capability (Q-V curve).

- $\quad$ Maximum power transfer limit (P-V curve).

- Voltage instability proximity index or the load flow feasibility index (LFF index).

2. Steady state stability methods, which test the existence of a stable equilibrium operating point of the power system. Some of the criteria proposed under this approach are:

- Eigenvalues of linearized dynamic equations (ELD).

- Singular value of Jacobian matrix (SVJ).

- Sensitivity matrices.

It is well known that voltage stability is indeed a dynamic phenomenon. The dynamic analysis implies the use of a model characterized by nonlinear differential and algebraic equations which include generators dynamics, induction motor loads, tap changing transformers, etc... through transient stability simulations. However, such simulations do not readily provide sensitivity information or the degree of stability. They are also time consuming in terms of computers speed and engineering required for analysis of results. Therefore, the dynamic simulation applications are limited to investigation of specific voltage collapse situations, which include fast or transient voltage collapse. Also, it is used for coordination of protection systems and controls.

On the other hand, voltage stability analysis regularly requires inspection of a wide range of the system conditions and a large number of contingency circumstances. Therefore, the approach based on steady state analysis is more attractive. It can provide excellent analysis as to the voltage stability problem [20]. 
CHAPTER 2 LITERATURE REVIEW

\subsection{Methods of Voltage Stability Analysis}

Many algorithms have been proposed in the literature for voltage stability analysis. Most of the utilities have a tendency to depend regularly on conventional load flows for such analysis. Some of the proposed methods are concerned with voltage instability analysis under small perturbations in system load parameters. The analysis of voltage stability, for planning and operation of a power system, involves the examination of two main aspects:

1. How close the system is to voltage instability (i.e. Proximity).

2. When voltage instability occurs, the key contributing factors such as the weak buses, area involved in collapse and generators and lines participating in the collapse are of interest (i.e. Mechanism of voltage collapse).

Proximity can provide information regarding voltage security while the mechanism gives useful information for operating plans and system modifications that can be implemented to avoid the voltage collapse.

Many techniques have been proposed in the literature for evaluating and predicting voltage stability using steady state analysis methods. Some of these techniques are P-V curves, Q-V curves, modal analysis, minimum singular value [8] and [14], sensitivity analysis [23], reactive power optimization [32], artificial neural networks [26], neuro-fuzzy networks [27], reduced Jacobian determinant, Energy function methods [24] and [25], thevenin and load impedance indicator and loading margin by multiple power-flow solutions. Some of these methods will be discussed briefly as follow.

\subsubsection{Q-V Curve}

Q-V curve technique is a general method of evaluating voltage stability [16]. It mainly presents the sensitivity and variation of bus voltages with respect to the reactive power injection. Q-V curves are used by many utilities for determining proximity to voltage collapse so that operators can make 
CHAPTER 2 LITERATURE REVIEW

a good decision to avoid losing system stability. In other words, by using Q-V curves, it is possible for the operators and the planners to know what is the maximum reactive power that can be achieved or added to the weakest bus before reaching minimum voltage limit or voltage instability. Furthermore, the calculated Mvar margins could relate to the size of shunt capacitor or static var compensation in the load area [17]. This method is discussed in more details in chapter 3.

\subsubsection{P-V curve}

The P-V curves, active power-voltage curve, are the most widely used method of predicting voltage security. They are used to determine the MW distance from the operating point to the critical voltage. A typical P-V curve is shown in Figure 2.1. Consider a single, constant power load connected through a transmission line to an infinite-bus. Let us consider the solution to the power flow equations, where $\mathrm{P}$, the real power of the load, is taken as a parameter that is slowly varied, and V is the voltage of the load bus. It is obvious that three regions can be related to the parameter P. In the first region, the power flow has two distinct solutions for each choice of P; one is the desired stable voltage and the other is the unstable voltage. As P is increased, the system enters the second region, where the two solutions intersect to form one solution for $\mathrm{P}$, which is the maximum. If $\mathrm{P}$ is further increased, the power flow equations fail to have a solution. This process can be viewed as a bifurcation of the power flow problem. In a large-scale power system the conventional parametric studies are computationally prohibitive.

The method of maximum power transfer by Barbier [35] determines critical limits on the load bus voltages, above which the system maintains steady-state operation. These limits are evaluated using a formula, which is an extension of the formula for the maximum power transfer limit of a transmission line connected by two buses. 


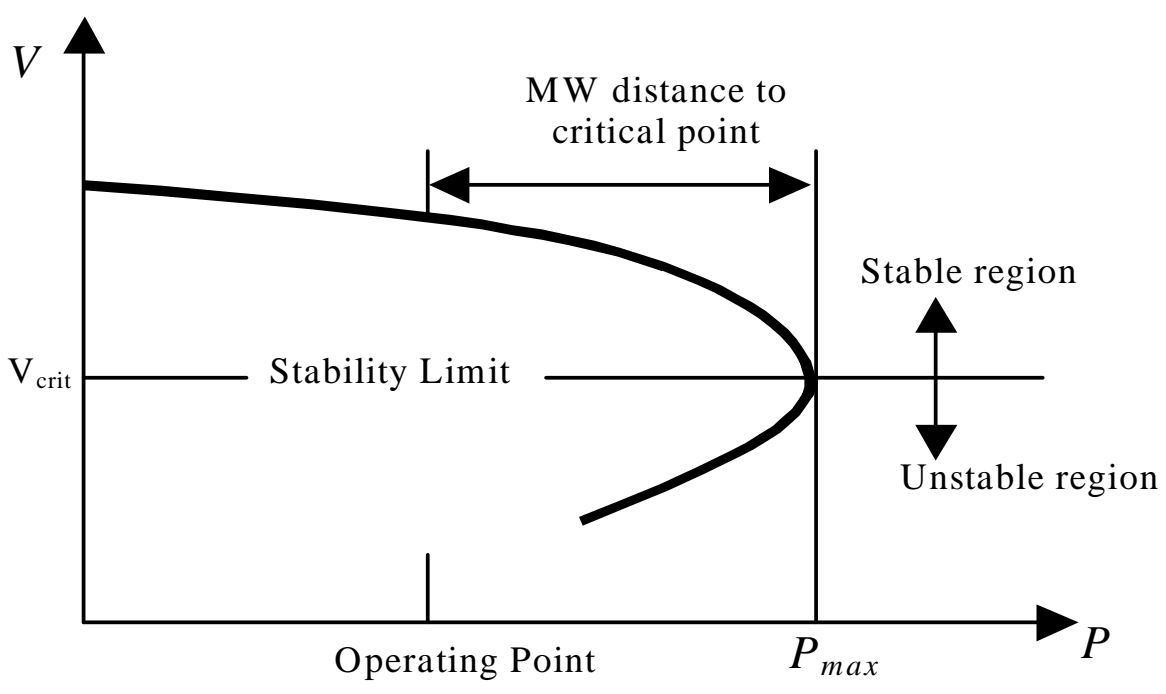

Figure 2.1 Typical P-V curve.

The most famous P-V curve is drawn for the load bus and the maximum transmissible power is calculated. It has been observed that the maximum transmissible power increases when power factor is leading, i.e. load compensation increases. Each value of the transmissible power corresponds a value of the voltage at the bus until $\mathrm{V}=\mathrm{V}_{\text {crit }}$ after which further increase in power results in deterioration of bus voltage. The top portion of the curve is acceptable operation whereas the bottom half is considered to be the worsening operation. The risk of voltage collapse is much lower if the bus voltage is further away, by an upper value, from the critical voltage corresponding to $\mathrm{P}_{\max }$.

\subsubsection{Multiple Power Flow Solutions}

In the method of multiple power flow solutions by Tamura [10], a matrix criterion is used to assess the load power-flow feasibility and to check whether some sensitivity matrix, which is derived from the Jacobian matrix of the steady-state model, satisfies certain matrix properties. Tamura used this approach as one of the three criteria to determine the load power-flow feasibility of multiple solutions to the steady-state model. Their sensitivity matrix relates the sensitivities of the 
CHAPTER 2 LITERATURE REVIEW

dependant variables (voltage magnitude at the PV-bus and reactive injection at the PQ-bus). The sensitivity matrix is evaluated at a known stable equilibrium solution and at each of the multiple solutions. The corresponding sign of the elements of the matrices are compared to ascertain which of the multiple solutions is stable. Instability is said to appear when two closely located multiple solutions are either both unstable or one is stable and the other is unstable. The three criteria suggested by the authors can be obtained by additional calculations during load power-flow calculations.

\subsubsection{Minimum Singular Value Decomposition.}

The main idea of the methods presented by Thomas and Lof [36], [22] and [4] discuses "How close is the Jacobian matrix to being singular"? One issue with this index is that it does not indicate how far in Mvars it is to the bifurcation point (singular Jacobian value). However, distance in Mvars can be approximated if the linearity of the index as a function of parameters could be proved. The more important use of the index is the relationship it provides for control. That is, if VAR compensation through capacitors, excitation control or other means is available, the index provides the answer to the problem of how to distribute the resource throughout the system for maximum benefit. A disadvantage of using the minimum singular value index is the large amount of CPU time required in performing singular value decomposition for a large matrix.

\subsubsection{Modal or Eigenvalue Analysis Method.}

Gao, Morison and Kundur [20] proposed this method in 1992. It can predict voltage collapse in complex power system networks. It involves mainly the computing of the smallest eigenvalues and associated eigenvectors of the reduced Jacobian matrix obtained from the load flow solution. The eigenvalues are associated with a mode of voltage and reactive power variation, which can provide a relative measure of proximity to voltage instability. Then, the participation factor can be used 
CHAPTER 2 LITERATURE REVIEW

effectively to find out the weakest nodes or buses in the system. A detailed discussion of this method is presented in chapter 3 .

\subsection{Power Flow Problem}

The power flow or load flow is widely used in power system analysis. It plays a major role in planning the future expansion of the power system as well as helping to run existing systems to run in the best possible way. The network load flow solution techniques are used for steady state and dynamic analysis programs [2] and [3].

The solution of power flow predicts what the electrical state of the network will be when it is subject to a specified loading condition. The result of the power flow is the voltage magnitude and the angle at each of the system nodes. These bus voltage magnitudes and angles are defined as the system state variables. That is because they allow all other system quantities to be computed such

as real and reactive power flows, current flows, voltage drops, power losses etc.... Power flow solution is closely associated with voltage stability analysis. It is an essential tool for voltage stability evaluation. Much of the research on voltage stability deals with the power-flow computation method.

The power-flow problem solves the complex matrix equation:

$$
I=Y V=\frac{S^{*}}{V^{*}}
$$

where,

$\mathrm{I}=$ nodal current injection matrix.

$\mathrm{Y}=$ system nodal admittance matrix.

$\mathrm{V}=$ unknown complex node voltage vector.

$\mathrm{S}=$ apparent power nodal injection vector representing specified load and generation at nodes where, 


$$
S=P+j Q
$$

The Newton-Raphson method is the most general and reliable algorithm to solve the power-flow problem. It involves iterations based on successive linearization using the first term of Taylor expansion of the equation to be solved. From Equation (2.1), we can write the equation for node $k$ (bus $k$ ) as:

$$
I_{k}=\sum_{m=1}^{n} Y_{k m} V_{m}
$$

where:

$\mathrm{n}=$ number of buses.

$$
P_{k}-j Q_{k}=V_{k}^{*} I_{k}=V_{k}^{*} \sum_{m=1}^{n} Y_{k m} V_{m}
$$

With the following notation:

$$
V_{k}=V_{k} e^{j \theta_{k}}, V_{m}=V_{m} e^{j \theta_{m}}, Y_{k m}=Y_{k m} e^{j \gamma_{k m}}
$$

Equation (2.4) becomes:

$$
P_{k}+j Q_{k}=\sum_{m=1}^{n} Y_{k m} V_{k} V_{m} \cos \left(\theta_{k}-\theta_{m}-\gamma_{k m}\right)+j \sum_{m=1}^{n} Y_{k m} V_{k} V_{m} \sin \left(\theta_{k}-\theta_{m}-\gamma_{k m}\right)
$$

The mismatch power at bus $\mathrm{k}$ is given by:

$$
\begin{gathered}
\Delta P_{k}=P_{k}^{s c h}-P_{k} \\
\Delta Q_{k}=Q_{k}^{s c h}-Q_{k}
\end{gathered}
$$

The $P_{k}$ and $Q_{k}$ are calculated from Equation (2.6).

The Newton-Raphson method solves the partitioned matrix equation:

$$
\left[\begin{array}{l}
\Delta P \\
\Delta Q
\end{array}\right]=J\left[\begin{array}{l}
\Delta \theta \\
\Delta V
\end{array}\right]
$$


where,

$\Delta \mathrm{P}$ and $\Delta \mathrm{Q}=$ mismatch active and reactive power vectors.

$\Delta \mathrm{V}$ and $\Delta \theta=$ unknown voltage magnitude and angle correction vectors.

$\mathrm{J}=\mathrm{Jacobian}$ matrix of partial derivative terms calculated from Equation (2.6)

Let $\quad Y_{k m}=G_{k m}+j B_{k m}$

The Jacobian matrix can be obtained by taking the partial derivatives of Equation (2.6) as follow:

$$
\begin{gathered}
\frac{\partial P_{k}}{\partial \theta_{m}}=V_{k} V_{m}\left(G_{k m} \sin \theta_{k m}-B_{k m} \cos \theta_{k m}\right) \\
V_{m} \frac{\partial P_{k}}{\partial V_{m}}=V_{k} V_{m}\left(G_{k m} \cos \theta_{k m}+B_{k m} \sin \theta_{k m}\right) \\
\frac{\partial Q_{k}}{\partial \theta_{m}}=-V_{m} \frac{\partial P_{k}}{\partial V_{m}} \\
V_{m} \frac{\partial Q_{k}}{\partial V_{m}}=\frac{\partial P_{k}}{\partial \theta_{m}} \\
\frac{\partial P_{k}}{\partial \theta_{k}}=-Q_{k}-B_{k k} V_{k}^{2} \\
\frac{\partial P_{k}}{\partial V_{k}}=P_{k}+G_{k k} V_{k}^{2} \\
\frac{\partial Q_{k}}{\partial \theta_{k}}=P_{k}-G_{k k} V_{k}^{2} \\
V_{k} \frac{\partial Q_{k}}{\partial V_{k}}=Q_{k}-B_{k k} V_{k}^{2}
\end{gathered}
$$

Then,

$$
J=\left[\begin{array}{ll}
\frac{\partial P_{k}}{\partial \theta} & \frac{\partial P_{k}}{\partial V} \\
\frac{\partial Q_{k}}{\partial \theta} & \frac{\partial Q_{k}}{\partial V}
\end{array}\right]
$$




\section{CHAPTER 3}

\section{METHOD OF ANALYSIS}

\subsection{Introduction}

It is important to have an analytical method to predict the voltage collapse in the power system, particularly with a complex and large one. The modal analysis or eigenvalue analysis can be used effectively as a powerful analytical tool to verify both proximity and mechanism of voltage instability. It involves the calculation of a small number of eigenvalues and related eigenvectors of a reduced Jacobian matrix. However, by using the reduced Jacobian matrix the focus is on the voltage and the reactive power characteristics. The weak modes (weak buses) of the system can be identified from the system reactive power variation sensitivity to incremental change in bus voltage magnitude. The stability margin or distance to voltage collapse can be estimated by generating the Q-V curves for that particular bus. Load characteristics have been found to have significant effect on power system stability. A simplified voltage dependent real and reactive power load model is used to figure out that effect. Induction machine is one of the important power system loads. It influences the system voltage stability especially when large amount of such load is installed in the system. The steady state induction machine load model is considered in this study.

\subsection{Modal Analysis}

The modal analysis mainly depends on the power-flow Jacobian matrix. An algorithm for the modal method analysis used in this study is shown in figure 3.1 .

Equation (2.9) can be rewritten as: 


$$
\left[\begin{array}{l}
\Delta P \\
\Delta Q
\end{array}\right]=\left[\begin{array}{l}
J_{11} J_{12} \\
J_{21} J_{22}
\end{array}\right]\left[\begin{array}{c}
\Delta \theta \\
\Delta V
\end{array}\right]
$$

By letting $\Delta P=0$ in Equation (3.1):

$$
\Delta P=0=J_{11} \Delta \theta+J_{12} \Delta V, \quad \Delta \theta=-J_{11}^{-1} J_{12} \Delta V
$$

and

$$
\Delta Q=J_{21} \Delta \theta+J_{22} \Delta V
$$

Substituting Equation (3.2) in Equation (3.3):

$$
\Delta Q=J_{R} \Delta V
$$

where

$$
J_{R}=\left[J_{22}-J_{21} J_{11}^{-1} J_{12}\right]
$$

$J_{R}$ is the reduced Jacobian matrix of the system.

Equation (3.4) can be written as

$$
\Delta V=J_{R}^{-1} \Delta Q
$$

The matrix $J_{R}$ represents the linearized relationship between the incremental changes in bus voltage $(\Delta V)$ and bus reactive power injection $(\Delta Q)$. It's well known that, the system voltage is affected by both real and reactive power variations. In order to focus the study of the reactive demand and supply problem of the system as well as minimize computational effort by reducing dimensions of the Jacobian matrix $J$ the real power $(\Delta P=0)$ and angle part from the system in Equation (3.1) are eliminated.

The eigenvalues and eigenvectors of the reduced order Jacobian matrix $J_{R}$ are used for the voltage stability characteristics analysis. Voltage instability can be detected by identifying modes of the eigenvalues matrix $J_{R}$. The magnitude of the eigenvalues provides a relative measure of proximity 


\section{CHAPTER 3 METHOD OF ANALYSIS}

to instability. The eigenvectors on the other hand present information related to the mechanism of loss of voltage stability.

Eigenvalue analysis of $J_{R}$ results in the following:

where

$$
J_{R}=\Phi \Lambda \Gamma
$$

$$
\begin{aligned}
& \Phi=\text { right eigenvector matrix of } J_{R} \\
& \Gamma=\text { left eigenvector matrix of } J_{R} \\
& \Lambda=\text { diagonal eigenvalue matrix of } J_{R}
\end{aligned}
$$

Equation (3.6) can be written as:

Where $\Phi \Gamma=I$

$$
J_{R}^{-1}=\Phi \Lambda^{-1} \Gamma
$$

Substituting Equation (3.7) in Equation (3.5):

$$
\Delta V=\Phi \Lambda^{-1} \Gamma \Delta Q
$$

or

$$
\Delta V=\sum_{i} \frac{\Phi_{i} \Gamma_{i}}{\lambda_{i}} \Delta Q
$$

where $\lambda_{i}$ is the $\mathrm{i}^{\text {th }}$ eigenvalue, $\Phi_{i}$ is the of $\mathrm{i}^{\text {th }}$ column right eigenvector and $\Gamma_{i}$ is the $\mathrm{i}^{\text {th }}$ row left eigenvector of matrix $J_{R}$.

Each eigenvalue $\lambda_{i}$ and corresponding right and left eigenvectors $\Phi_{i}$ and $\Gamma_{i}$, define the $\mathrm{i}^{\text {th }}$ mode of the system. The $\mathrm{i}^{\text {th }}$ modal reactive power variation is defined as:

$$
\Delta Q_{m i}=K_{i} \Phi_{i}
$$

where $K_{i}$ is a scale factor to normalize vector $\Delta Q_{i}$ so that

$$
K_{i}^{2} \sum_{j} \Phi_{j i}^{2}=1
$$

with $\Phi_{j i}$ the $j^{\text {th }}$ element of $\Phi_{i}$.

The corresponding $\mathrm{i}^{\text {th }}$ modal voltage variation is:

$$
\Delta V_{m i}=\frac{1}{\lambda_{i}} \Delta Q_{m i}
$$

Equation (3.11) can be summarized as follows: 


\section{CHAPTER 3 METHOD OF ANALYSIS}

1. If $\lambda_{i}=0$, the $\mathrm{i}^{\text {th }}$ modal voltage will collapse because any change in that modal reactive power will cause infinite modal voltage variation.

2. If $\lambda_{i}>0$, the $\mathrm{i}^{\text {th }}$ modal voltage and $\mathrm{i}^{\text {th }}$ reactive power variation are along the same direction, indicating that the system is voltage stable.

3. If $\lambda_{i}<0$, the $\mathrm{i}^{\text {th }}$ modal voltage and the $\mathrm{i}^{\text {th }}$ reactive power variation are along the opposite directions, indicating that the system is voltage unstable.

In general it can be said that, a system is voltage stable if the eigenvalues of $J_{R}$ are all positive. This is different from dynamic systems where eigenvalues with negative real parts are stable. The relationship between system voltage stability and eigenvalues of the $J_{R}$ matrix is best understood by relating the eigenvalues with the V-Q sensitivities of each bus (which must be positive for stability). $J_{R}$ can be taken as a symmetric matrix and therefore the eigenvalues of $J_{R}$ are close to being purely real. If all the eigenvalues are positive, $J_{R}$ is positive definite and the V-Q sensitivities are also positive, indicating that the system is voltage stable.

The system is considered voltage unstable if at least one of the eigenvalues is negative. A zero eigenvalue of $J_{R}$ means that the system is on the verge of voltage instability. Furthermore, small eigenvalues of $J_{R}$ determine the proximity of the system to being voltage unstable [20].

There is no need to evaluate all the eigenvalues of $J_{R}$ of a large power system because it is known that once the minimum eigenvalues becomes zeros the system Jacobian matrix becomes singular and voltage instability occurs. So the eigenvalues of importance are the critical eigenvalues of the reduced Jacobian matrix $J_{R}$. Thus, the smallest eigenvalues of $J_{R}$ are taken to be the least stable modes of the system. The rest of the eigenvalues are neglected because they are considered to be strong enough modes. Once the minimum eigenvalues and the corresponding left and right eigenvectors have been calculated the participation factor can be used to identify the weakest node or bus in the system. 
CHAPTER 3 METHOD OF ANALYSIS

\subsection{Identification of the Weak Load Buses}

The minimum eigenvalues, which become close to instability, need to be observed more closely. The appropriate definition and determination as to which node or load bus participates in the selected modes become very important. This necessitates a tool, called the participation factor, for identifying the weakest nodes or load buses that are making significant contribution to the selected modes [31].

If $\Phi_{i}$ and $\Gamma_{i}$ represent the right- and left- hand eigenvectors, respectively, for the eigenvalue $\lambda_{i}$ of the matrix $J_{R}$, then the participation factor measuring the participation of the $\mathrm{k}^{\text {th }}$ bus in $\mathrm{i}^{\text {th }}$ mode is defined as

$$
P_{k i}=\Phi_{k i} \Gamma_{i k}
$$

Note that for all the small eigenvalues, bus participation factors determine the area close to voltage instability.

Equation (3.12) implies that $P_{k i}$ shows the participation of the $i^{\text {th }}$ eigenvalue to the V-Q sensitivity at bus $k$. The node or bus $k$ with highest $P_{k i}$ is the most contributing factor in determining the V-Q sensitivity at $i^{\text {th }}$ mode. Therefore, the bus participation factor determines the area close to voltage instability provided by the smallest eigenvalue of $J_{R}$.

A Matlab m-file is developed to compute the participating factor at $i^{\text {th }}$ mode. 


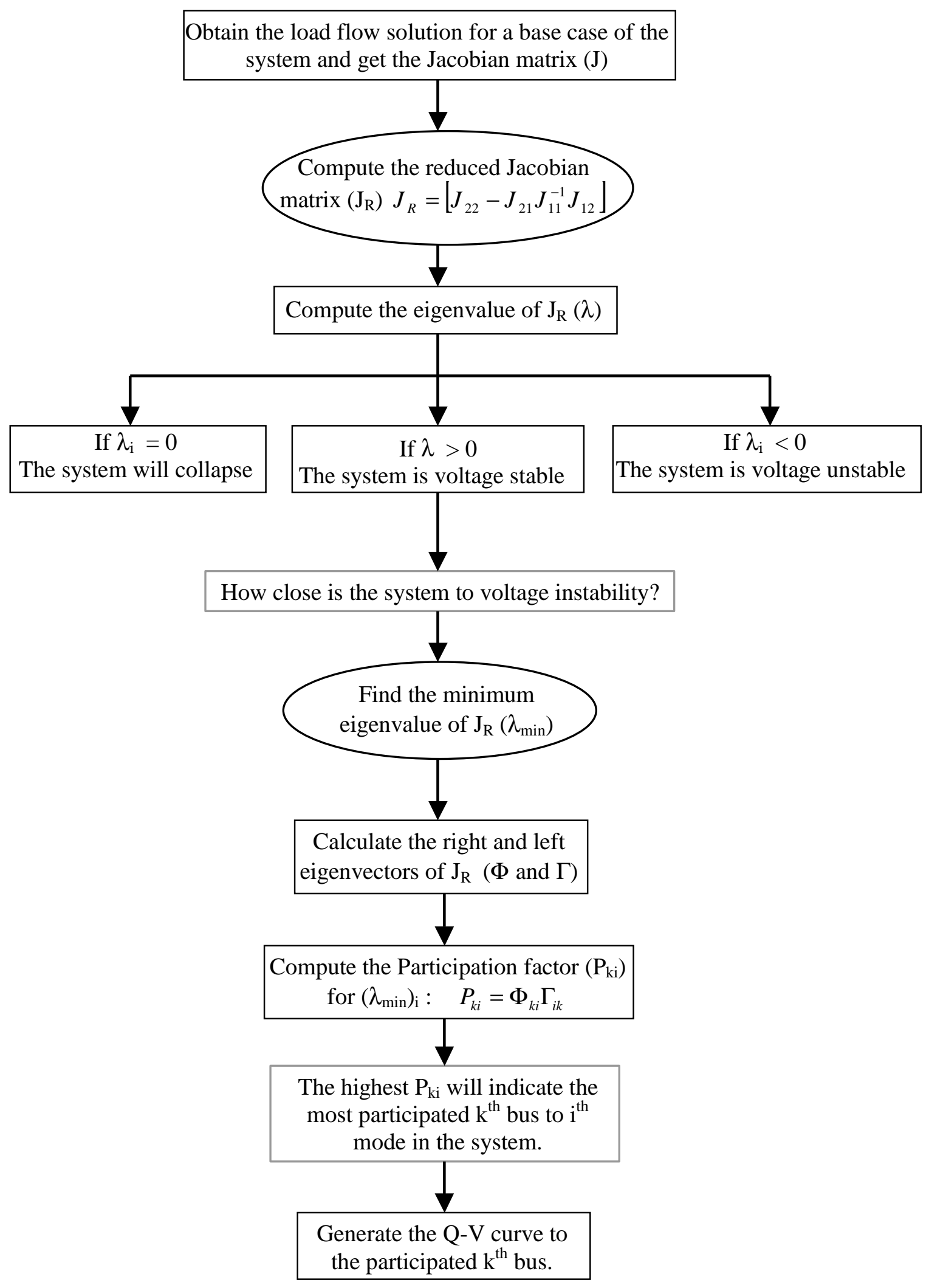

Figure 3.1 Algorithm for the voltage stability analysis. 
CHAPTER 3 METHOD OF ANALYSIS

\subsection{Q-V Curve}

V-Q or voltage- reactive power curves are generated by series of power flow simulation. They plot the voltage at a test bus or critical bus versus reactive power at the same bus. The bus is considered to be a PV bus, where the reactive output power is plotted versus scheduled voltage. Most of the time these curves are termed Q-V curves rather than V-Q curves. Scheduling reactive load rather than voltage produces $\mathrm{Q}-\mathrm{V}$ curves. These curves are a more general method of assessing voltage stability. They are used by utilities as a workhorse for voltage stability analysis to determine the proximity to voltage collapse and to establish system design criteria based on $\mathrm{Q}$ and $\mathrm{V}$ margins determined from the curves. Operators may use the curves to check whether the voltage stability of the system can be maintained or not and take suitable control actions. The sensitivity and variation of bus voltages with respect to the reactive power injection can be observed clearly. The main drawback with Q-V curves is that it is generally not known previously at which buses the curves should be generated.

As a traditional solution in system planning and operation, the voltage level is used as an index of system voltage instability. If it exceeds the limit, reactive support is installed to improve voltage profiles. With such action, voltage level can be maintained within acceptable limits under a wide range of MW loadings. In reality, voltage level may never decline below that limit as the system approaches its steady state stability limits. Consequently, voltage levels should not be used as a voltage collapse warning index.

Figure 3.2 shows a typical $\mathrm{Q}-\mathrm{V}$ curve. The $\mathrm{Q}$ axis shows the reactive power that needs to be added or removed from the bus to maintain a given voltage at a given load. The reactive power margin is the Mvar distance from the operating point to the bottom of the curve. The curve can be used as an index for voltage instability ( $\mathrm{dQ} / \mathrm{dV}$ goes negative). Near the nose of a $\mathrm{Q}-\mathrm{V}$ curve, sensitivities get very large and then reverse sign. Also, it can be seen that the curve shows two possible values of 


\section{CHAPTER 3 METHOD OF ANALYSIS}

voltage for the same value of power. The power system operated at lower voltage value would require very high current to produce the power. That is why the bottom portion of the curve is classified as an unstable region; the system can't be operated, in steady state, in this region. Accordingly, any discussion regarding such kind of operation is just educational. The steady state voltage problem analysis will be focused on the practical range of an operating system; the top portion of the curve. Hence, the top portion of the curve represents the stability region while the bottom portion from the stability limit indicates the unstable operating region. It is preferred to keep the operating point far from the stability limit.

In normal operating condition, an operator will attempt to correct the low voltage condition by increasing the terminal voltage. However, if the system is operating on the lower portion of the curve, the unstable region, increasing the terminal voltage will cause an even further drop in the load voltage; an unstable situation.

The Q-V curves have several advantages [1]:

1. Voltage security is closely related to reactive power, where the reactive power margin for a test bus can be determined from these curves.

2. Characteristics of test bus shunt reactive compensation (capacitor, SVC or synchronous condenser) can be plotted directly on the Q-V curve. The operating point is the intersection of the Q-V system characteristic and the reactive power compensation characteristic. This is useful since the reactive compensation is often a solution to voltage stability problems.

3. Q-V curves can be computed at points along P-V curve to test system robustness.

4. The slope of the Q-V curve indicates the stiffness of the test bus. 


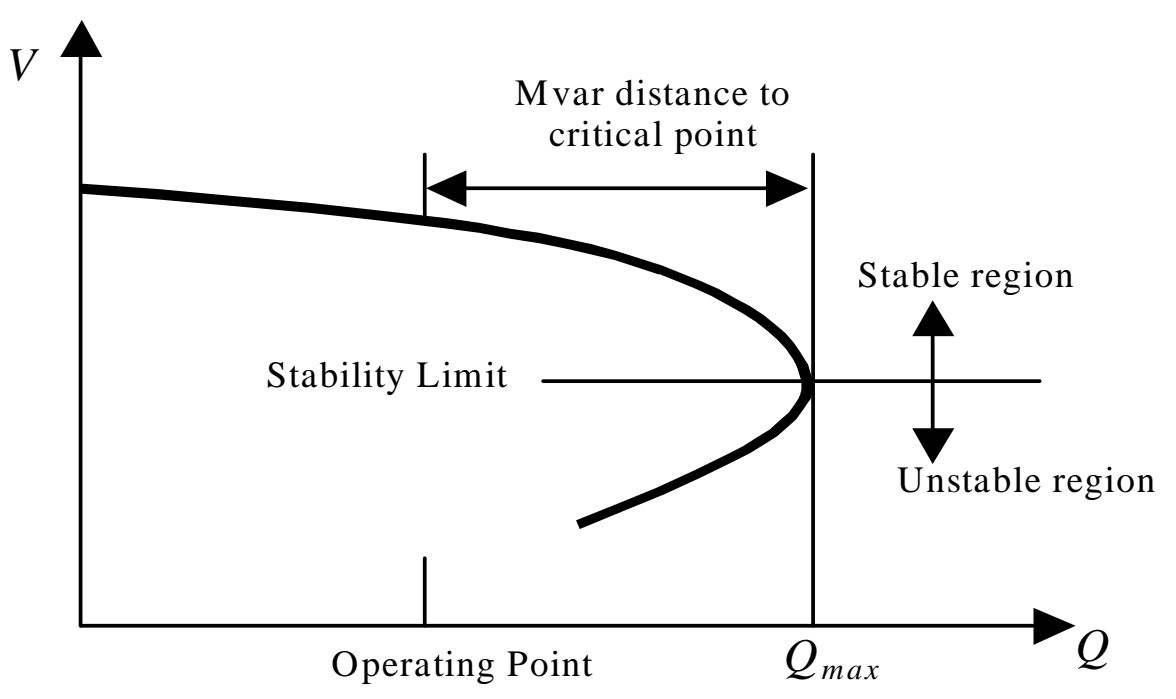

Figure 3.2 Typical Q-V curve.

\subsection{Effect of Load Modeling}

Normally, stability was often regarded as a problem of generators and their controls, while the effect of loads was considered as a secondary factor. The load representation can play an important factor in the power system stability. The effects of load characteristics on power system stability have been studied. Many of research results showed that the load characteristics affect the behavior of the power system.

The load characteristics can be divided into two categories, static characteristics and dynamic characteristics. The effect of the static characteristics is discussed in this section [28].

Recently, the load representation has become more important in power system stability studies. In the previous analysis, the load was represented by considering the active power and reactive power. Both were represented by combination of constant impedance (resistance or reactance), constant current and constant power (active or reactive) elements. This kind of load modeling has been used in many of the power system steady state analyses. However the load may be modeled as a function of voltage, frequency etc... depending on the type of study. On the other hand, there is no single load model that leads to conservative design for all system configurations [29]. 


\section{CHAPTER 3 METHOD OF ANALYSIS}

The effect of the static load modeling on voltage stability is presented in this section. A voltage dependent load model is proposed. The new load model is used instead of the constant load used previously. A significant change in the stability limit or distance to voltage collapse should be noticed clearly.

\subsubsection{Voltage Dependent Load.}

Voltage dependency of reactive power affects the steady state stability of power system. This effect primarily appears on voltages, which in turn affect the active power. It is well known that the stability improves and the system becomes voltage stable by installing static reactive power compensators or synchronous condensers [15].

The active and reactive proposed static load model for a particular load bus in this study is an exponent function of the per unit bus voltage as shown in the following equations:

$$
\begin{gathered}
P_{k}=P_{o} \frac{V_{k}^{n p}}{V_{o}} \\
Q_{k}=Q_{o} \frac{V_{k}^{n q}}{V_{o}}
\end{gathered}
$$

where:

$\mathrm{P}_{\mathrm{o}}=$ initial bus load active power.

$\mathrm{Q}_{\mathrm{o}}=$ initial bus load reactive power.

Vo = initial bus load voltage.

$\mathrm{np}=$ active power voltage exponent.

$\mathrm{nq}=$ reactive power voltage exponent.

Then the load flow equation (2.6) at load bus k can be written as:

$$
\begin{gathered}
0=P_{o} \frac{V_{k}^{n p}}{V_{o}}+\sum_{m=1}^{n} Y_{k m} V_{k} V_{m} \cos \left(\theta_{k}-\theta_{m}-\gamma_{k m}\right) \\
0=Q_{o} \frac{V_{k}^{n q}}{V_{o}}+\sum_{m=1}^{n} Y_{k m} V_{k} V_{m} \sin \left(\theta_{k}-\theta_{m}-\gamma_{k m}\right)
\end{gathered}
$$




\section{CHAPTER 3 METHOD OF ANALYSIS}

Equations (3.15) and (3.16) will update the load equations in the load flow. Then, the nonlinear equations will be solved to obtain a new load flow solutions. A load flow Matlab based program is developed to include the proposed load model. After that, the same algorithm used before in figure 3.1 can be followed with the new load flow solution.

\subsection{Effect of Induction Motor Load.}

Induction machine motor is one of the most popular loads in the power system. About $50-70 \%$ of all generated power is consumed by electric motors with about $90 \%$ of this being used by induction motors [1]. Therefore, it is considered an important part of the power system load and a significant attention regarding this type of load has been taken for both dynamic and steady state analysis.

In this research, the induction machine load is considered using the steady state model equivalent circuit [3] as shown in Figure 3.3

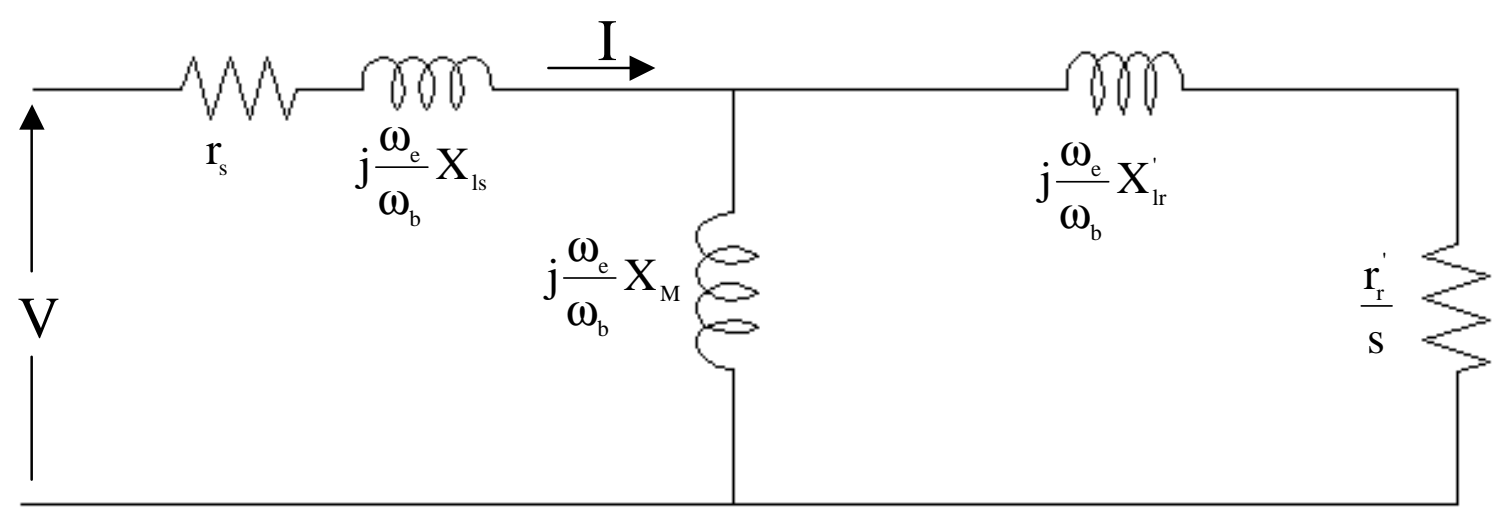

Figure 3.3 Equivalent circuit for steady state operation of a symmetrical induction machine.

The input impedance of the equivalent circuit shown in Figure 3.3 is: 


$$
Z=\frac{\frac{r_{s} r_{r}^{\prime}}{s}+\left(\frac{\omega_{e}}{\omega_{b}}\right)^{2}\left(X_{M}^{2}-X_{s s} X_{r r}^{\prime}\right)+j \frac{\omega_{e}}{\omega_{b}}\left(\frac{r_{r}^{\prime}}{s} X_{s s}+r_{s} X_{r r}^{\prime}\right)}{\frac{r_{r}^{\prime}}{s}+j \frac{\omega_{e}}{\omega_{b}} X_{r r}^{\prime}}
$$

where,

$\mathrm{s}=\frac{\omega_{\mathrm{e}}-\omega_{\mathrm{r}}}{\omega_{\mathrm{e}}}$

$\omega_{\mathrm{e}}$

$\mathrm{X}_{\mathrm{ss}}=\mathrm{X}_{\mathrm{ls}}+\mathrm{X}_{\mathrm{M}}$

$\mathrm{X}_{\mathrm{rr}}^{\prime}=\mathrm{X}_{\mathrm{lr}}^{\prime}+\mathrm{X}_{\mathrm{M}}$

$\omega_{\mathrm{b}}=\omega_{\mathrm{e}}=2 \pi \mathrm{f}$

$\mathrm{s}=$ machine slip.

$\mathrm{r}_{\mathrm{s}}=$ stator resistance.

$\mathrm{r}_{\mathrm{r}}=$ rotor resistance referred to the stator side.

$\mathrm{X}_{\mathrm{ls}}=$ stator leakage inductance.

$\mathrm{X}_{\mathrm{lr}}{ }^{\prime}=$ rotor leakage inductance referred to the stator side.

Since,

$$
\vec{I}=\frac{\vec{V}}{Z}
$$

Then the power consumed by the induction motor is:

$$
\begin{gathered}
S=\vec{V} \vec{I}^{*} \\
S=P+j Q
\end{gathered}
$$

From Equations (3.17) to (3.20), it can be seen that both the active and reactive power consumed by the induction motor are function of the bus voltage and the machine slip. A load flow program using Matlab is developed to include the proposed induction machine load model. The algorithm used before in Figure 3.1 can be followed with the new load flow solution. 


\section{CHAPTER 4}

\section{RESULTS AND DISCUSSION}

\subsection{Introduction.}

The Modal analysis method has been successfully applied to three different electric power systems. The Q-V cures are generated for selected buses in order to monitor the voltage stability margin. Different voltage dependent load and Induction machine load models are simulated. A power flow program based on Matlab is developed to:

1. Calculate the power flow solution.

2. Analyze the voltage stability based on modal analysis.

3. Generate the Q-V curves.

4. Demonstrate the impact of voltage dependent load and Induction machine load models on the system voltage stability.

\subsection{Test Systems Description}

Three systems have been simulated and tested in this project to illustrate the proposed analysis methods:

1. Western System Coordinating Council (WSCC) 3-Machines 9-Bus system. The single line diagram is shown in Figure 4.1.

2. The IEEE 14 Bus Test Case represents a portion of the American Electric Power System (in the Midwestern US) . The single line diagram is shown in Figure 4.2.

3. The IEEE 30 Bus Test Case represents a portion of the American Electric Power System (in the Midwestern US). The single line diagram is shown in Figure 4.3. 


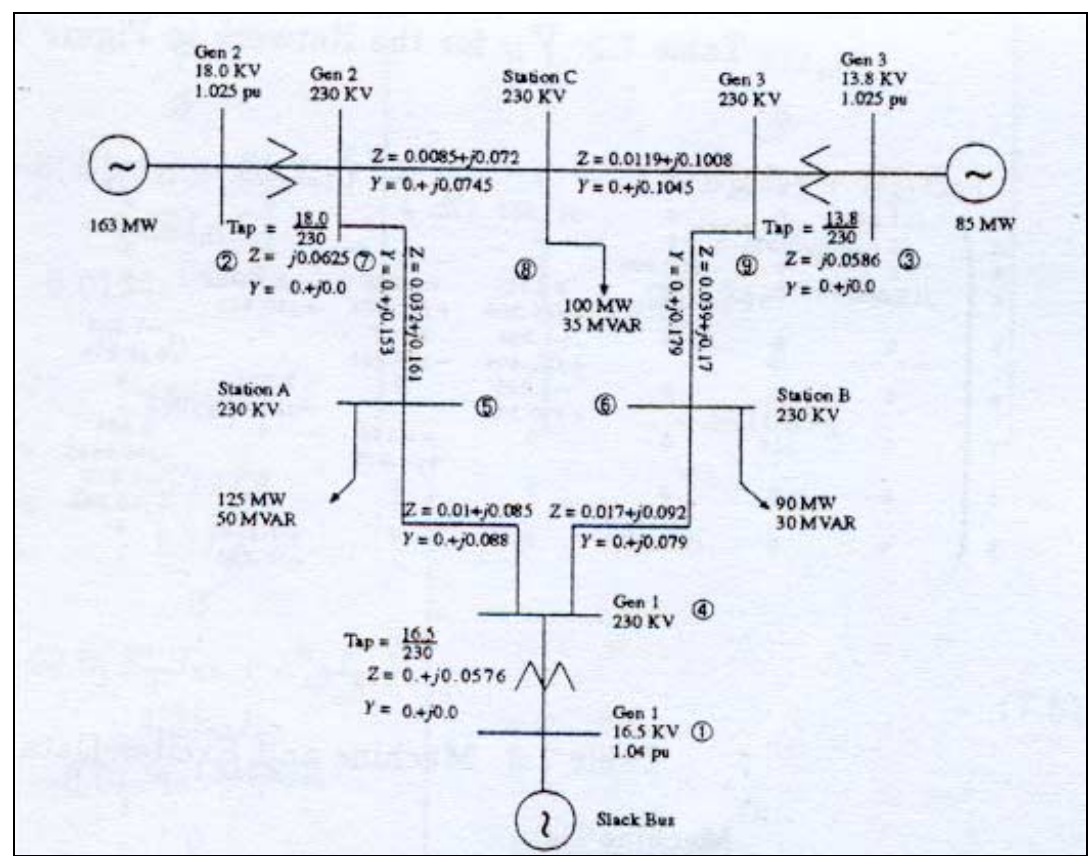

Figure 4.1 Western System Coordinating Council (WSCC) 3-Machines 9-Bus system.

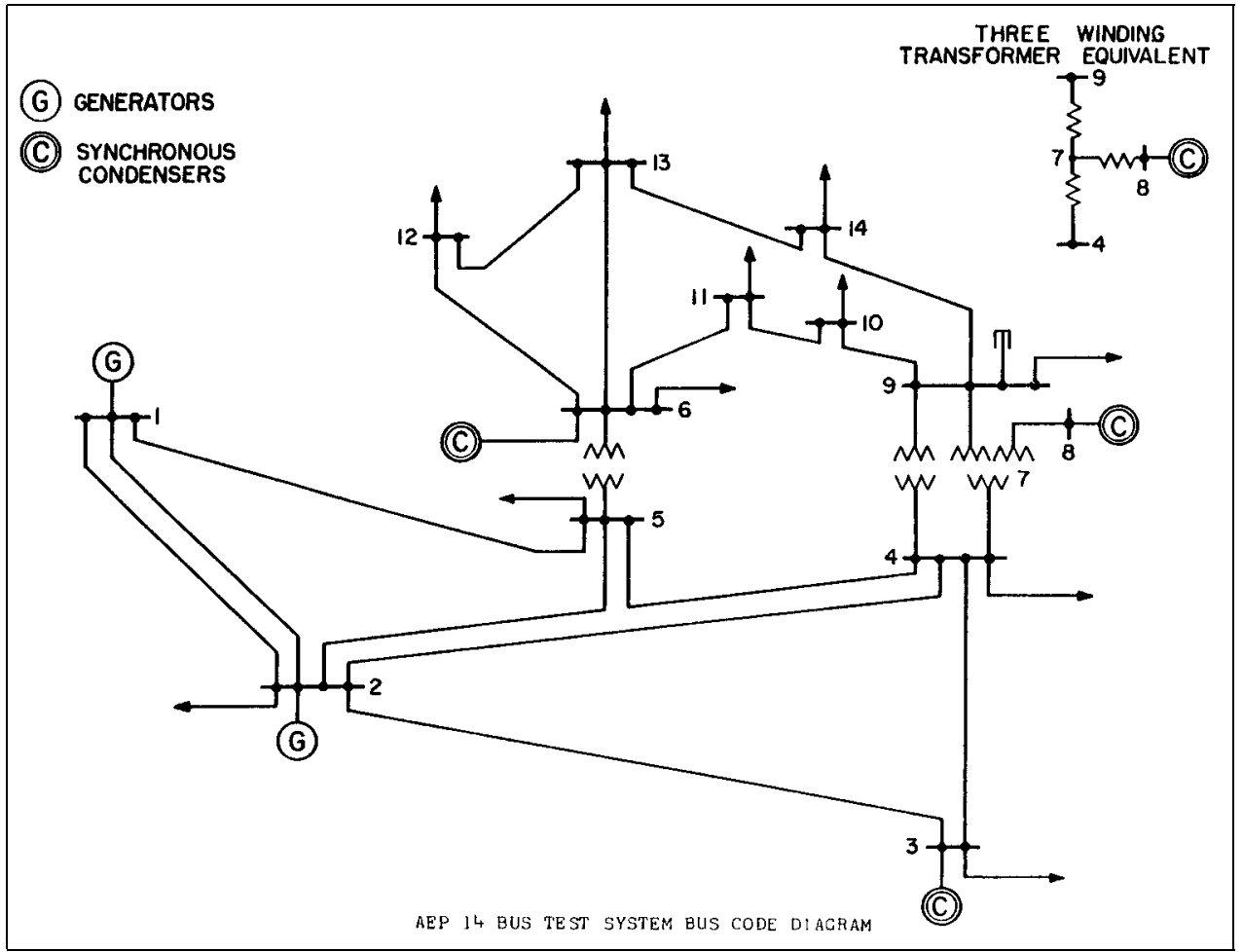

Figure 4.2 Single line diagram of the IEEE 14 Bus System. 


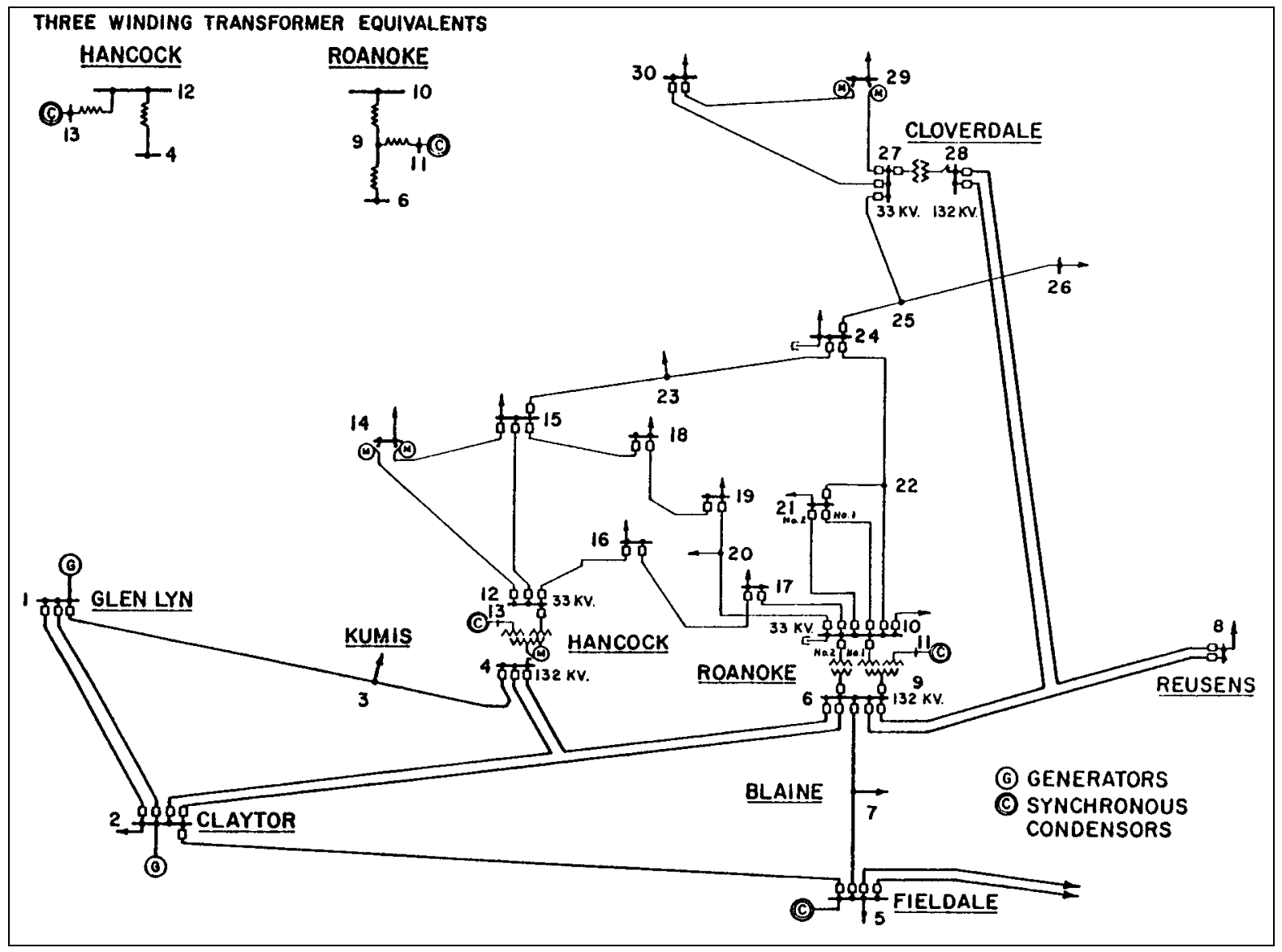

Figure 4.3 Single line diagram of the IEEE 30 Bus System.

\subsection{Analysis with Constant Impedance Load.}

The modal analysis method is applied to the three suggested test systems. The voltage profile of the buses is presented from the load flow simulation. Then, the minimum eigenvalue of the reduced Jacobian matrix is calculated. After that, the weakest load buses, which are subject to voltage collapse, are identified by computing the participating factors. The results are shown in Figure 4.4 to Figure 4.12 .

\subsubsection{Western System Coordinating Council (WSCC) 3-Machines 9-Bus system.}

Figure 4.4 shows the voltage profile of all buses of the Western System Coordinating Council (WSCC) 3-Machines 9-Bus system as obtained form the load flow. It can be seen that all the bus 
voltages are within the acceptable level $( \pm 5 \%)$; some standards consider $( \pm 10 \%)$. The lowest voltage compared to the other buses can be noticed in bus number 5 .

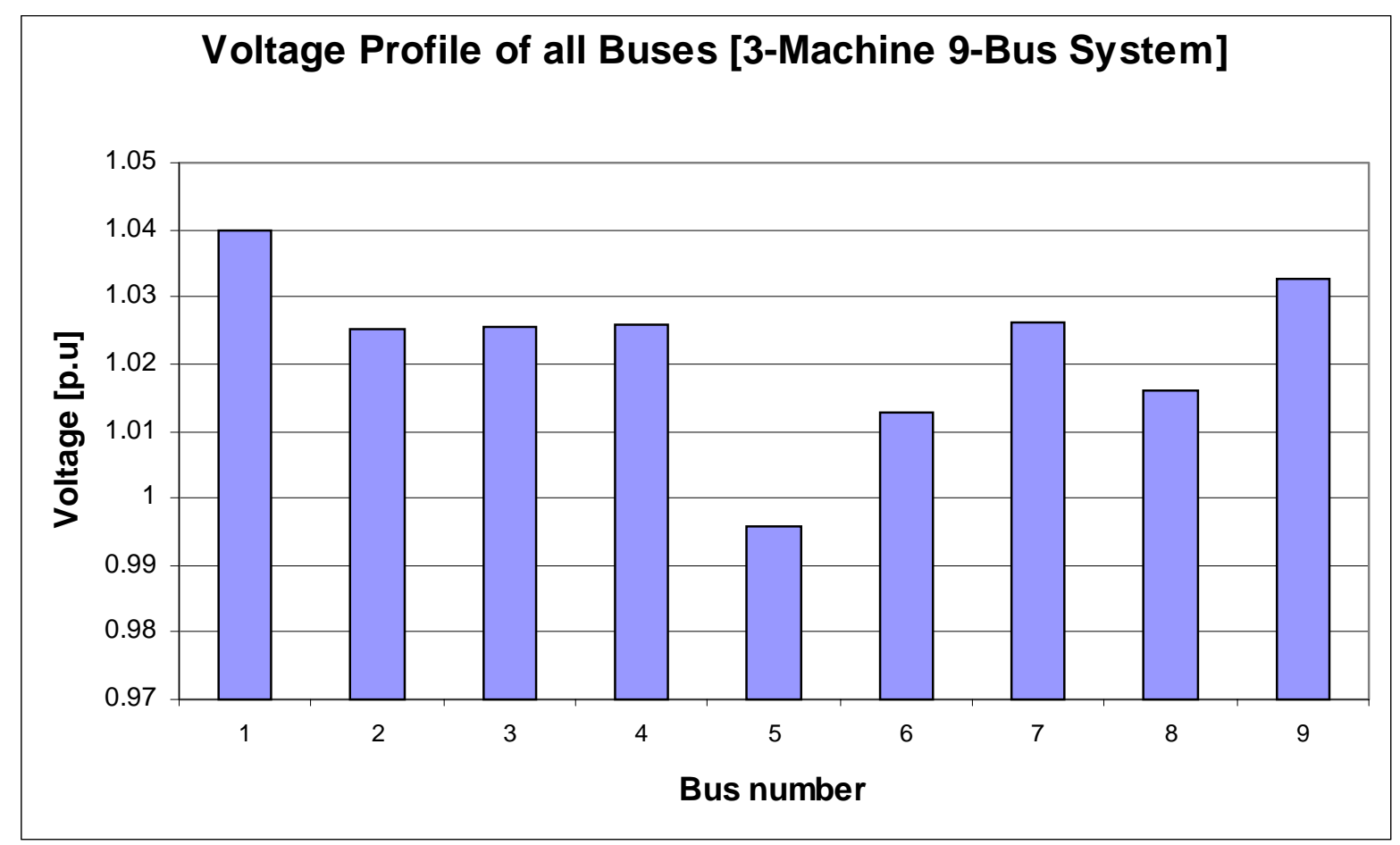

Figure 4.4 Voltage profiles of all buses of the WSCC 3-Machines 9-Bus system.

Since there are nine buses among which there is one swing bus and two PV buses, then the total number of eigenvalues of the reduced Jacobian matrix $J_{R}$ is expected to be six as shown in Table4.1. Note that all the eigenvalues are positive which means that the system voltage is stable.

Table 4.1 WSCC 3-Machines 9-Bus system eigenvalues.

\begin{tabular}{|c||c|c|c|c|c|c||}
\hline$\#$ & 1 & 2 & 3 & 4 & 5 & 6 \\
\hline Eigenvalue & 51.0938 & 5.9589 & 46.6306 & 12.9438 & 14.9108 & 36.3053 \\
\hline
\end{tabular}

From Table 4.1, it can be noticed that the minimum eigenvalue $\lambda=5.9589$ is the most critical mode. The participating factor for this mode has been calculated and the result is shown in Figure 4.5. The result shows that, the buses 5,6 and 8 have the highest participation factors to the 
critical mode. The largest participation factor value $(0.3)$ at bus \# 5 indicates the highest contribution of this bus to the voltage collapse.

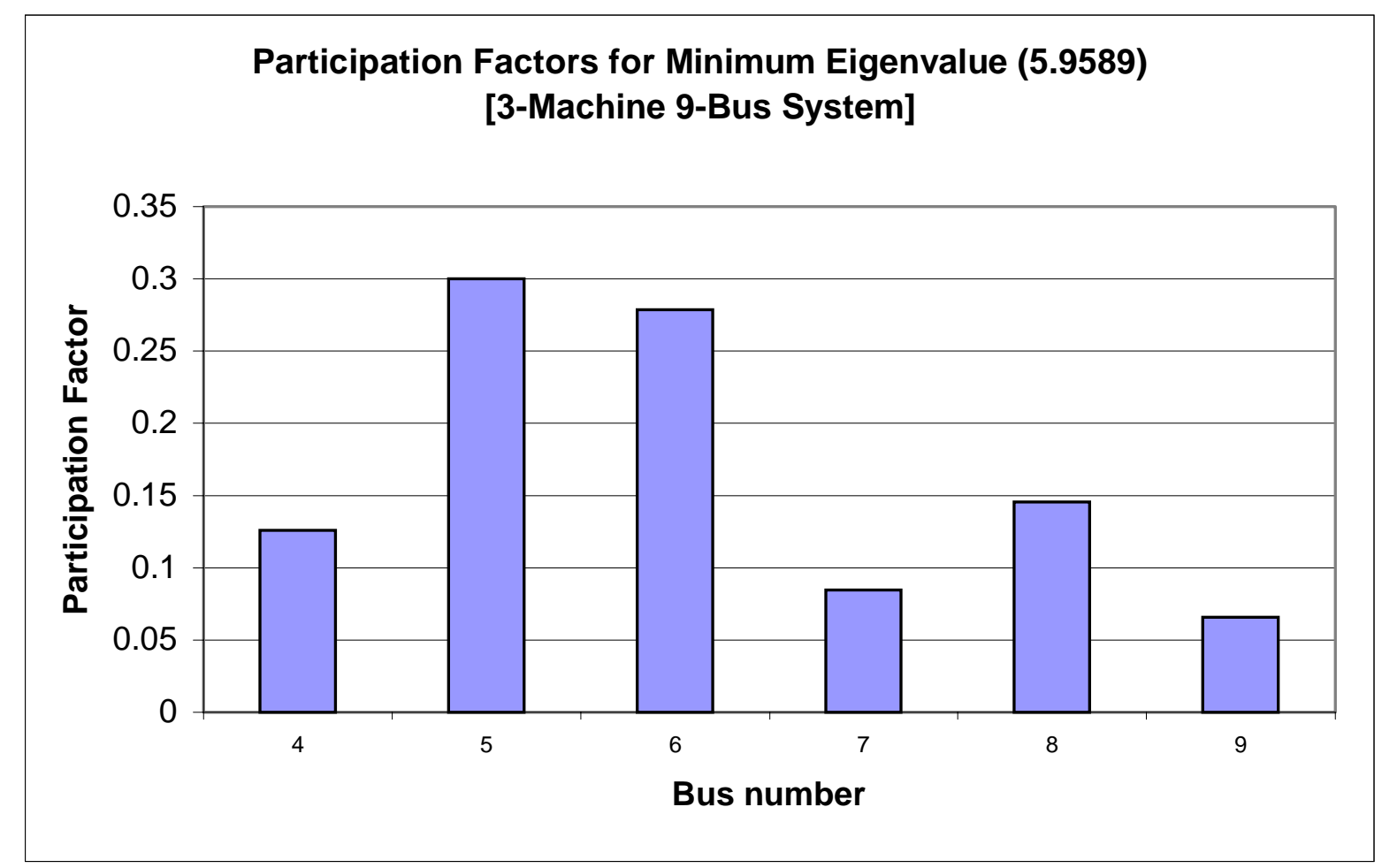

Figure 4.5 The participating factor of all buses for most critical mode for the WSCC 3-Machines 9-Bus system.

The Q-V curves are used to determine the Mvar distance to the voltage instability point or the voltage stability margins. The margins were determined between the base case loading points and the maximum loading points before the voltage collapse. Consequently, these curves can be used to predict the maximum-security margins that can be reached. In other words, by using Q-V curves, it is possible for the operators and the planners to know what is the maximum reactive power that can be achieved or added to the weakest bus before reaching minimum voltage limit or voltage instability. In addition, the calculated Mvar margins could relate to the size of shunt capacitor or static var compensation in the load area. 
The Q-V curves were computed for the weakest buses of the critical mode in the Western System Coordinating Council (WSCC) 3-Machines 9-Bus system as expected by the modal analysis method. The curves are shown in Figure 4.6.

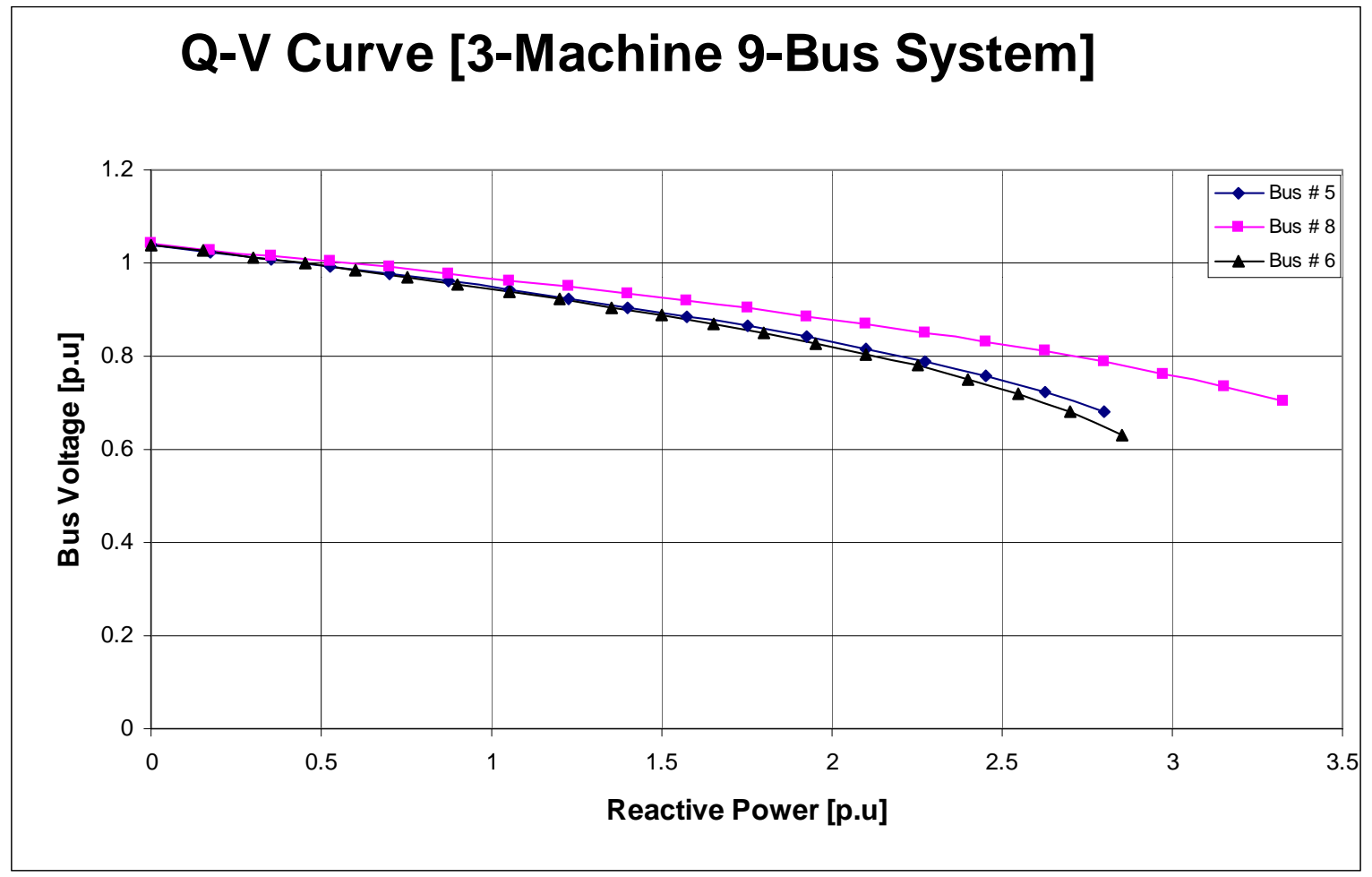

Figure 4.6 The Q-V curves at buses 5, 8 and 6 for the WSCC 3-Machines 9-Bus system.

The Q-V curves shown in figure 4.6 confirm the results obtained previously by the modal analysis method. It can be seen clearly that bus \# 5 is the most critical bus compared with the other buses, where any more increase in the reactive power demand at that bus will cause a voltage collapse.

Table 4.2 Voltage and reactive power margins for the WSCC 3-Machines 9-Bus system from Q-V curves.

\begin{tabular}{|c|c|c|c|c|c|c|c|c|c|c|c|c|c|c|}
\hline \multicolumn{5}{|c|}{ Bus \# 5} & \multicolumn{5}{|c|}{ Bus \# 6} & \multicolumn{5}{|c|}{ Bus \# 8} \\
\hline \multicolumn{2}{|c|}{$\begin{array}{c}\text { Operating } \\
\text { Point } \\
\end{array}$} & \multicolumn{2}{|c|}{$\begin{array}{l}\text { Maximum } \\
\text { withstand }\end{array}$} & \multirow{2}{*}{$\begin{array}{c}\text { Stability } \\
\text { Margin }\end{array}$} & \multicolumn{2}{|c|}{$\begin{array}{c}\text { Operating } \\
\text { Point } \\
\end{array}$} & \multicolumn{2}{|c|}{$\begin{array}{l}\text { Maximum } \\
\text { withstand }\end{array}$} & \multirow{2}{*}{$\begin{array}{l}\text { Stability } \\
\text { Margin } \\
\text { Q (pu) }\end{array}$} & \multicolumn{2}{|c|}{$\begin{array}{c}\text { Operating } \\
\text { Point } \\
\end{array}$} & \multicolumn{2}{|c|}{$\begin{array}{c}\text { Maximum } \\
\text { withstand }\end{array}$} & \multirow{2}{*}{$\begin{array}{c}\text { Stability } \\
\text { Margin } \\
\mathrm{Q}(\mathrm{pu})\end{array}$} \\
\hline $\begin{array}{c}\mathrm{V} \\
(\mathrm{pu})\end{array}$ & $\begin{array}{c}\mathrm{Q} \\
(\mathrm{pu})\end{array}$ & $\begin{array}{c}\mathrm{V} \\
(\mathrm{pu})\end{array}$ & $\begin{array}{c}\mathrm{Q} \\
(\mathrm{pu})\end{array}$ & & $\begin{array}{c}\mathrm{V} \\
(\mathrm{pu})\end{array}$ & $\begin{array}{c}\mathrm{Q} \\
(\mathrm{pu})\end{array}$ & $\mathrm{V}(\mathrm{pu})$ & $\begin{array}{c}\mathrm{Q} \\
(\mathrm{pu})\end{array}$ & & $\begin{array}{c}\mathrm{V} \\
(\mathrm{pu})\end{array}$ & $\begin{array}{c}\mathrm{Q} \\
(\mathrm{pu})\end{array}$ & $\mathrm{V}(\mathrm{pu})$ & $\begin{array}{c}\mathrm{Q} \\
(\mathrm{pu})\end{array}$ & \\
\hline 1 & 0.5 & 0.724 & 2.625 & 2.125 & 1 & 0.3 & 0.6297 & 2.85 & 2.55 & 1 & 0.35 & 0.7042 & 3.325 & 2.975 \\
\hline
\end{tabular}

Table 4.2 shows evaluation of the buses 5,6 , and 8 Q-V curves. These results can be used effectively in planning or operation of this system. 


\subsubsection{The IEEE 14 Bus system.}

Figure 4.7 shows the voltage profile of all buses of the IEEE 14 Bus system as obtained form the load flow. It can be seen that all the bus voltages are within the acceptable level $( \pm 5 \%)$. The lowest voltage compared to the other buses can be noticed in bus number 4 .

Since there are 14 buses among which there is one swing bus and 4 PV buses, then the total number of eigenvalues of the reduced Jacobian matrix $J_{R}$ is expected to be 9 as shown in table 4.3 .

Table 4.3 IEEE 14 Bus system eigenvalues.

\begin{tabular}{|c||c|c|c|c|c|c|c|c|c||}
\hline$\#$ & 1 & 2 & 3 & 4 & 5 & 6 & 7 & 8 & 9 \\
\hline \hline Eigenvalue & 62.5497 & 40.0075 & 21.5587 & 2.7811 & 11.1479 & 15.7882 & 5.4925 & 18.7197 & 7.5246 \\
\hline
\end{tabular}

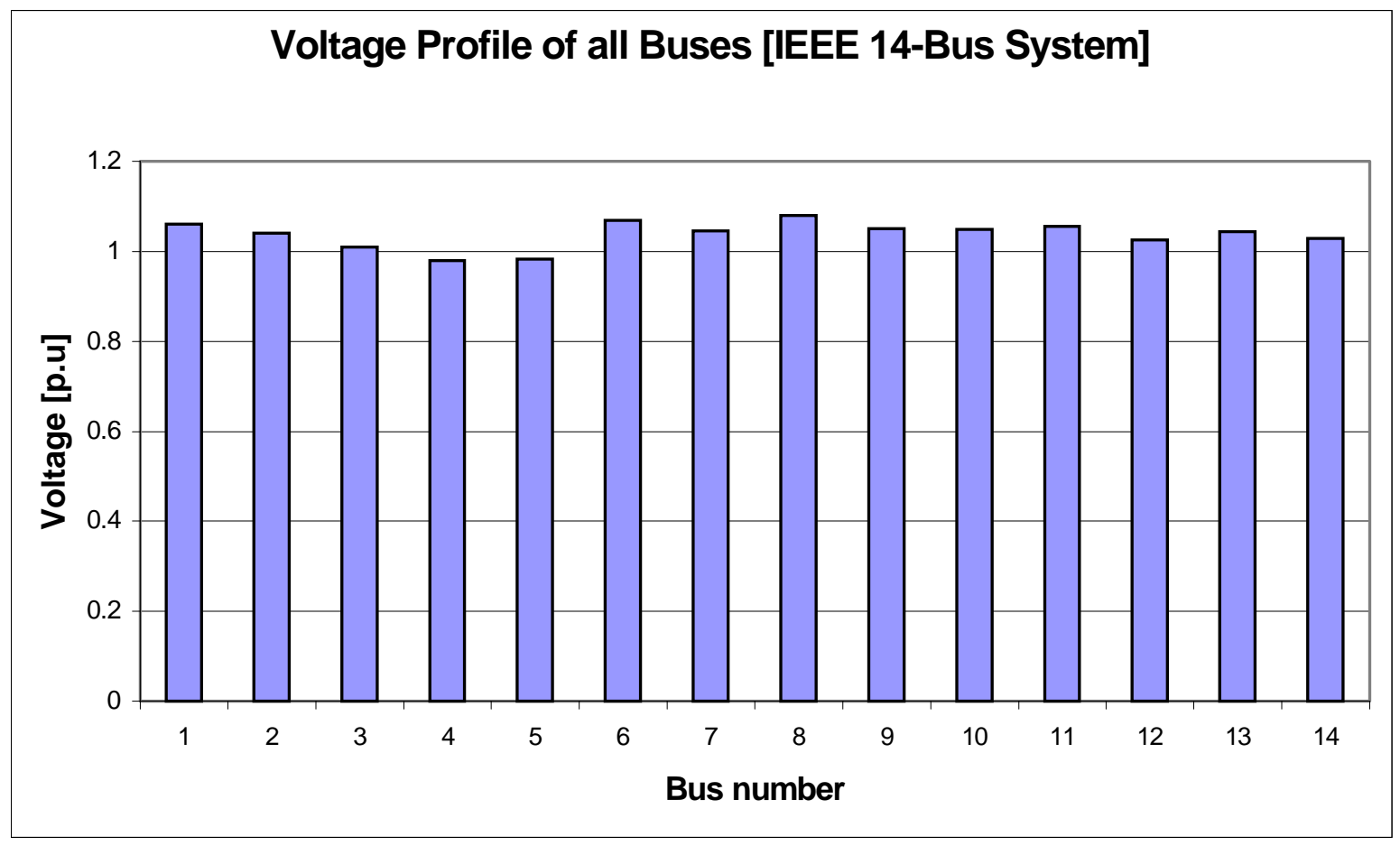

Figure 4.7 Voltage profiles of all buses of the IEEE 14 Bus system.

Note that all the eigenvalues are positive which means that the system voltage is stable. 
From Table 4.3, it can be noticed that the minimum eigenvalue $\lambda=2.7811$ is the most critical mode. The participating factor for this mode has been calculated and the result is shown in Figure 4.8 .

The result shows that, the buses 14,10 and 9 have the highest participation factors for the critical mode. The largest participation factor value $(0.327)$ at bus 14 indicates the highest contribution of this bus to the voltage collapse.

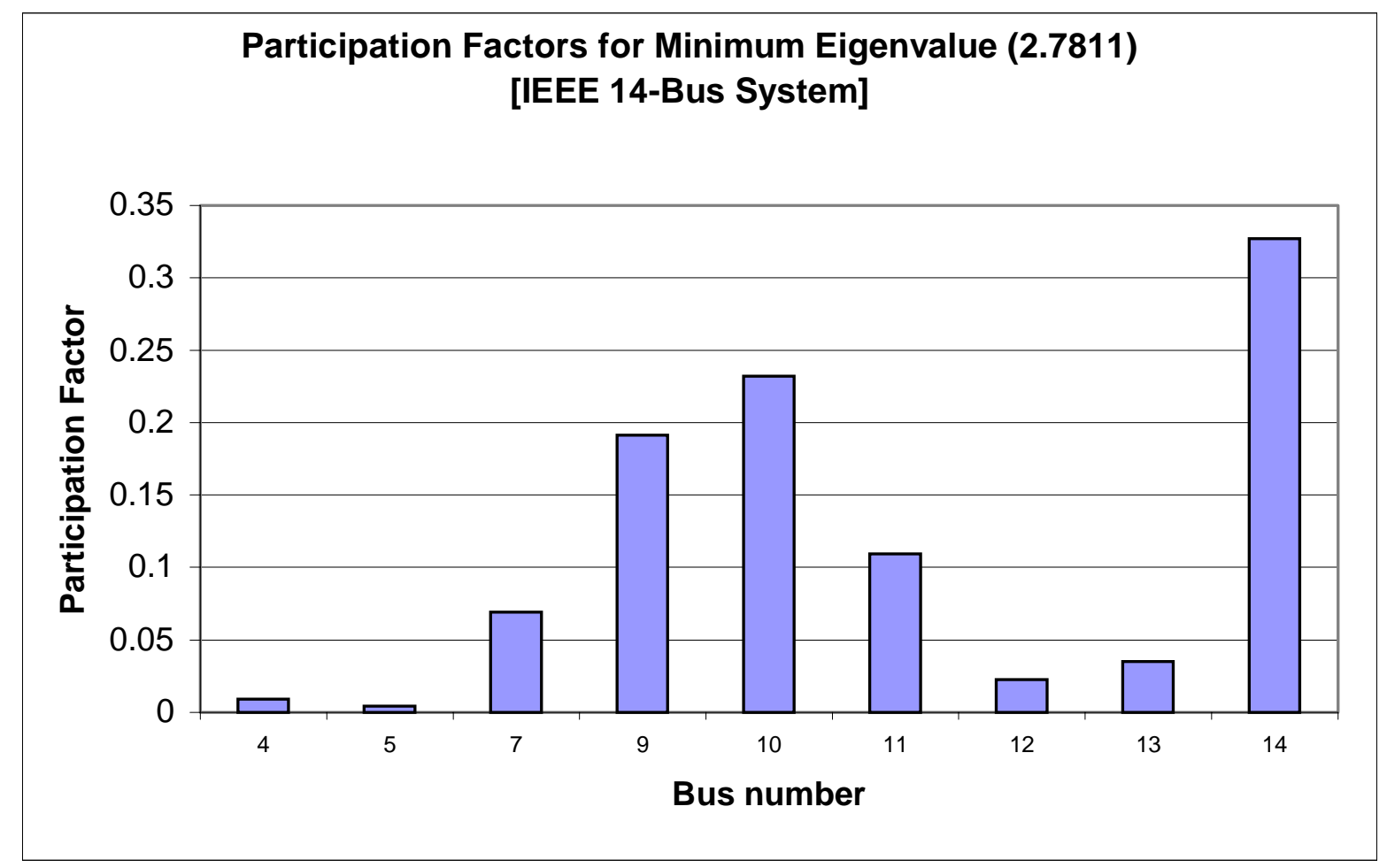

Figure 4.8 The participating factor of all buses for most critical mode for the IEEE 14 Bus system.

The Q-V curves were computed for the weakest buses of the critical mode in the IEEE 14 Bus system as expected by the modal analysis method. The curves are shown in Figure 4.9.

Figures 4.9, Q-V curves, prove the results obtained previously by modal analysis method. It can be seen clearly that bus \# 14 is the most critical bus compared the other buses, where any more increase in the reactive power demand in that bus will cause a voltage collapse. 


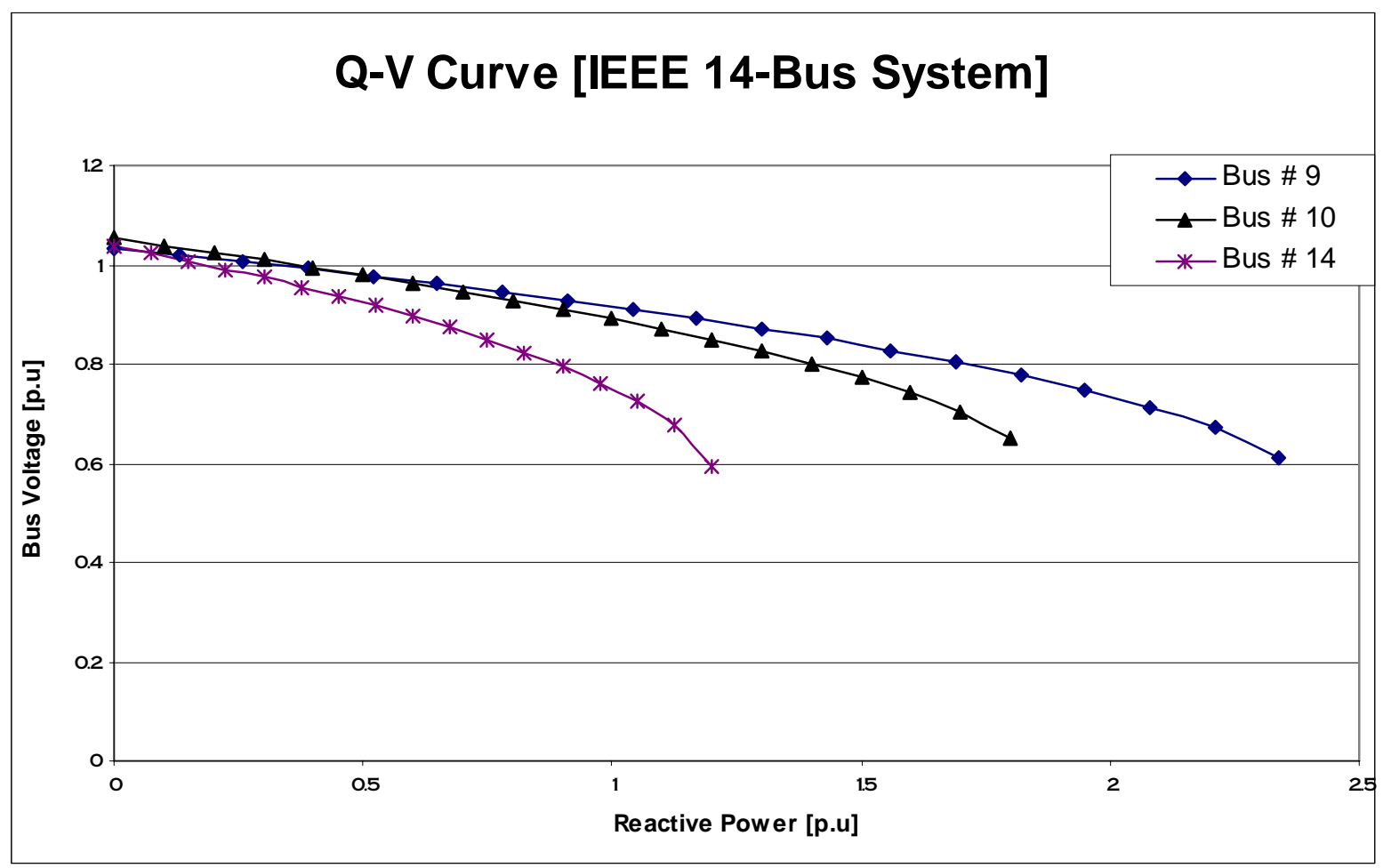

Figure 4.9 The $Q$-V curves at buses 9,10 and 14 for the IEEE 14 Bus system.

Table 4.4 Voltage and reactive power margins for the IEEE 14 Bus system from $Q$-V curves.

\begin{tabular}{|c|c|c|c|c|c|c|c|c|c|c|c|c|c|c|}
\hline \multicolumn{5}{|c|}{ Bus \# 9} & \multicolumn{5}{|c|}{ "Bus \# 10} & \multicolumn{5}{|c|}{ "Bus \# 14} \\
\hline \multicolumn{2}{|c|}{$\begin{array}{c}\text { Operating } \\
\text { Point }\end{array}$} & \multicolumn{2}{|c|}{$\begin{array}{l}\text { Maximum } \\
\text { withstand }\end{array}$} & \multirow{2}{*}{$\begin{array}{c}\begin{array}{c}\text { Stability } \\
\text { Margin }\end{array} \\
\mathrm{Q}(\mathrm{pu})\end{array}$} & \multicolumn{2}{|c|}{$\begin{array}{c}\text { Operating } \\
\text { Point }\end{array}$} & \multicolumn{2}{|c|}{$\begin{array}{l}\text { Maximum } \\
\text { withstand }\end{array}$} & \multirow{2}{*}{$\begin{array}{c}\begin{array}{c}\text { Stability } \\
\text { Margin }\end{array} \\
\mathrm{Q}(\mathrm{pu})\end{array}$} & \multicolumn{2}{|c|}{$\begin{array}{c}\text { Operating } \\
\text { Point }\end{array}$} & \multicolumn{2}{|c|}{$\begin{array}{c}\text { Maximum } \\
\text { withstand }\end{array}$} & \multirow{2}{*}{$\begin{array}{c}\begin{array}{c}\text { Stability } \\
\text { Margin }\end{array} \\
\mathrm{Q}(\mathrm{pu})\end{array}$} \\
\hline $\begin{array}{c}\mathrm{V} \\
(\mathrm{pu})\end{array}$ & $\mathrm{Q}(\mathrm{pu})$ & $\mathrm{V}(\mathrm{pu})$ & $\begin{array}{c}\mathrm{Q} \\
\text { (pu) }\end{array}$ & & $\begin{array}{c}\mathrm{V} \\
(\mathrm{pu})\end{array}$ & $\begin{array}{c}\mathrm{Q} \\
(\mathrm{pu})\end{array}$ & $\mathrm{V}(\mathrm{pu})$ & $\begin{array}{c}\mathrm{Q} \\
(\mathrm{pu})\end{array}$ & & $\begin{array}{c}\mathrm{V} \\
(\mathrm{pu})\end{array}$ & $\begin{array}{c}\mathrm{Q} \\
(\mathrm{pu})\end{array}$ & $\mathrm{V}(\mathrm{pu})$ & $\begin{array}{c}\mathrm{Q} \\
(\mathrm{pu})\end{array}$ & \\
\hline 1 & $\begin{array}{c}- \\
0.1421\end{array}$ & 0.6102 & 2.34 & 2.4821 & 1 & 0.032 & 0.6521 & 1.8 & 1.768 & 1 & 0.05 & 0.6349 & 1.17 & 1.12 \\
\hline
\end{tabular}

Table 4.4 shows evaluation of the buses 9,10 , and $14 \mathrm{Q}-\mathrm{V}$ curves. These results can be used effectively in planning or operation of this system.

\subsubsection{The IEEE 30 Bus system.}

Figure 4.10 shows the voltage profile of all buses of the IEEE 30 Bus system as obtained form the load flow. It can be seen that all the bus voltages are within the acceptable level $( \pm 5 \%)$ except bus 
number 30, which is about 0.944 p.u. The lowest voltage compared to the other buses can be noticed in bus number 30 .

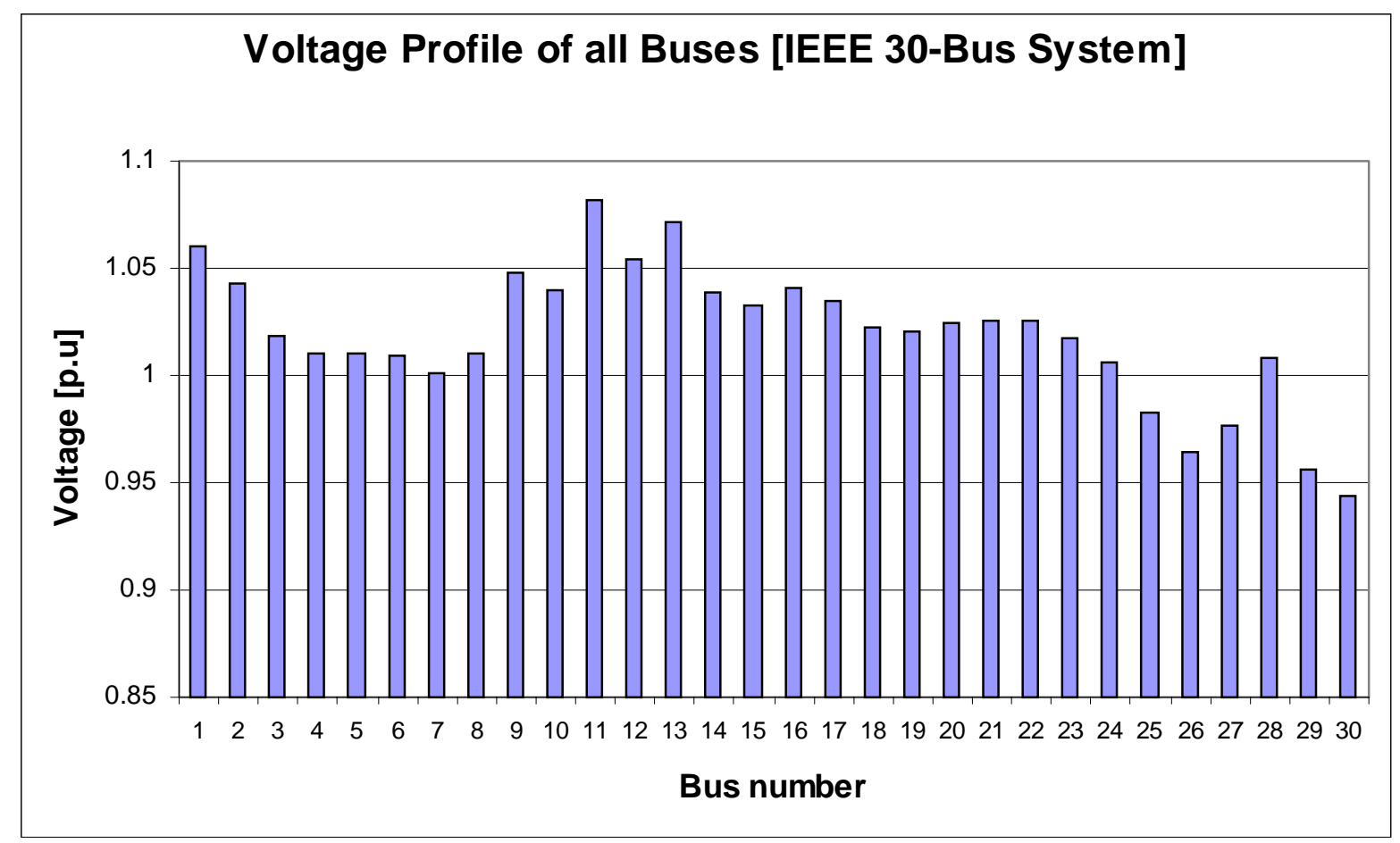

Figure 4.10 Voltage profiles of all buses of the IEEE 30 Bus system.

Since there are 30 buses among which there is one swing bus and 5 PV buses, then the total number of eigenvalues of the reduced Jacobian matrix $J_{R}$ is expected to be 24 as shown in Table 4.5.

Note that all the eigenvalues are positive which means that the system voltage is stable. From Table 4.5 , it can be noticed that the minimum eigenvalue $\lambda=0.506$ is the most critical mode. The participating factor for this mode has been calculated and the result is shown in Figure 4.11.

The result shows that, the buses 30, 29 and 26 have the highest participation factors for the critical mode. The largest participation factor value $(0.2118)$ at bus 30 indicates the highest contribution of this bus to the voltage collapse. 
Table 4.5 IEEE 30 Bus system eigenvalues sorted by ascending values.

\begin{tabular}{|c|c|}
\hline$\#$ & Eigenvalue \\
\hline \hline 1 & 110.2056 \\
\hline 2 & 100.6465 \\
\hline 3 & 65.9541 \\
\hline 4 & 59.5431 \\
\hline 5 & 37.8188 \\
\hline 6 & 35.3863 \\
\hline 7 & 23.0739 \\
\hline 8 & 23.4238 \\
\hline 9 & 19.1258 \\
\hline 10 & 19.7817 \\
\hline 11 & 18.0785 \\
\hline 12 & 16.3753 \\
\hline 13 & 0.506 \\
\hline 14 & 13.7279 \\
\hline 15 & 13.6334 \\
\hline 16 & 1.0238 \\
\hline 17 & 11.0447 \\
\hline 18 & 1.7267 \\
\hline 19 & 8.7857 \\
\hline 20 & 3.5808 \\
\hline 21 & 4.0507 \\
\hline 22 & 7.436 \\
\hline 23 & 6.0207 \\
\hline 24 & 5.4527 \\
\hline
\end{tabular}

The Q-V curves were computed for the weakest buses of the critical mode in the IEEE 30 Bus system as expected by the modal analysis method. The curves are shown in Figure 4.12.

Figure 4.12, Q-V curves, verifies the results obtained previously by modal analysis method. It can be seen clearly that bus \# 30 is the most critical bus compared the other buses, where any more increase in the reactive power demand in that bus will cause a voltage collapse.

Table 4.6 Voltage and reactive power margins for the IEEE 30 Bus system from $Q$-V curves.

\begin{tabular}{|c|c|c|c|c|c|c|c|c|c|c|c|c|c|c|}
\hline \multicolumn{5}{|c|}{ Bus \# 26} & \multicolumn{5}{|c|}{ Bus \# 29} & \multicolumn{5}{|c|}{ Bus \# 30} \\
\hline \multicolumn{2}{|c|}{$\begin{array}{l}\text { Operating } \\
\text { Point }\end{array}$} & \multicolumn{2}{|c|}{$\begin{array}{l}\text { Maximum } \\
\text { withstand }\end{array}$} & \multirow{2}{*}{$\begin{array}{c}\begin{array}{c}\text { Stability } \\
\text { Margin }\end{array} \\
\mathrm{Q}(\mathrm{pu})\end{array}$} & \multicolumn{2}{|c|}{$\begin{array}{c}\text { Operating } \\
\text { Point }\end{array}$} & \multicolumn{2}{|c|}{$\begin{array}{c}\text { Maximum } \\
\text { withstand }\end{array}$} & \multirow{2}{*}{$\begin{array}{c}\text { Stability } \\
\text { Margin } \\
\mathrm{Q}(\mathrm{pu})\end{array}$} & \multicolumn{2}{|c|}{$\begin{array}{c}\text { Operating } \\
\text { Point }\end{array}$} & \multicolumn{2}{|c|}{$\begin{array}{c}\text { Maximum } \\
\text { withstand }\end{array}$} & \multirow{2}{*}{$\begin{array}{l}\text { Stability } \\
\text { Margin } \\
\text { Q (pu) }\end{array}$} \\
\hline $\begin{array}{c}\mathrm{V} \\
(\mathrm{pu})\end{array}$ & $\begin{array}{c}\mathrm{Q} \\
(\mathrm{pu})\end{array}$ & $\mathrm{V}(\mathrm{pu})$ & $\begin{array}{c}\mathrm{Q} \\
(\mathrm{pu})\end{array}$ & & $\begin{array}{c}\mathrm{V} \\
(\mathrm{pu})\end{array}$ & $\begin{array}{c}\mathrm{Q} \\
(\mathrm{pu})\end{array}$ & $\mathrm{V}(\mathrm{pu})$ & $\begin{array}{c}\mathrm{Q} \\
(\mathrm{pu})\end{array}$ & & $\begin{array}{c}\mathrm{V} \\
(\mathrm{pu})\end{array}$ & $\begin{array}{c}\mathrm{Q} \\
(\mathrm{pu})\end{array}$ & $\mathrm{V}(\mathrm{pu})$ & $\begin{array}{c}\mathrm{Q} \\
(\mathrm{pu})\end{array}$ & \\
\hline 1 & 0.023 & 0.5768 & 0.315 & 0.292 & 1 & 0.009 & 0.5452 & 0.36 & 0.351 & 1 & 0.019 & 0.6688 & 0.285 & 0.266 \\
\hline
\end{tabular}


Table 4.6 shows evaluation of the buses 30, 29, and 26 Q-V curves. These results can be used effectively in planning or operation of this system.

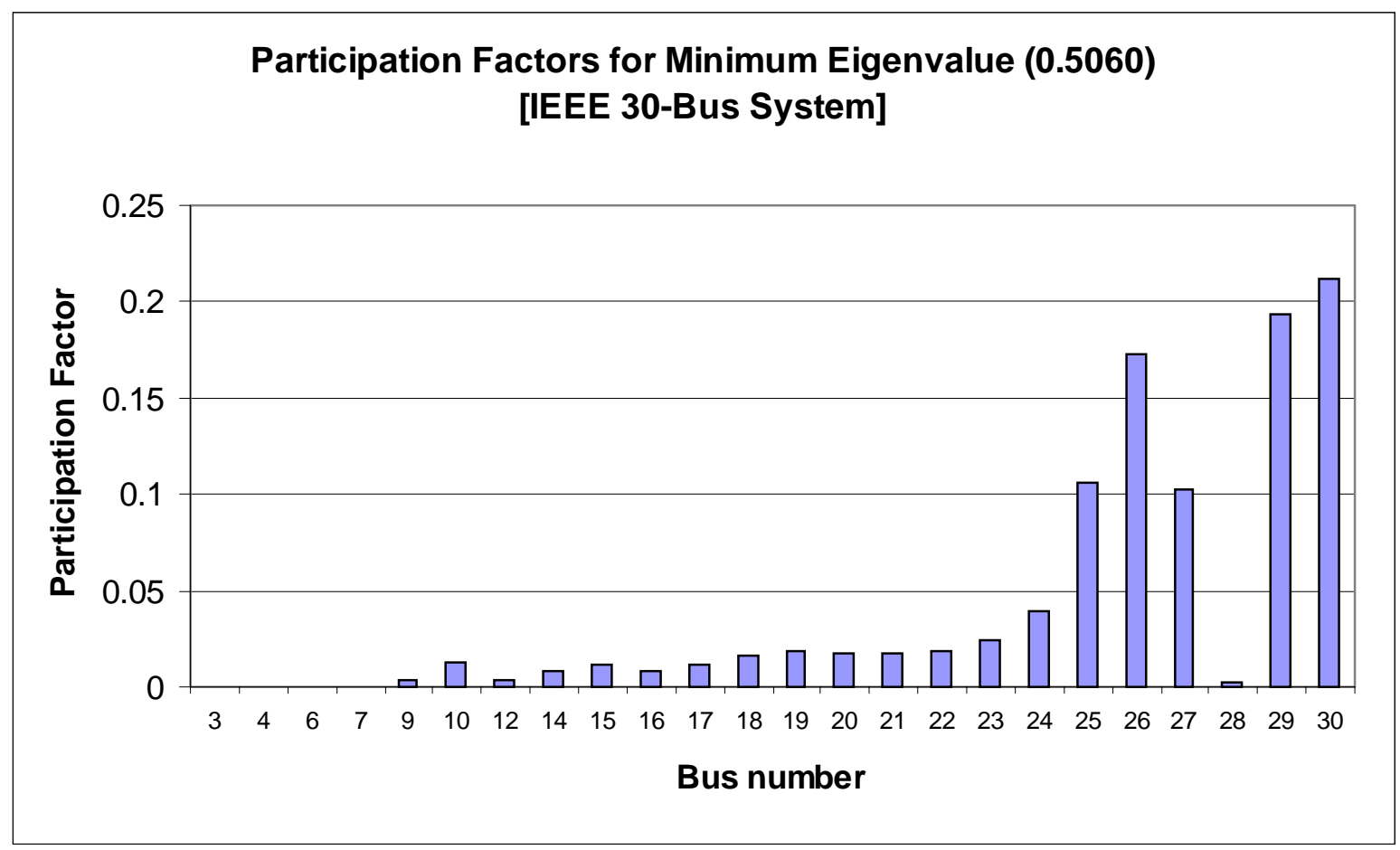

Figure 4.11 The participating factor of all buses for most critical mode for the IEEE 30 Bus system.

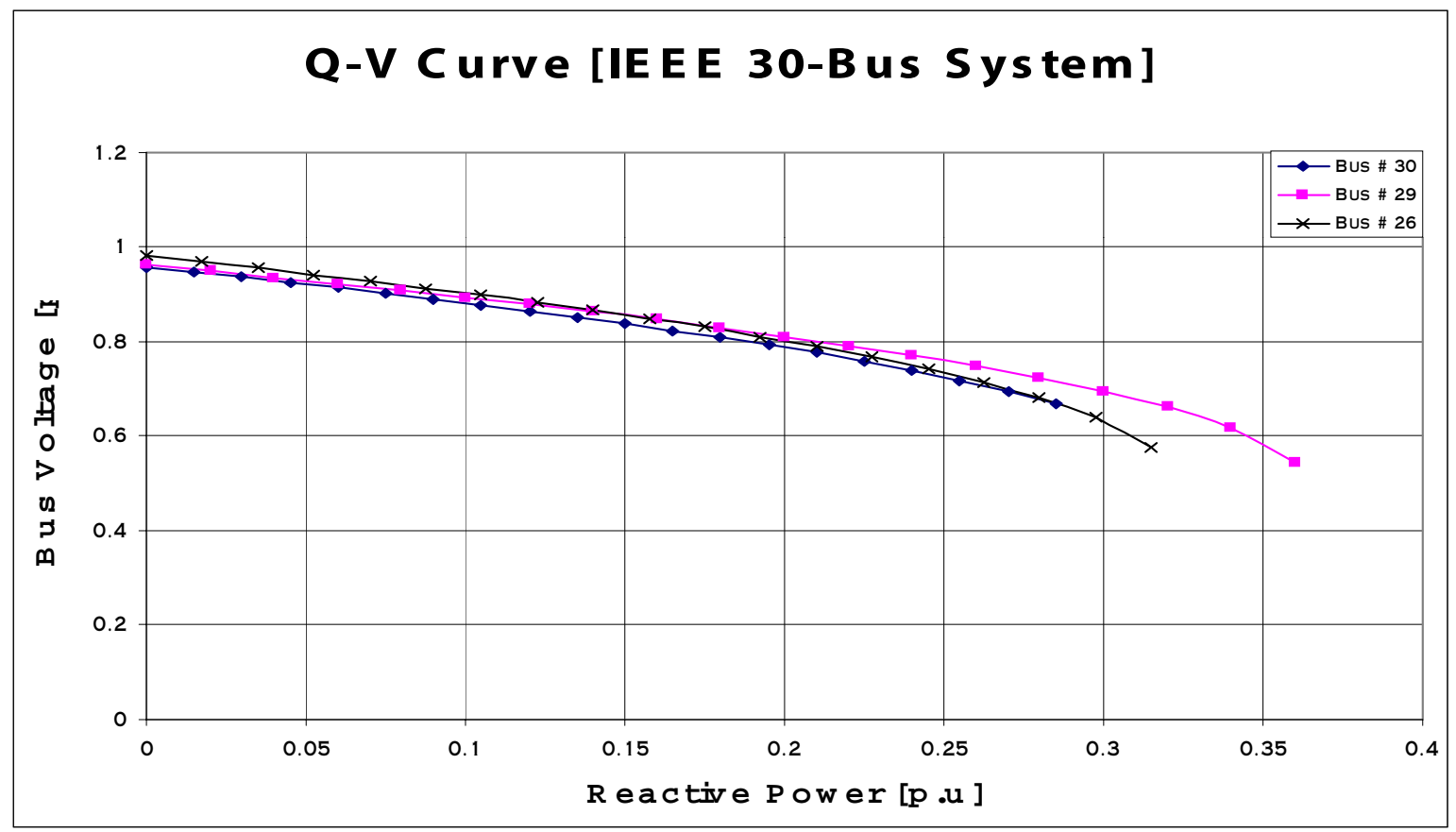

Figure 4.12 The Q-V curves at buses 30, 29 and 26 for the IEEE 30 Bus system. 


\subsection{Analysis Considering Load Characteristics.}

The modal analysis including load characteristics is performed for the three suggested test systems. Different voltage dependent load models can be implemented by changing the $\mathrm{np}$ and nq values in equations (3.15) and (3.16). The voltage profile of the buses is presented from the load flow solution. Then, the minimum eigenvalue of the reduced Jacobian matrix is calculated. After that, computing the participating factors identifies the weakest load buses, which are subject to voltage collapse. The results are shown in Figure 4.13 to Figure 4.26.

\subsubsection{Western System Coordinating Council (WSCC) 3-Machines 9-Bus system.}

Figure 4.13 shows the voltage profiles of all buses of the Western System Coordinating Council (WSCC) 3-Machines 9-Bus system as obtained form the load flow considering different load characteristics. The result shows four types of loads, including constant load $(n p=n q=0)$ and three different voltage dependent loads $(n p=n q=1, n p=n q=2$ and $n p=n q=3)$. It can be seen that all the bus voltages are within the acceptable level $( \pm 5 \%)$; some standards consider $( \pm 10 \%)$. In general, the lowest voltage compared to the other buses can be noticed at bus number 5 in all cases.

Table 4.7 WSCC 3-Machines 9-Bus system eigenvalues at different $n p$ and nq values.

\begin{tabular}{||c|c|c|c|c|}
\cline { 2 - 5 } \multicolumn{1}{c|}{} & $\begin{array}{c}\lambda \text { at np }=\mathrm{nq}= \\
0\end{array}$ & $\begin{array}{c}\lambda \text { at } \mathrm{np}=\mathrm{nq}= \\
1\end{array}$ & $\begin{array}{c}\lambda \text { at } \mathrm{np}=\mathrm{nq}= \\
2\end{array}$ & $\lambda$ at $\mathrm{np}=\mathrm{nq}=3$ \\
\hline 1 & 51.0938 & 50.8757 & 50.8106 & 50.8012 \\
\hline 2 & 5.9589 & 5.9003 & 5.8806 & 5.8778 \\
\hline 3 & 46.6306 & 46.3852 & 46.3063 & 46.2921 \\
\hline 4 & 12.9438 & 12.7244 & 12.6545 & 12.6397 \\
\hline 5 & 14.9108 & 14.8586 & 14.8505 & 14.8531 \\
\hline 6 & 36.3053 & 36.1263 & 36.0700 & 36.0590 \\
\hline
\end{tabular}

Again the total number of eigenvalues of the reduced Jacobian matrix $J_{R}$ is expected to be six as shown in Table 4.7. The eigenvalues are listed for the all simulated load types. Note that all the eigenvalues are positive which means that the system voltage is stable. 


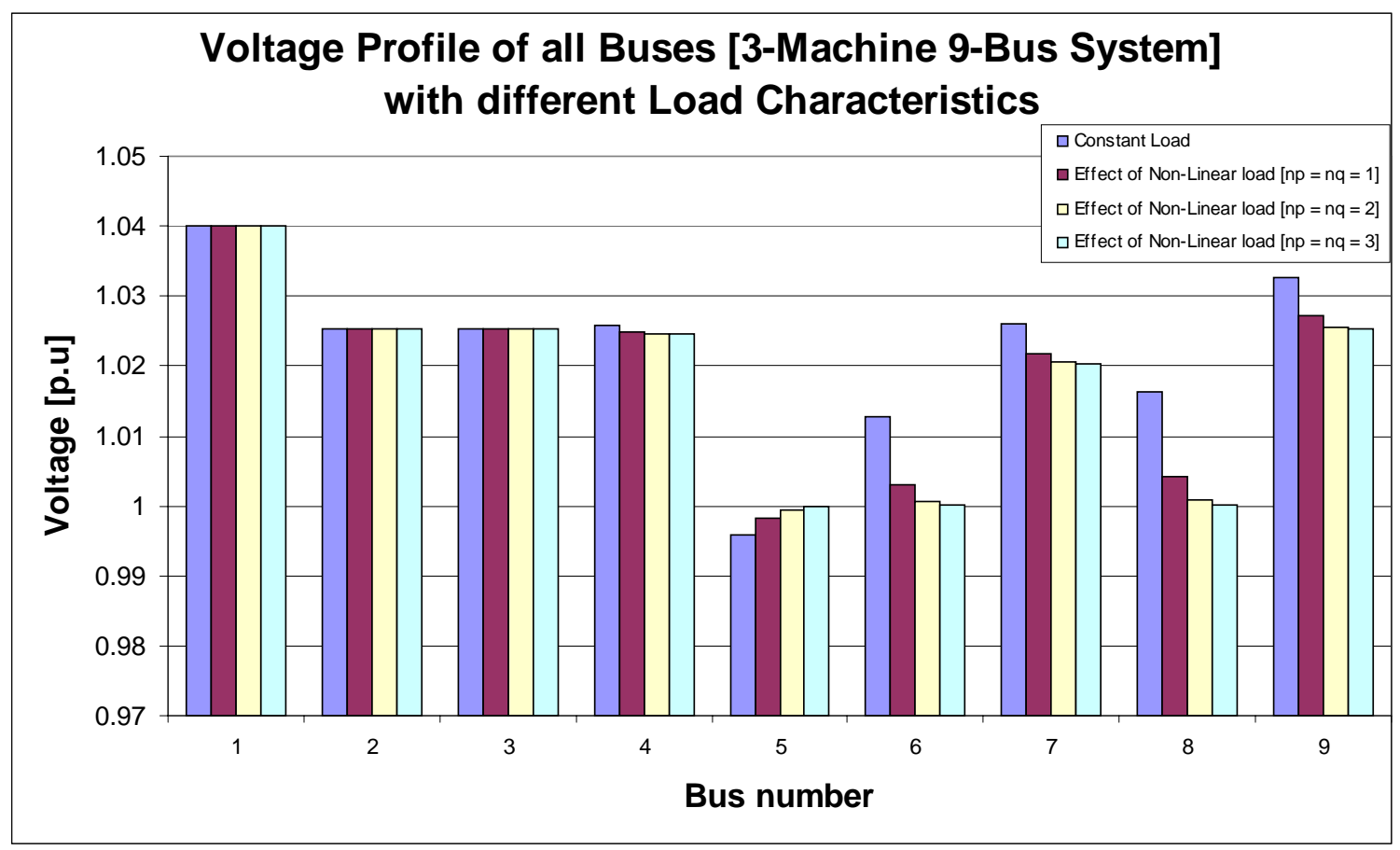

Figure 4.13 Voltage profiles of all buses of the WSCC 3-Machines 9-Bus system at different load models.

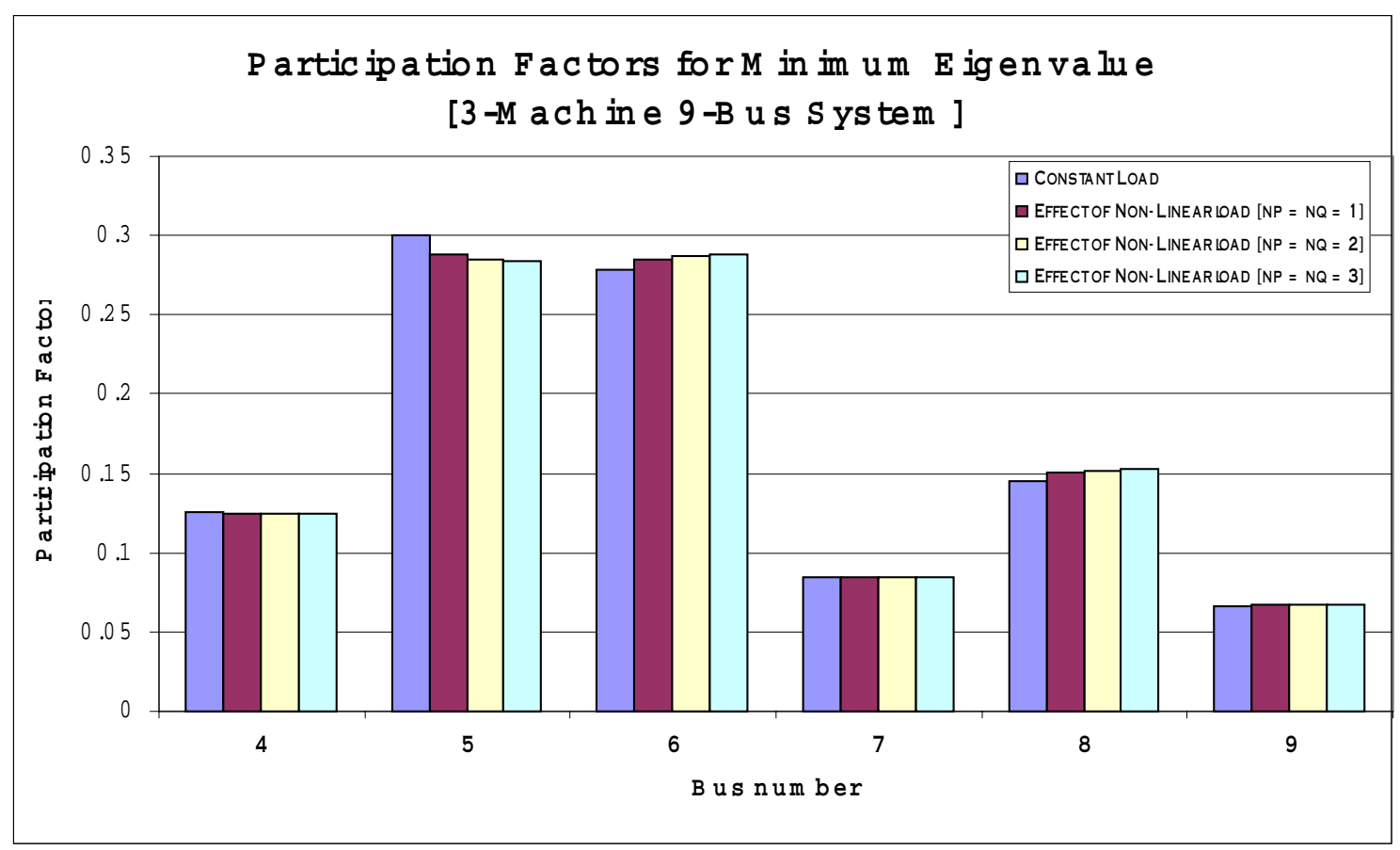

Figure 4.14 The participating factor of all buses for most critical modes for the WSCC 3-Machines 9-Bus system at different load models. 


\section{CHAPTER 4 RESULTS AND DISCUSSION}

From Table 4.7, it can be noticed that the minimum eigenvalue located in the $2^{\text {nd }}$ mode, which is the most critical mode. The participating factors for these modes have been calculated and the result is shown in Figure 4.14. In general, the result shows that, the buses 5,6 and 8 have the highest participation factors to the critical mode, which are similar as obtained before using the constant load model. The largest participation factor value at bus \# 5 indicates a high contribution of this bus to the voltage collapse especially with constant load and when $n p=n q=1$ for the load model. However, the situation changes a little bit with the load models $n p=n q=2$ and $n p=n q=3$ and bus \# 6 appears to be the most critical bus.

The Q-V curves were generated for the weakest buses, bus \# 5 and bus \# 6, of the critical mode in the Western System Coordinating Council (WSCC) 3-Machines 9-Bus system as expected by the modal analysis method at different voltage dependent load models. The curves are shown in Figure 4.15 and Figure 4.16.

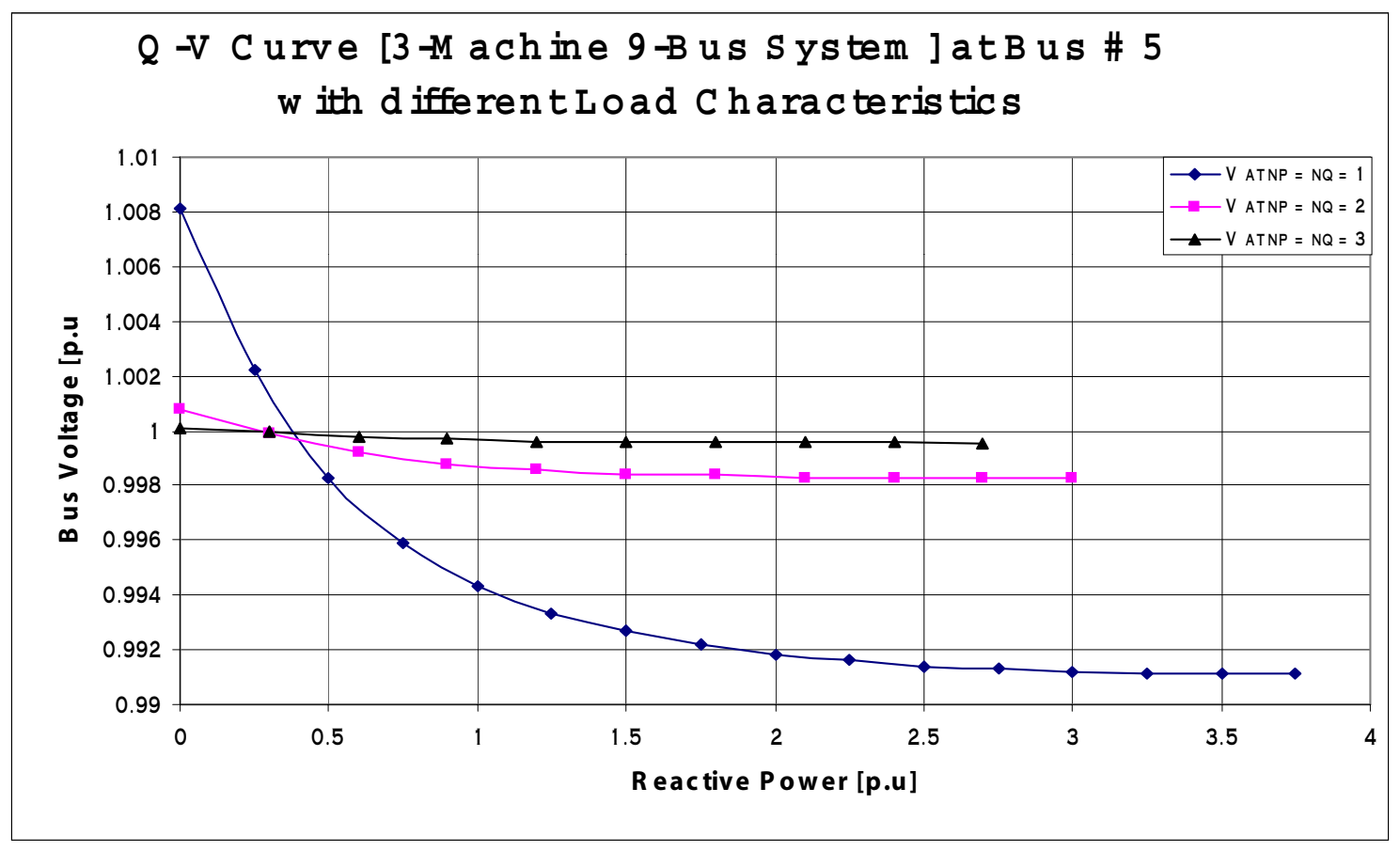

Figure 4.15 The Q-V curves at bus 5 for the WSCC 3-Machines 9-Bus system at different load models. 


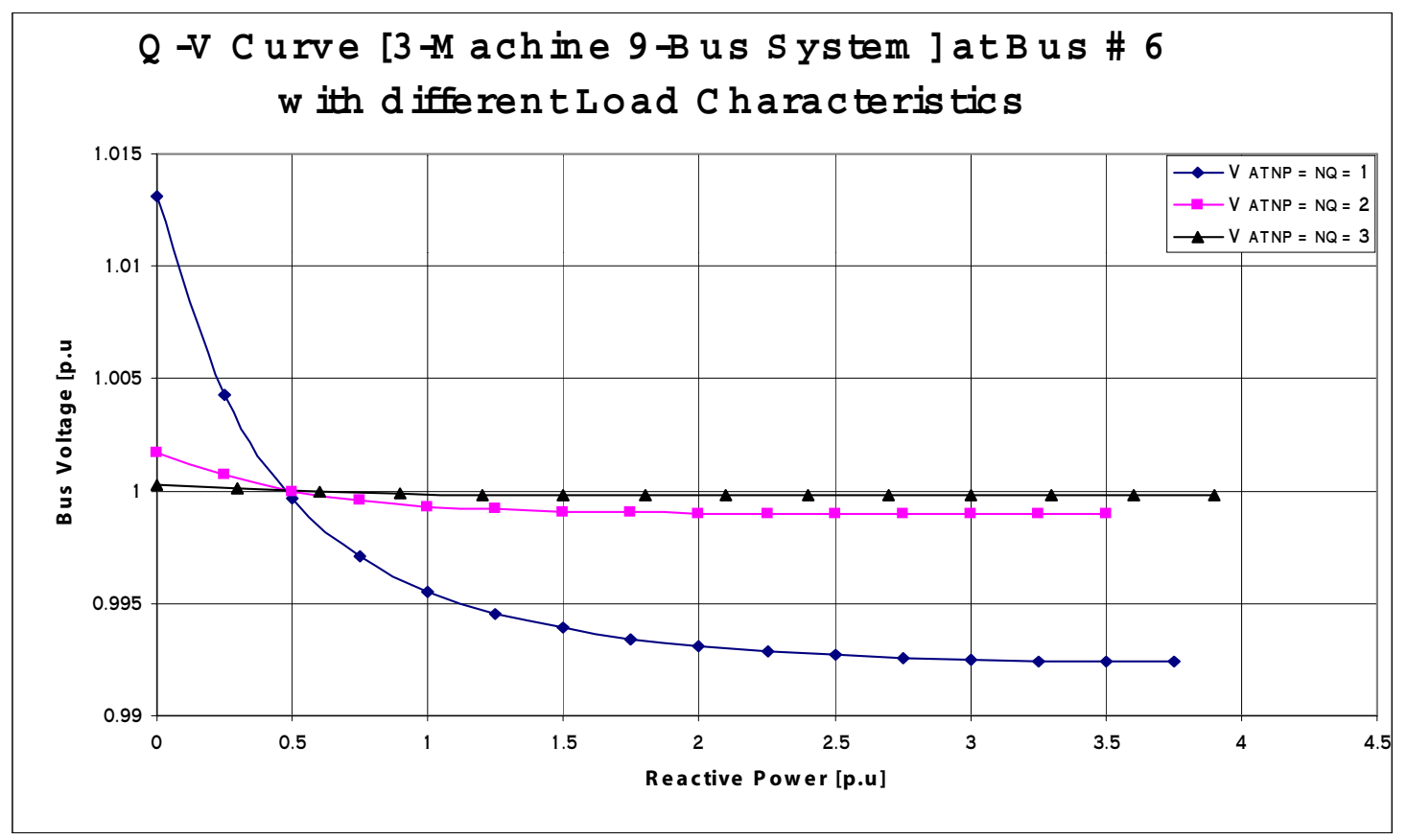

Figure 4.16 The Q-V curves at bus 6 for the WSCC 3-Machines 9-Bus system at different load models.

Table 4.8 Voltage and reactive power margins for the WSCC system from Q-V curves for bus \# 5.

\begin{tabular}{|c|c|c|c|c|c|c|c|c|c|c|c|c|c|c|c|c|c|}
\hline \multirow{2}{*}{\multicolumn{2}{|c|}{$\begin{array}{c}\text { Operating } \\
\text { Point }\end{array}$}} & \multicolumn{4}{|c|}{$\mathrm{np}=\mathrm{nq}=0$} & \multicolumn{4}{|c|}{$\mathrm{np}=\mathrm{nq}=1$} & \multicolumn{4}{|c|}{$\mathrm{np}=\mathrm{nq}=2$} & \multicolumn{4}{|c|}{$\mathrm{np}=\mathrm{nq}=3$} \\
\hline & & \multicolumn{2}{|c|}{$\begin{array}{l}\text { Maximum } \\
\text { withstand }\end{array}$} & \multicolumn{2}{|c|}{ Margin } & \multicolumn{2}{|c|}{$\begin{array}{l}\text { Maximum } \\
\text { withstand }\end{array}$} & \multicolumn{2}{|c|}{ Margin } & \multicolumn{2}{|c|}{$\begin{array}{l}\text { Maximum } \\
\text { withstand }\end{array}$} & \multicolumn{2}{|c|}{ Margin } & \multicolumn{2}{|c|}{$\begin{array}{l}\text { Maximum } \\
\text { withstand }\end{array}$} & \multicolumn{2}{|c|}{ Margin } \\
\hline V & $\mathrm{Q}$ & V & Q & $\Delta \mathrm{V}$ & $\Delta \mathrm{Q}$ & $\mathrm{V}$ & Q & $\Delta \mathrm{V}$ & $\Delta \mathrm{Q}$ & $\mathrm{V}$ & $\mathrm{Q}$ & $\Delta \mathrm{V}$ & $\Delta \mathrm{Q}$ & $\mathrm{V}$ & $\mathrm{Q}$ & $\Delta \mathrm{V}$ & $\Delta \mathrm{Q}$ \\
\hline- & ? & 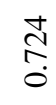 & $\begin{array}{l}\text { î } \\
\text { ì }\end{array}$ & స̃ & $\frac{n}{i}$ & $\bar{\sigma}$ & $\stackrel{n}{r}$ & $\begin{array}{l}\mathscr{8} \\
\stackrel{8}{0} \\
0\end{array}$ & $\stackrel{\sim}{\sim}$ & 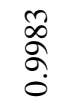 & $m$ & $\frac{1}{8}$ & ñ & ڤू & $\hat{i}$ & $\begin{array}{l}n \\
\delta \\
8\end{array}$ & กิ \\
\hline
\end{tabular}

Table 4.9 Voltage and reactive power margins for the WSCC system from Q-V curves for bus \# 6.

\begin{tabular}{|c|c|c|c|c|c|c|c|c|c|c|c|c|c|c|c|c|c|}
\hline \multirow{2}{*}{\multicolumn{2}{|c|}{$\begin{array}{c}\text { Operating } \\
\text { Point }\end{array}$}} & \multicolumn{4}{|c|}{$\mathrm{np}=\mathrm{nq}=0$} & \multicolumn{4}{|c|}{$\mathrm{np}=\mathrm{nq}=1$} & \multicolumn{4}{|c|}{$n p=n q=2$} & \multicolumn{4}{|c|}{$\mathrm{np}=\mathrm{nq}=3$} \\
\hline & & \multicolumn{2}{|c|}{$\begin{array}{l}\text { Maximum } \\
\text { withstand }\end{array}$} & \multicolumn{2}{|c|}{ Margin } & \multicolumn{2}{|c|}{$\begin{array}{l}\text { Maximum } \\
\text { withstand }\end{array}$} & \multicolumn{2}{|c|}{ Margin } & \multicolumn{2}{|c|}{$\begin{array}{l}\text { Maximum } \\
\text { withstand }\end{array}$} & \multicolumn{2}{|c|}{ Margin } & \multicolumn{2}{|c|}{$\begin{array}{l}\text { Maximum } \\
\text { withstand }\end{array}$} & \multicolumn{2}{|c|}{ Margin } \\
\hline $\mathrm{V}$ & $\mathrm{Q}$ & $\mathrm{V}$ & $\mathrm{Q}$ & $\Delta \mathrm{V}$ & $\Delta \mathrm{Q}$ & $\mathrm{V}$ & $\mathrm{Q}$ & $\Delta \mathrm{V}$ & $\Delta \mathrm{Q}$ & $\mathrm{V}$ & $\mathrm{Q}$ & $\Delta \mathrm{V}$ & $\Delta \mathrm{Q}$ & V & $\mathrm{Q}$ & $\Delta \mathrm{V}$ & $\Delta \mathrm{Q}$ \\
\hline- & $\tilde{3}$ & 氕 & $\begin{array}{l}\mathscr{n} \\
\infty \\
i\end{array}$ & ?ֶ? & 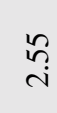 & 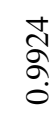 & $\stackrel{n}{n}$ & 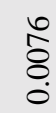 & $\stackrel{n}{\stackrel{n}{r}}$ & $\begin{array}{l}\stackrel{\Omega}{\sigma} \\
\text { ळे }\end{array}$ & $\ddot{n}$ & $\stackrel{0}{8}$ & $\ddot{n}$ & $\stackrel{\infty}{\circ}$ & $\hat{m}$ & 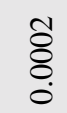 & $\stackrel{b}{\oplus}$ \\
\hline
\end{tabular}




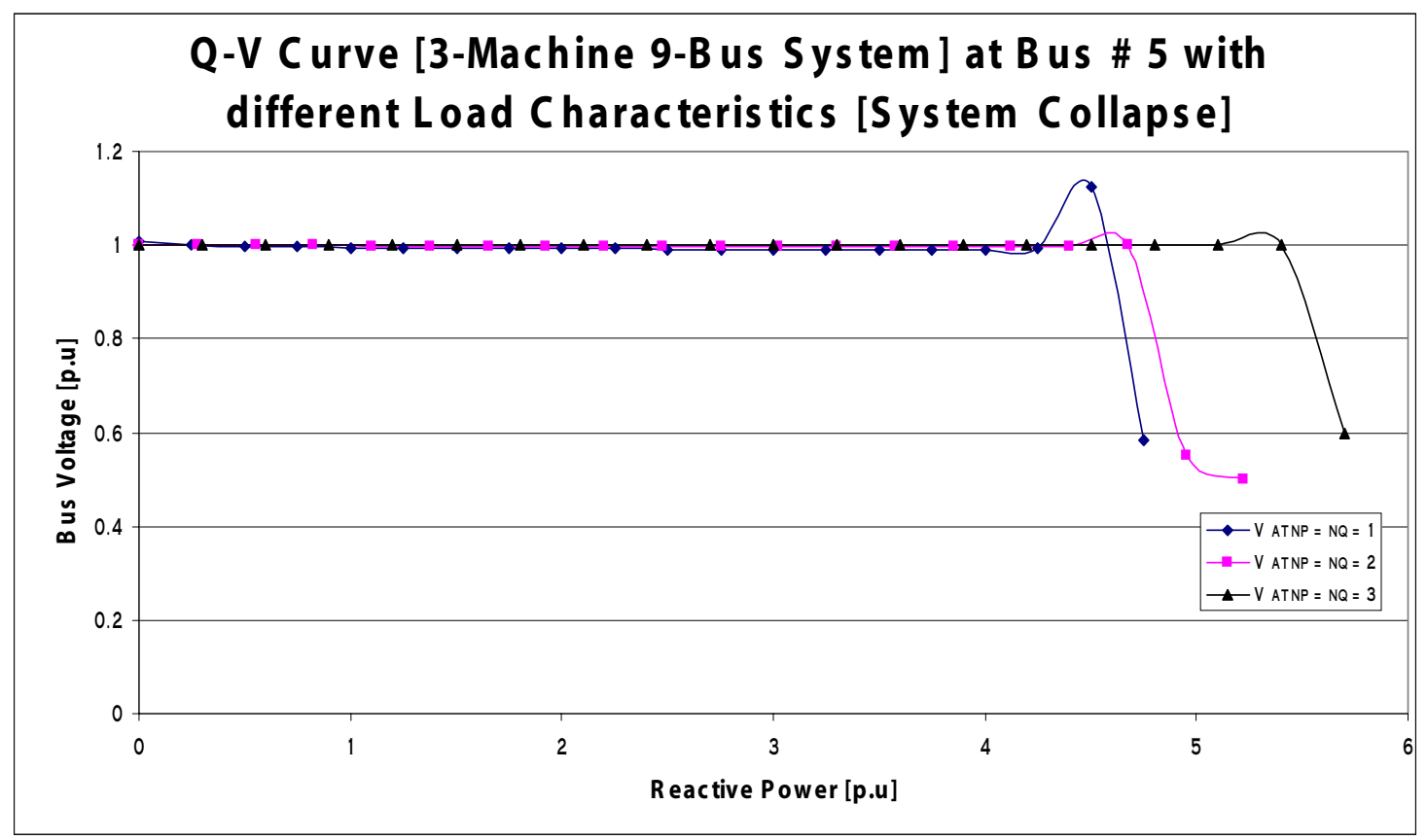

Figure 4.17 The Q-V curves at bus 5 for the WSCC 3-Machines 9-Bus system at different load models (Unstable system).

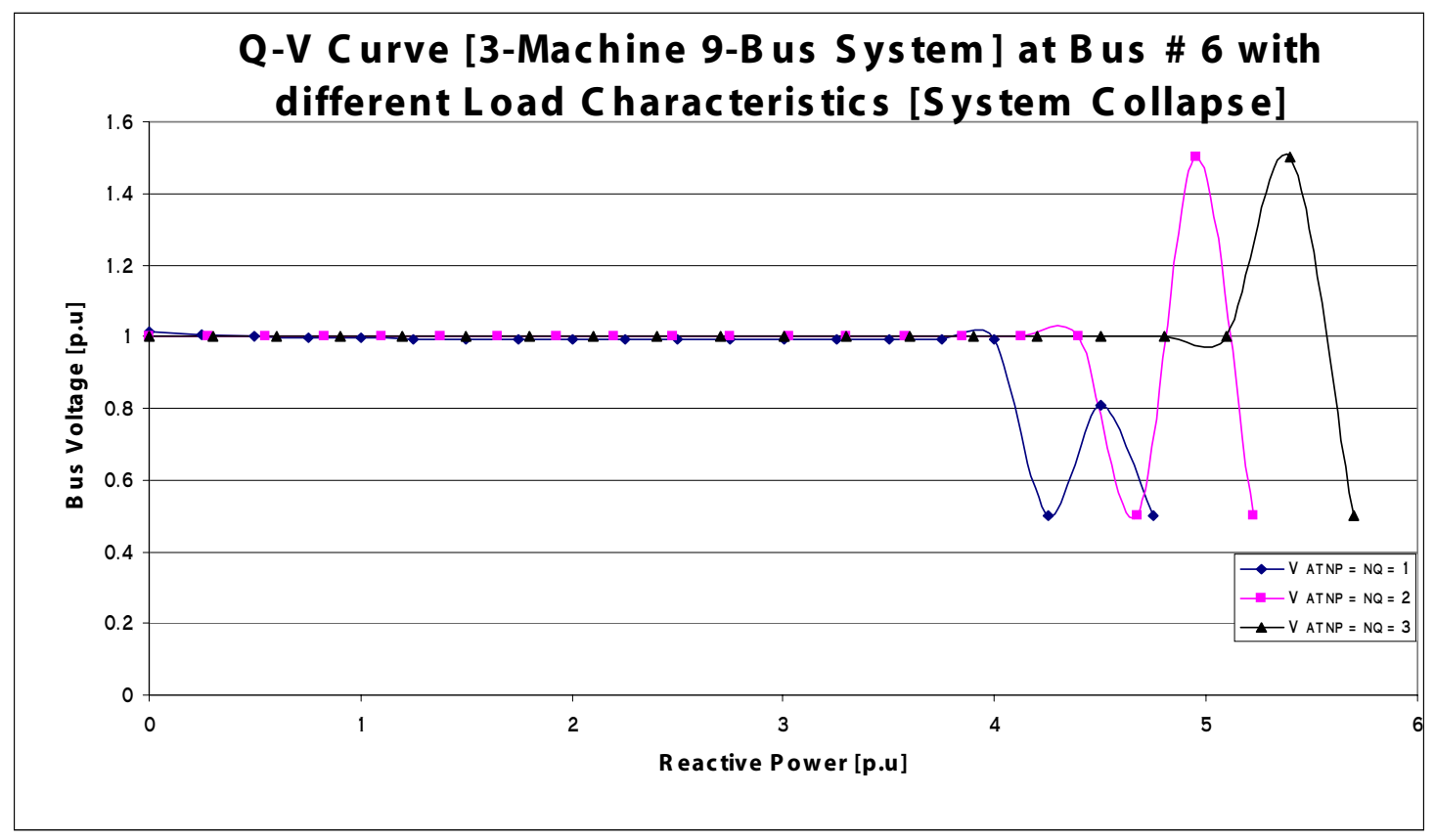

Figure 4.18 The Q-V curves at bus 6 for the WSCC 3-Machines 9-Bus system at different load models (Unstable system). 


\section{CHAPTER 4 RESULTS AND DISCUSSION}

From Table 4.8 and Table 4.9, the voltage dependent load model affected the stability margin. However, these models didn't change the location of the weakest buses allocated by the constant load model. On the other hand a noticed change in the voltage level as well as in the distance to voltage collapse appeared clearly. The voltage level improved by increasing the value of np and nq, while the distance to voltage collapse reduced as the value of $\mathrm{np}$ and nq increased.

Figure 4.17 and Figure 4.18 show the Q-V curves of bus 5 and bus 6 respectively of the Western System Coordinating Council (WSCC) 3-Machines 9-Bus system while the stability margins are exceeded. The curves shows unstable operation and the system has a voltage collapse.

\subsubsection{The IEEE 14 Bus system.}

Figure 4.19 shows the voltage profiles of all buses of the IEEE 14 Bus system as obtained form the load flow considering different load characteristics. The result shows four types of loads, including constant load $(n p=n q=0)$ and three different voltage dependent loads $(n p=n q=1, n p=n q=2$ and $n p=n q=3$ ). It can be seen that all the bus's voltages are within the acceptable voltage level. The lowest voltage compared to the other buses can be noticed in bus number 4 in all cases.

Table 4.10 IEEE 14 Bus system eigenvalues at different $n p$ and nq values.

\begin{tabular}{|c||c|c|c|c||}
\cline { 2 - 5 } \multicolumn{1}{c|}{} & $\mathrm{np}=\mathrm{nq}=0$ & $\mathrm{np}=\mathrm{nq}=1$ & $\mathrm{np}=\mathrm{nq}=2$ & $\mathrm{np}=\mathrm{nq}=3$ \\
\hline \hline 1 & 62.5497 & 61.6267 & 58.5146 & 57.3693 \\
\hline 2 & 40.0075 & 39.8004 & 38.6511 & 38.3935 \\
\hline 3 & 21.5587 & 21.1833 & 20.0812 & 19.7594 \\
\hline 4 & 2.7811 & 2.6887 & 2.4167 & 2.3092 \\
\hline 5 & 11.1479 & 10.8571 & 14.1818 & 13.8291 \\
\hline 6 & 15.7882 & 15.3665 & 9.9570 & 9.5893 \\
\hline 7 & 5.4925 & 5.3190 & 5.1743 & 5.1691 \\
\hline 8 & 18.7197 & 18.1899 & 17.8498 & 17.8003 \\
\hline 9 & 7.5246 & 7.3038 & 7.1718 & 7.1901 \\
\hline
\end{tabular}

Again the total number of eigenvalues of the reduced Jacobian matrix $J_{R}$ is expected to be nine as shown in Table 4.10. The eigenvalues are listed for the all simulated load types. Note that all the eigenvalues are positive which means that the system voltage is stable. 


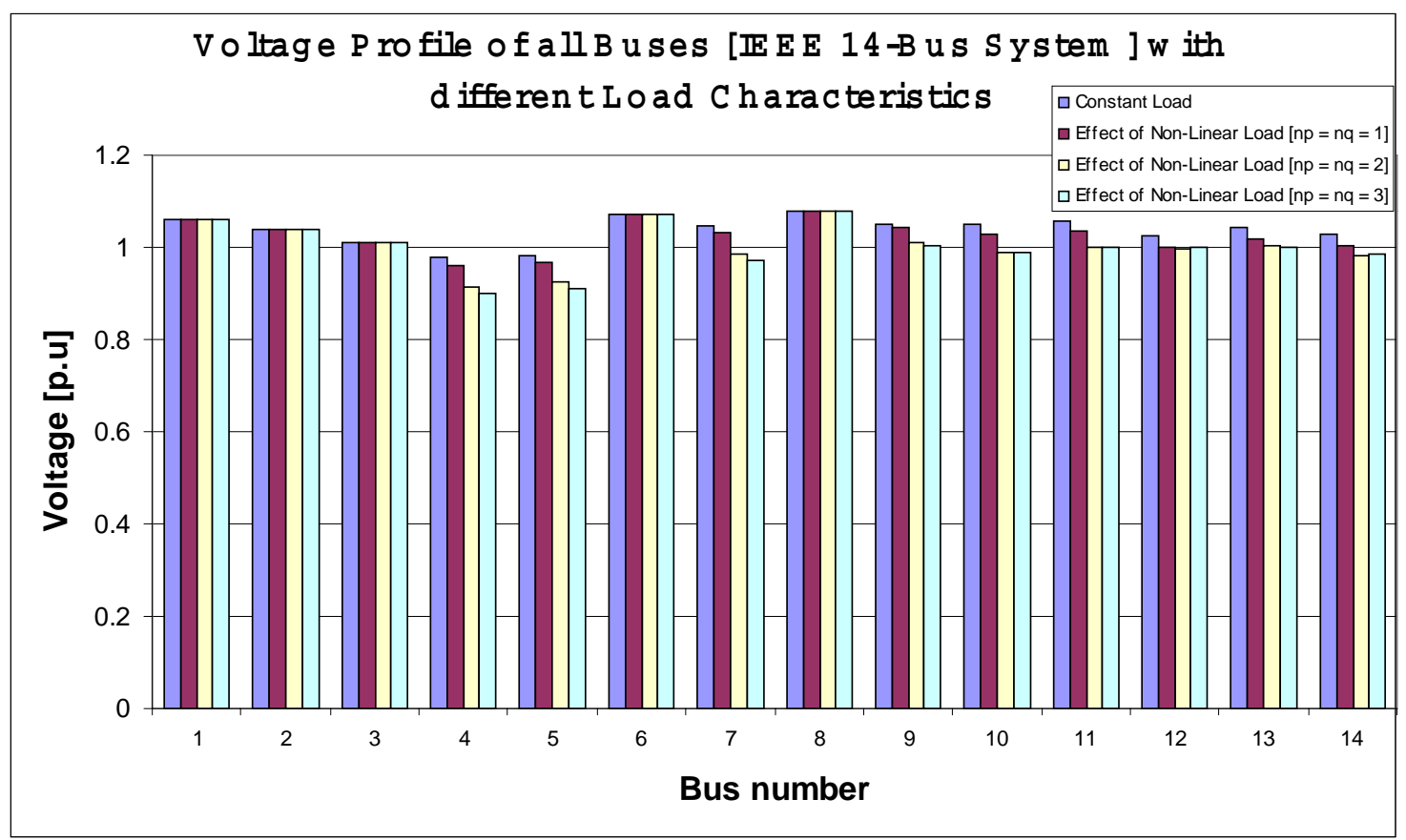

Figure 4.19 Voltage profiles of all buses of the IEEE 14 Bus system at different load's models.

From Table 4.10, it can be noticed that the minimum eigenvalue located in the $4^{\text {th }}$ mode, is the most critical mode. The participating factors for these modes have been calculated and the result are shown in Figure 4.20. In general, the result shows that, the buses 14,10 and 9 have the highest participation factors to the critical mode, which are similar as obtained before using the constant load model. The largest participation factor value at bus \# 14 indicates the highest contribution of this bus to the voltage collapse.

The Q-V curves were generated for the weakest bus, bus \# 14, of the critical mode in the IEEE 14Bus system identified by the modal analysis method. The curves are shown in Figure 4.21.

From Table 4.11, the voltage dependent load model affected the stability margin. However those models didn't change the expected participated weakest buses to the voltage collapse compared to the constant load model. On the other hand, a noticed change in the voltage level as well as in the distance to voltage collapse appeared clearly. The voltage level improved by increasing the value 
of $\mathrm{np}$ and $\mathrm{nq}$, while the distance to voltage collapse reduced as the value of $\mathrm{np}$ and $\mathrm{nq}$ was increased.

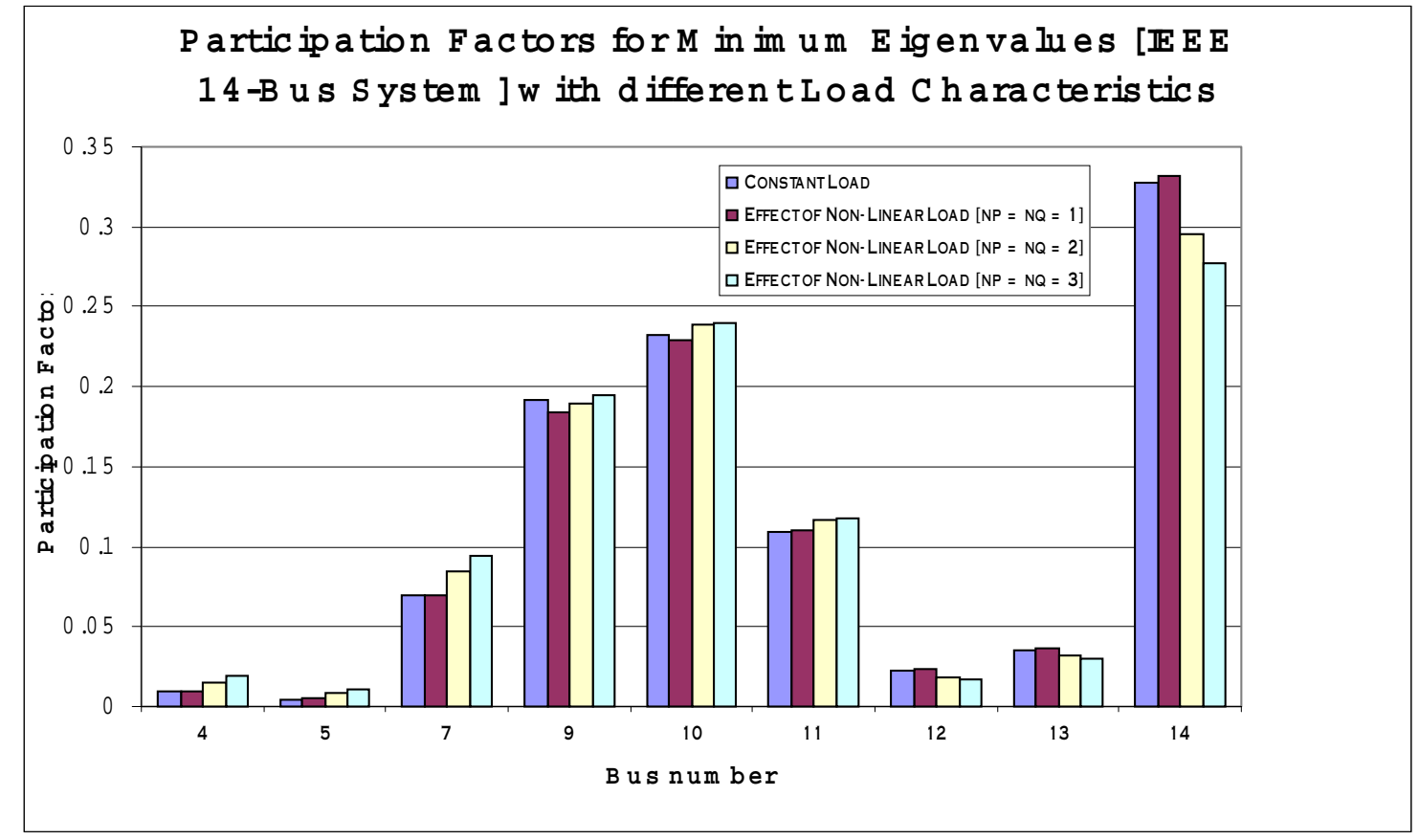

Figure 4.20 The participating factor of all buses for most critical modes for the IEEE 14 Bus system at different load's models.

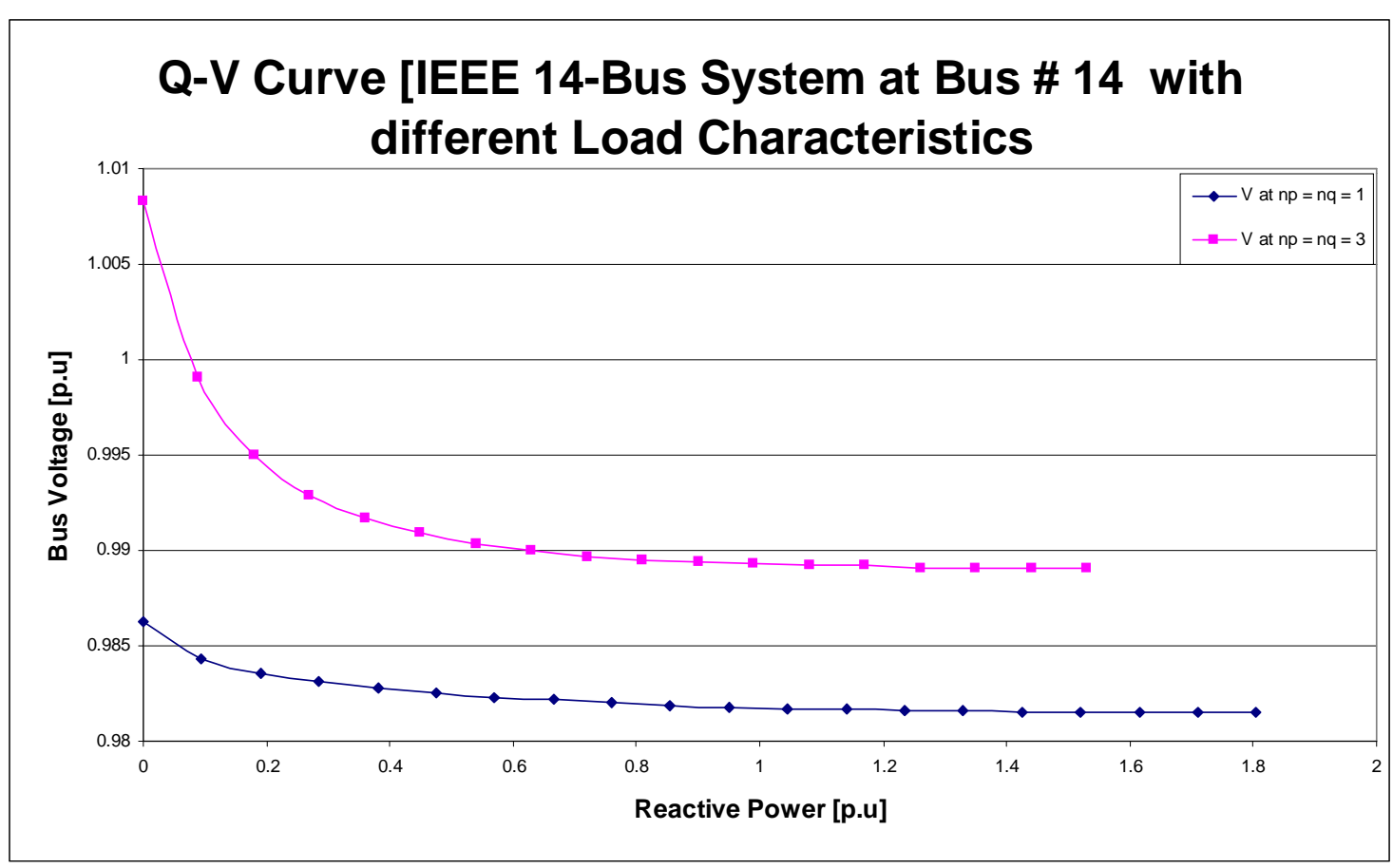

Figure 4.21 The Q-V curves at bus 14 for the IEEE 14 Bus system at different load's models. 
CHAPTER 4 RESULTS AND DISCUSSION

Table 4.11 Voltage and reactive power margins for the IEEE 14 Bus system from Q-V curves for bus \# 14.

\begin{tabular}{|c|c|c|c|c|c|c|c|c|c|c|c|c|c|}
\hline \multirow{2}{*}{\multicolumn{2}{|c|}{ Operating Point }} & \multicolumn{4}{|c|}{$n p=n q=0$} & \multicolumn{4}{|c|}{$\mathrm{np}=\mathrm{nq}=1$} & \multicolumn{4}{|c|}{$\mathrm{np}=\mathrm{nq}=3$} \\
\hline & & \multicolumn{2}{|c|}{$\begin{array}{l}\text { Maximum } \\
\text { withstand }\end{array}$} & \multicolumn{2}{|c|}{ Margin } & \multicolumn{2}{|c|}{$\begin{array}{l}\text { Maximum } \\
\text { withstand }\end{array}$} & \multicolumn{2}{|c|}{ Margin } & \multicolumn{2}{|c|}{$\begin{array}{l}\text { Maximum } \\
\text { withstand }\end{array}$} & \multicolumn{2}{|c|}{ Margin } \\
\hline $\mathrm{V}$ & $\mathrm{Q}$ & $\mathrm{V}$ & $\mathrm{Q}$ & $\Delta \mathrm{V}$ & $\Delta \mathrm{Q}$ & $\mathrm{V}$ & $\mathrm{Q}$ & $\Delta \mathrm{V}$ & $\Delta \mathrm{Q}$ & $\mathrm{V}$ & Q & $\Delta \mathrm{V}$ & $\Delta \mathrm{Q}$ \\
\hline 1 & 0.05 & 0.5984 & 1.2 & 0.4016 & 1.15 & 0.9815 & 1.805 & 0.0185 & 1.755 & 0.9891 & 1.53 & 0.0109 & 1.48 \\
\hline
\end{tabular}

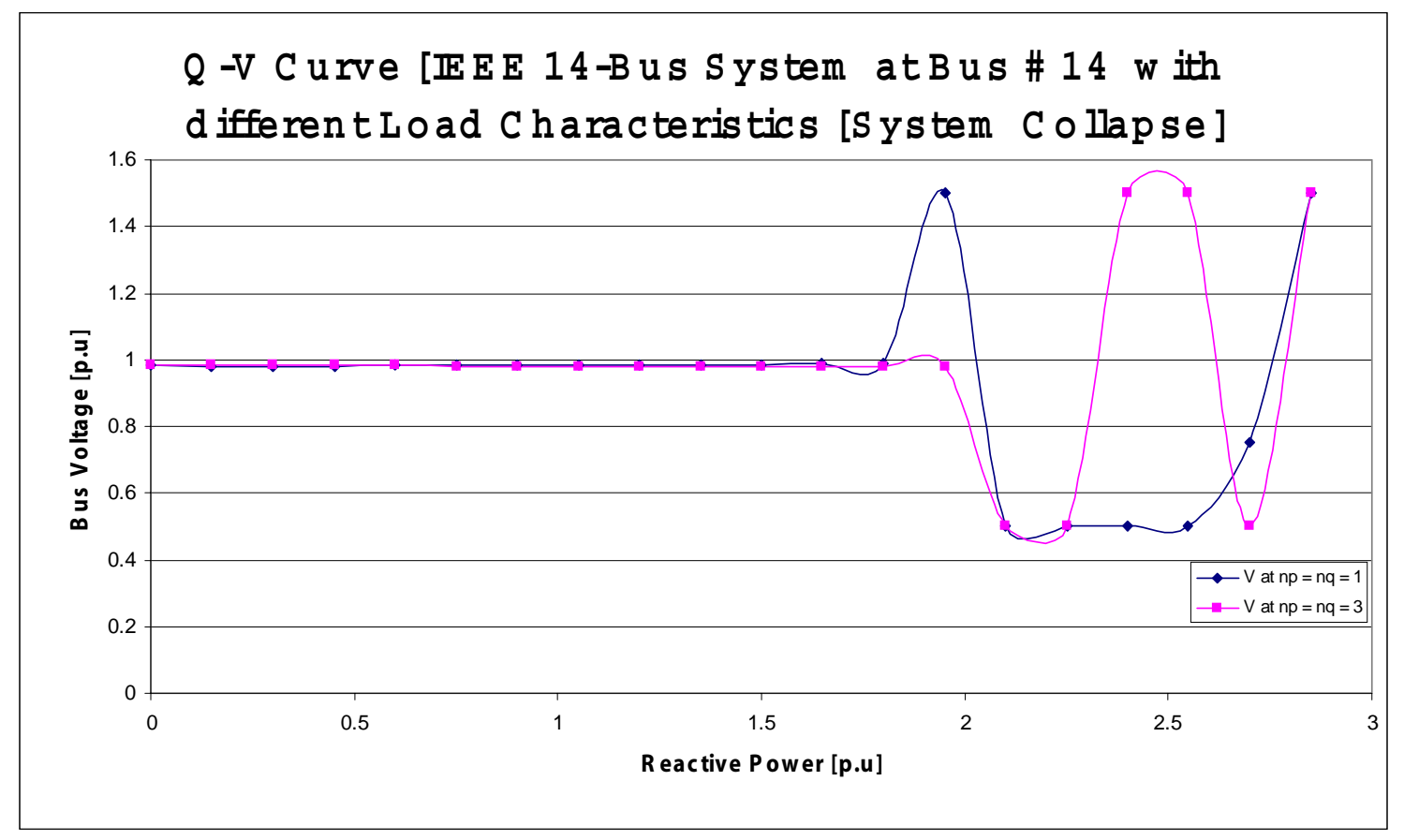

Figure 4.22 The Q-V curves at bus 14 for the IEEE 14 Bus system at different load models (Unstable system).

Figure 4.22 shows the Q-V curves of bus number 14 of the IEEE 14 Bus system while the stability margins is exceeded. The curve demonstrates unstable operation.

\subsubsection{The IEEE 30 Bus system.}

Figure 4.23 shows the voltage profiles of all buses of the IEEE 30 Bus system as obtained form the load flow considering different load characteristics. The result shows four types of load; including constant load $(n p=n q=0)$ and three different voltage dependent loads $(n p=n q=1, n p=n q=2$ 


\section{CHAPTER 4 RESULTS AND DISCUSSION}

and $n p=n q=3$ ). It can be seen that all the bus voltages are within the acceptable level. The lowest voltage compared to the other buses can be noticed in bus number 30 in all cases.

Again the total number of eigenvalues of the reduced Jacobian matrix $J_{R}$ is expected to be 24 as shown in Table 4.12. The eigenvalues are listed for the all simulated load types. Note that all the eigenvalues are positive which means that the system voltage is stable.

Table 4.12 IEEE 30 Bus system eigenvalues at different $n p$ and $n q$ values.

\begin{tabular}{||c||c|c|c|c||}
\cline { 2 - 5 } \multicolumn{1}{c|}{} & $\mathrm{np}=\mathrm{nq}=0$ & $\mathrm{np}=\mathrm{nq}=1$ & $\mathrm{np}=\mathrm{nq}=2$ & $\mathrm{np}=\mathrm{nq}=3$ \\
\hline 1 & 110.2056 & 109.3343 & 108.9713 & 108.8641 \\
\hline 2 & 100.6465 & 98.2252 & 97.8875 & 97.9381 \\
\hline 3 & 65.9541 & 65.2630 & 64.9428 & 64.8389 \\
\hline 4 & 59.5431 & 58.2062 & 57.9080 & 57.8431 \\
\hline 5 & 37.8188 & 36.7889 & 33.7897 & 36.7142 \\
\hline 6 & 35.3863 & 34.3580 & 36.6533 & 33.5617 \\
\hline 7 & 23.0739 & 23.0379 & 23.0083 & 23.0114 \\
\hline 8 & 23.4238 & 22.7018 & 22.4379 & 22.3712 \\
\hline 9 & 19.1258 & 19.4576 & 19.3834 & 19.3744 \\
\hline 10 & 19.7817 & 18.8395 & 18.7544 & 18.7458 \\
\hline 11 & 18.0785 & 17.8041 & 17.7496 & 17.7568 \\
\hline 12 & 16.3753 & 16.2569 & 16.2474 & 16.2684 \\
\hline 13 & 0.5060 & 0.5145 & 0.5178 & 0.5207 \\
\hline 14 & 13.7279 & 0.9988 & 0.9943 & 0.9960 \\
\hline 15 & 13.6334 & 1.7635 & 1.7800 & 1.7902 \\
\hline 16 & 1.0238 & 10.8959 & 10.8333 & 10.8170 \\
\hline 17 & 11.0447 & 3.4832 & 3.4729 & 3.4803 \\
\hline 18 & 1.7267 & 8.5203 & 3.8759 & 3.8708 \\
\hline 19 & 8.7857 & 3.9180 & 8.4374 & 8.4306 \\
\hline 20 & 3.5808 & 7.4443 & 7.4613 & 7.4813 \\
\hline 21 & 4.0507 & 6.1538 & 13.5159 & 6.2256 \\
\hline 22 & 7.4360 & 13.5377 & 6.1989 & 13.5359 \\
\hline 23 & 6.0207 & 5.3471 & 5.3146 & 5.3156 \\
\hline 24 & 5.4527 & 13.2696 & 13.2050 & 13.2213 \\
\hline & & & & \\
\hline
\end{tabular}

From Table 4.12, it can be noticed that the minimum eigenvalue located in mode number 13, which is the most critical mode. The participating factors for these modes have been calculated and the result is shown in Figure 4.24. In general, the result shows that, the buses 30, 29 and 26 have the highest participation factors for the critical mode, which are similar to obtained before 
using the constant load model. The largest participation factor value at bus \# 30 indicates a high contribution of this bus to the voltage collapse.

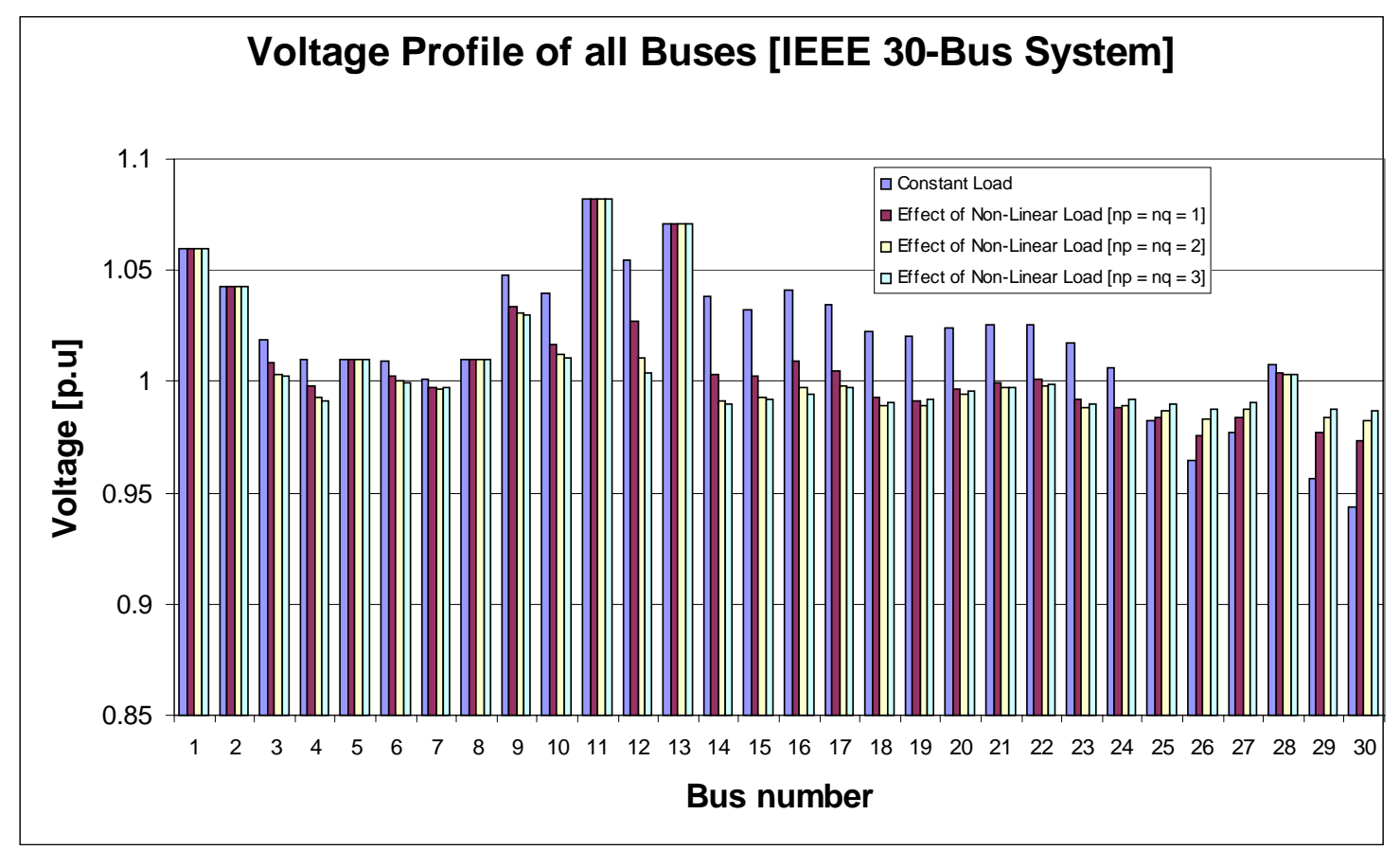

Figure 4.23 Voltage profiles of all buses of the IEEE 30 Bus system at different types of load models.

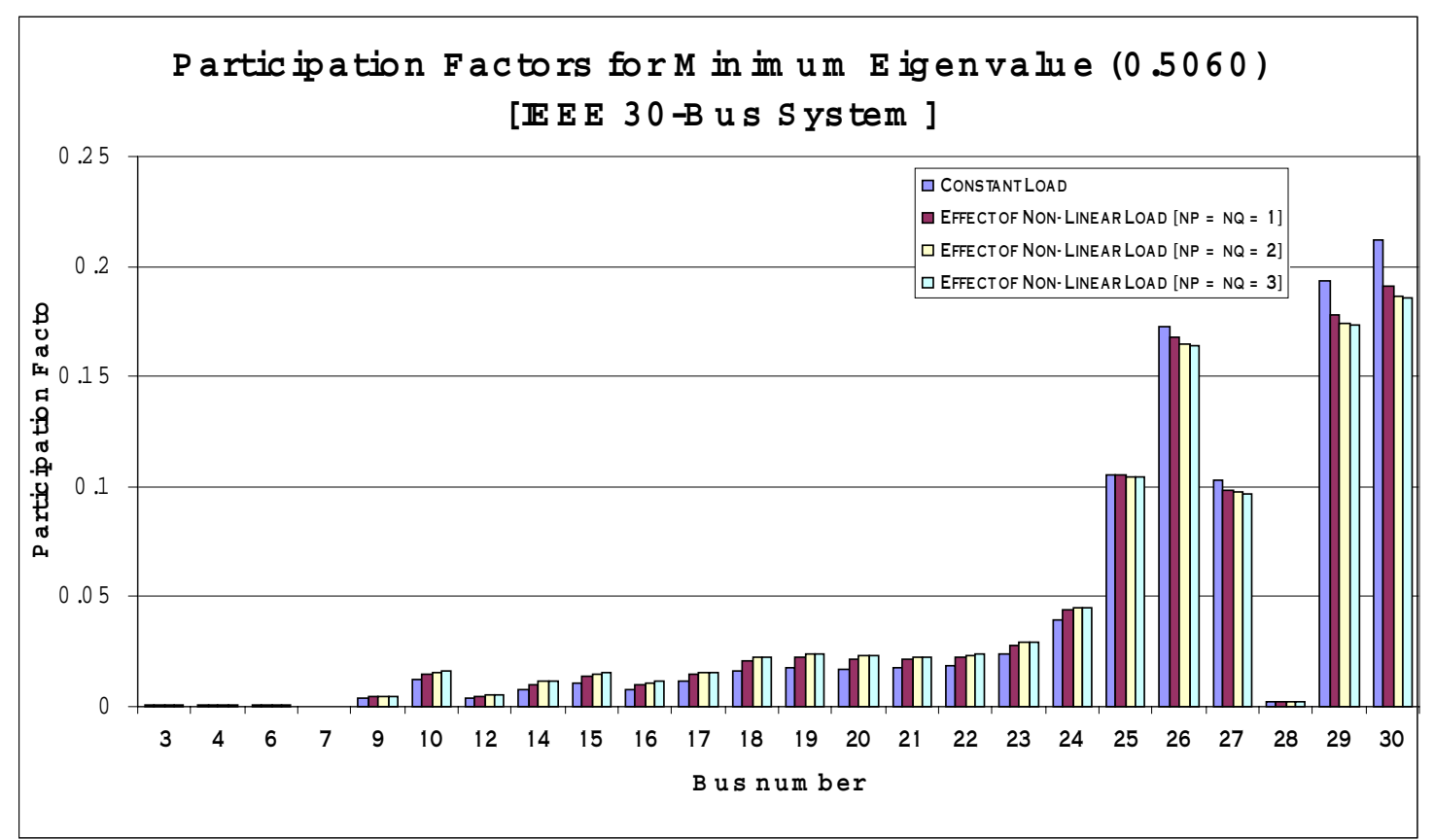

Figure 4.24 The participating factor of all buses for most critical modes for the IEEE 30 Bus at different types of load models. 
The Q-V curves were generated for the weakest buses, bus \# 30, of the critical mode in the IEEE 30-Bus system as expected by the modal analysis method at different voltage dependent load models. The curves are shown in Figure 4.25.

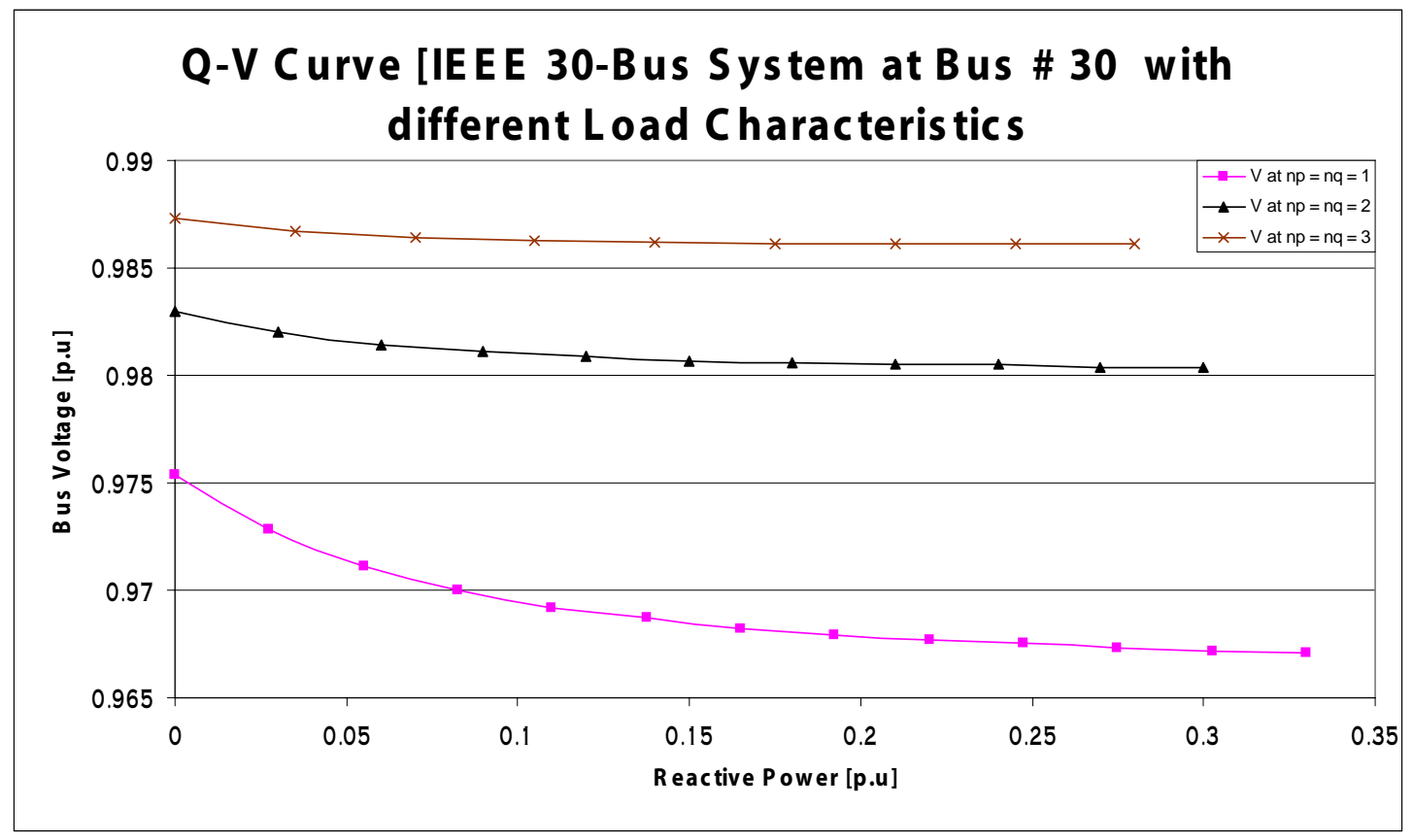

Figure 4.25 The Q-V curves at bus 30 for the IEEE 30 Bus system at different types of load.

From Table 4.13, the voltage dependent load model affected the stability margin. However, those models didn't change the expected participated weakest buses to the voltage collapse compared to the constant load model. There was a noticed improvement in the voltage level as the value of np and $\mathrm{nq}$ increased, while the distance to voltage collapse reduced as the value of $\mathrm{np}$ and $\mathrm{nq}$ increased.

Table 4.13 Voltage and reactive power margins for the IEEE 30 Bus system from Q-V curves for bus \# 30.

\begin{tabular}{|c|c|c|c|c|c|c|c|c|c|c|c|c|c|c|c|c|c|}
\hline \multirow{2}{*}{\multicolumn{2}{|c|}{$\begin{array}{c}\text { Operating } \\
\text { Point }\end{array}$}} & \multicolumn{4}{|c|}{$\mathrm{np}=\mathrm{nq}=0$} & \multicolumn{4}{|c|}{$\mathrm{np}=\mathrm{nq}=1$} & \multicolumn{4}{|c|}{$\mathrm{np}=\mathrm{nq}=2$} & \multicolumn{4}{|c|}{$\mathrm{np}=\mathrm{nq}=3$} \\
\hline & & \multicolumn{2}{|c|}{$\begin{array}{l}\text { Maximum } \\
\text { withstand }\end{array}$} & \multicolumn{2}{|c|}{ Margin } & \multicolumn{2}{|c|}{$\begin{array}{l}\text { Maximum } \\
\text { withstand }\end{array}$} & \multicolumn{2}{|c|}{ Margin } & \multicolumn{2}{|c|}{$\begin{array}{l}\text { Maximum } \\
\text { withstand }\end{array}$} & \multicolumn{2}{|c|}{ Margin } & \multicolumn{2}{|c|}{$\begin{array}{l}\text { Maximum } \\
\text { withstand }\end{array}$} & \multicolumn{2}{|c|}{ Margin } \\
\hline $\mathrm{V}$ & $\mathrm{Q}$ & V & $\mathrm{Q}$ & $\Delta \mathrm{V}$ & $\Delta \mathrm{Q}$ & $\mathrm{V}$ & $\mathrm{Q}$ & $\Delta \mathrm{V}$ & $\Delta \mathrm{Q}$ & V & $\mathrm{Q}$ & $\Delta \mathrm{V}$ & $\Delta \mathrm{Q}$ & V & $\mathrm{Q}$ & $\Delta \mathrm{V}$ & $\Delta \mathrm{Q}$ \\
\hline- & $\frac{9}{0}$ & $\begin{array}{l}\infty \\
\infty \\
\infty \\
0 \\
0 \\
0\end{array}$ & $\stackrel{n}{\infty}$ & $\stackrel{\stackrel{N}{m}}{\stackrel{0}{0}}$ & $\begin{array}{l}\text { ஜ } \\
\text { ஸे }\end{array}$ & $\begin{array}{l}\bar{\sigma} \\
\stackrel{0}{0}\end{array}$ & $\stackrel{m}{0}$ & $\begin{array}{l}\text { ते } \\
\text { ठै } \\
\text {. }\end{array}$ & ๗ై & $\begin{array}{l}\text { む } \\
\text { } \\
\text { ఏ }\end{array}$ & $\stackrel{m}{0}$ & $\frac{\circ}{\circ}$ & $\begin{array}{l}\bar{\infty} \\
\stackrel{0}{0}\end{array}$ & $\begin{array}{l}\overline{0} \\
\infty \\
\vdots \\
0\end{array}$ & $\stackrel{\infty}{\sim}$ & $\frac{\stackrel{0}{0}}{0}$ & స్ \\
\hline
\end{tabular}




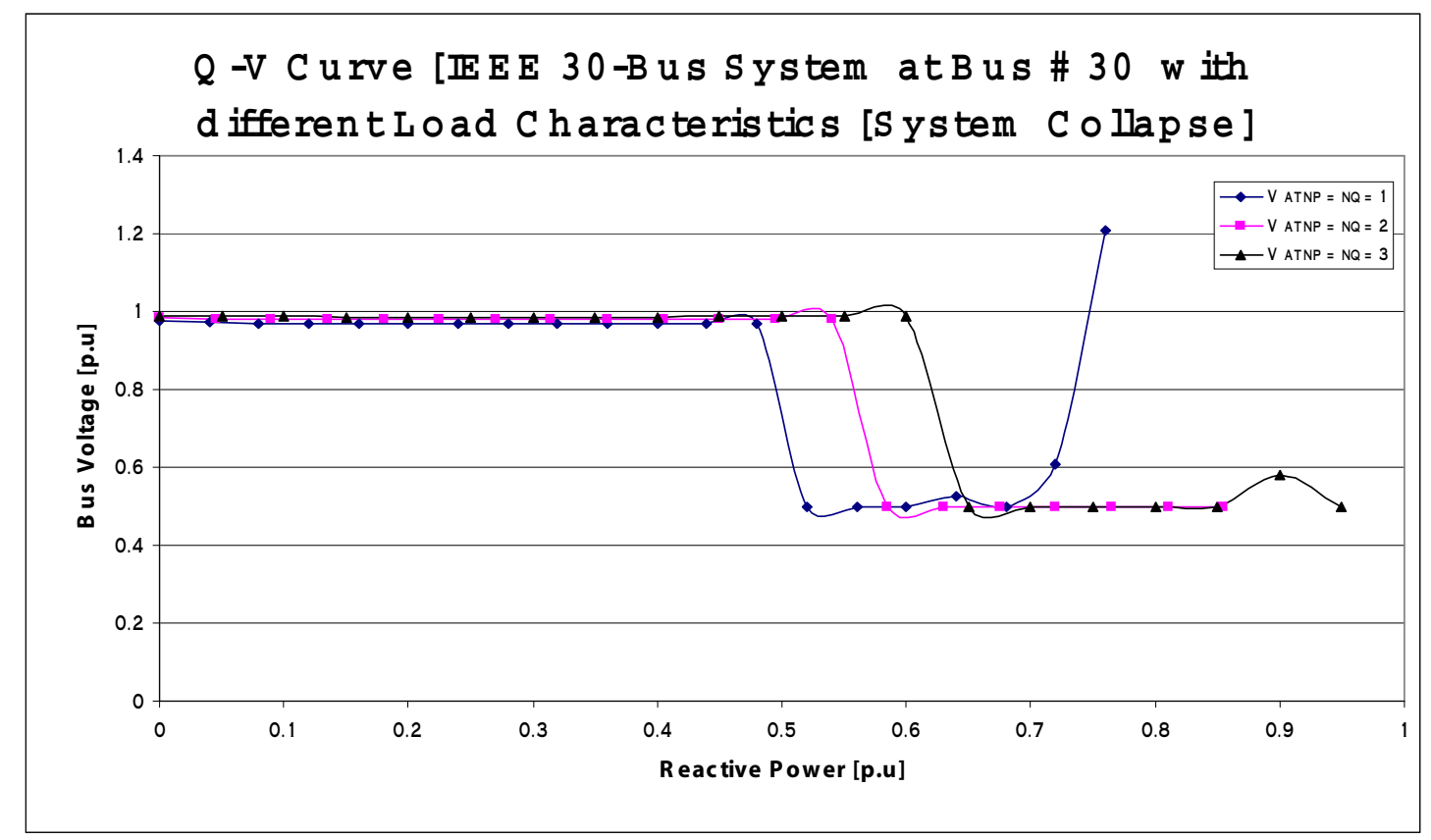

Figure 4.26 The $Q$-V curves at bus 30 for the IEEE 30 Bus system at different load's models (Unstable system).

Figure 4.26 shows the Q-V curves of bus number 30 of the IEEE 30 Bus system while the stability margins is exceeded. The curve indicates unstable operation.

\subsection{Analysis Considering Effect of Induction Machine Load.}

The modal analysis including the induction machine load is performed for the three suggested test systems. The induction machine load can be connected to any bus in the tested system. In this study two induction machine loads with different ratings have been selected for the analysis. The machines data are shown in Table 4.14. The voltage profile of the buses is presented from the load flow solution. Then, the minimum eigenvalue of the reduced Jacobian matrix is calculated. After that, computing the participating factors identifies the weakest load buses, which are subject to voltage collapse. Finally, the Q-V curves are generated to specific buses and the results are shown in Figure 4.27 to Figure 4.38. 
Table 3.14 Induction machine parameters.

\begin{tabular}{|c|c|c|c|c|c|c|c|c|c|c|}
\hline \multicolumn{3}{|c|}{ Machine rating } & & & & & & & & \\
\hline $\mathrm{hp}$ & volts & $\mathrm{rpm}$ & $\begin{array}{c}\mathrm{T}_{\mathrm{B}} \\
\text { N.m }\end{array}$ & $\begin{array}{r}\mathrm{I}_{\mathrm{B}(\mathrm{abc})} \\
\mathrm{amps}\end{array}$ & $\begin{array}{l}\mathrm{r}_{\mathrm{s}} \\
\Omega\end{array}$ & $\begin{array}{c}\mathrm{X}_{\mathrm{ls}} \\
\Omega\end{array}$ & $\begin{array}{c}\mathrm{X}_{\mathrm{M}} \\
\Omega \\
\end{array}$ & $\begin{array}{c}\mathrm{X}_{\mathrm{lr}}^{\prime} \\
\Omega\end{array}$ & $\begin{array}{l}\mathrm{r}_{\mathrm{r}} \\
\Omega\end{array}$ & $\begin{array}{c}\mathrm{J} \\
\text { kg. } \mathrm{m}^{2}\end{array}$ \\
\hline 500 & 2300 & 1773 & 1980 & 93.6 & 0.262 & 1.206 & 54.02 & 1.206 & 1.187 & 11.06 \\
\hline 2250 & 2300 & 1786 & 8900 & 421.2 & 0.029 & 0.226 & 13.04 & 0.226 & 0.022 & 63.87 \\
\hline
\end{tabular}

\subsubsection{Western System Coordinating Council (WSCC) 3-Machines 9-Bus system.}

Figure 4.27 shows the voltage profiles of all buses of the Western System Coordinating Council (WSCC) 3-Machines 9-Bus system as obtained form the load flow including induction machine load at bus \# 5. The result shows the effect of both induction machine and the constant loads. It can be seen that all the bus voltages are within the acceptable level $( \pm 5 \%)$. In general, the lowest voltage compared to the other buses can be noticed at bus number 5 in all cases.

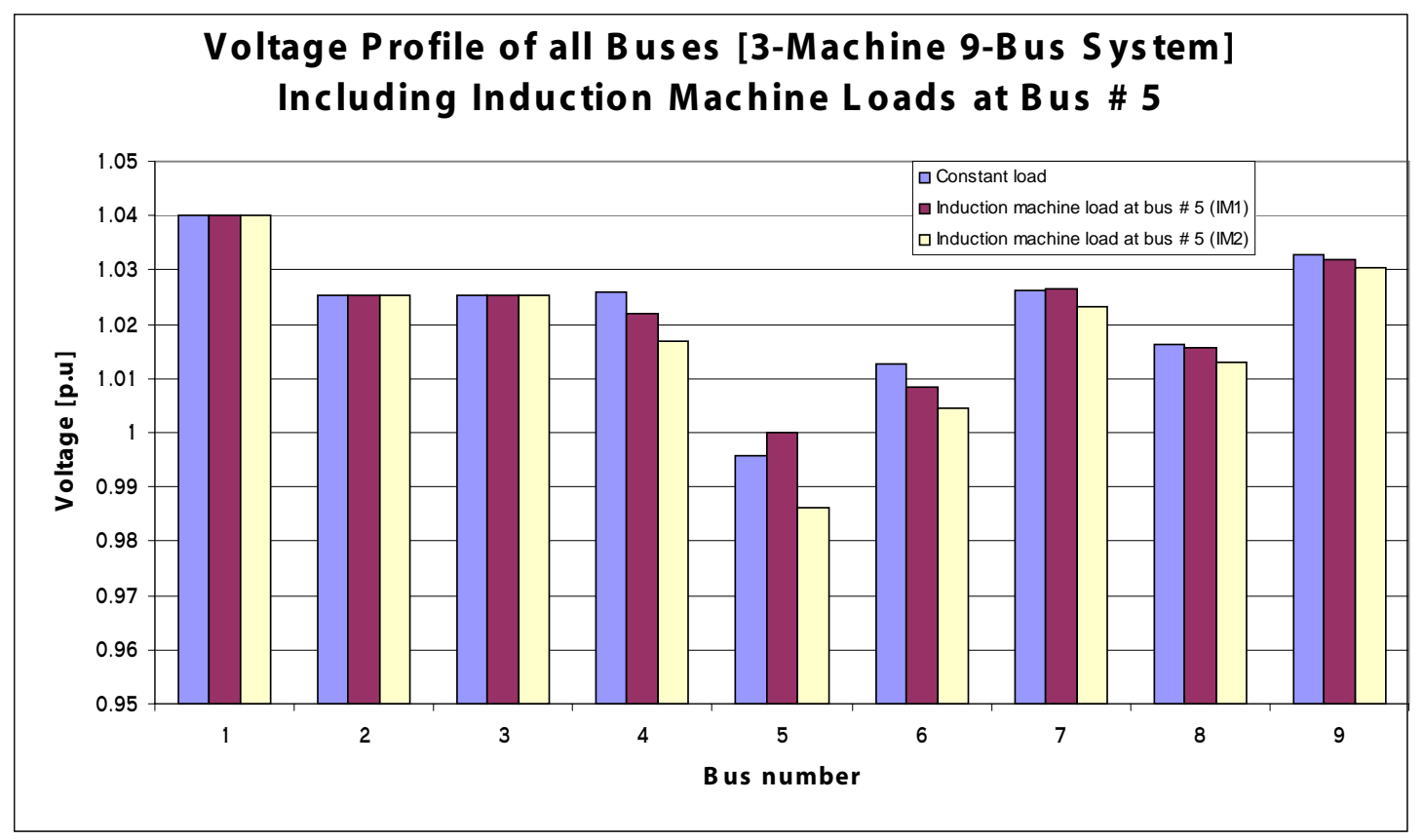

Figure 4.27 Voltage profiles of all buses of the WSCC 3-Machines 9-Bus system including Induction machine load at bus \# 5. 
Again the total number of eigenvalues of the reduced Jacobian matrix $J_{R}$ is expected to be six as shown in Table 4.15. The eigenvalues are listed for the all simulated load types. Note that all the eigenvalues are positive which means that the system voltage is stable.

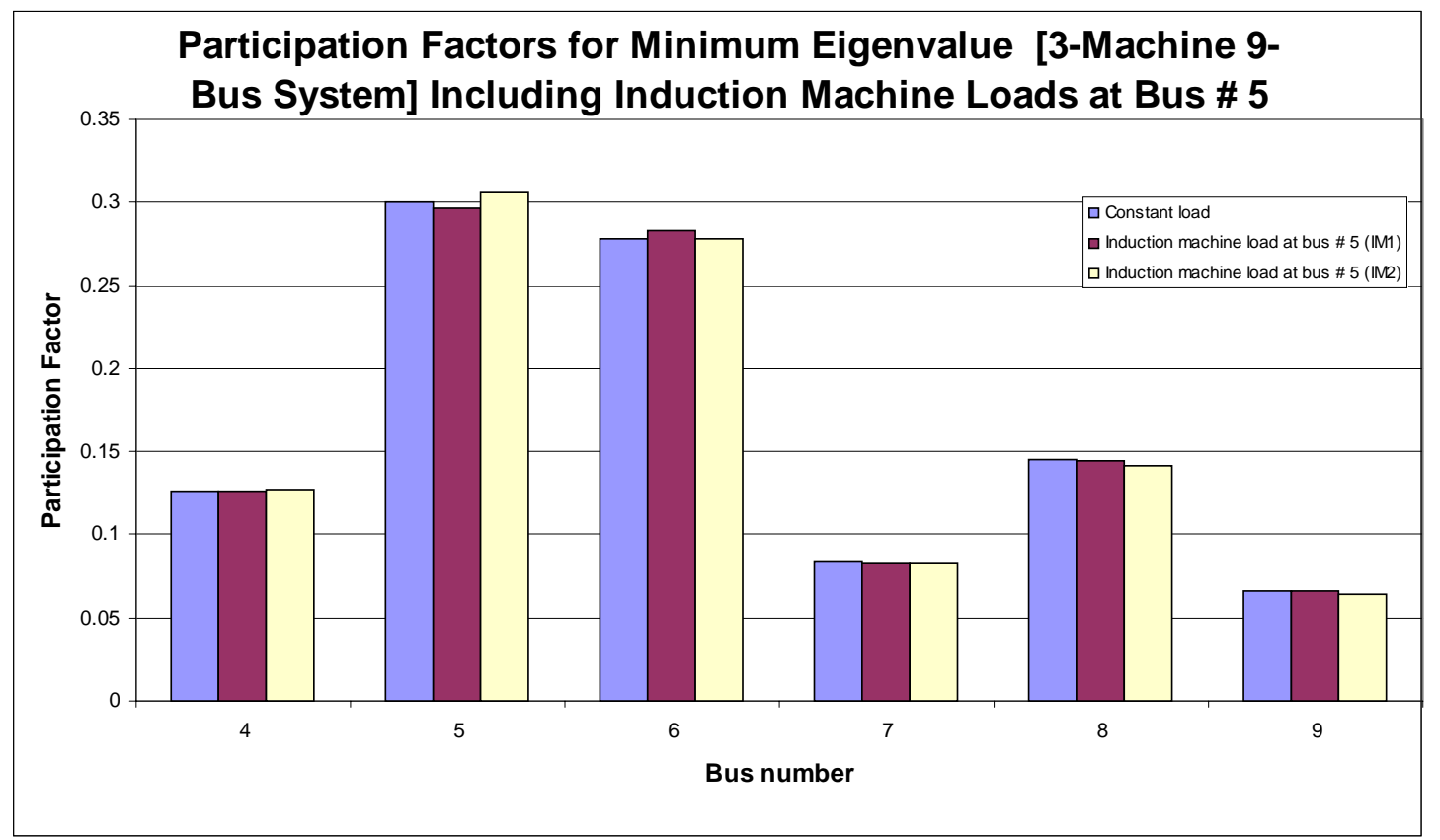

Figure 4.28 The participating factor of all buses for the most critical modes for the WSCC 3-Machines 9-

Bus system at different load models at bus \# 5.

Table 4.15 WSCC 3-Machines 9-Bus system eigenvalues at different loads in bus \# 5.

\begin{tabular}{||c|c|c|c||}
\cline { 2 - 4 } \multicolumn{1}{c|}{} & $\begin{array}{c}\lambda \text { at constant } \\
\text { load }\end{array}$ & $\begin{array}{c}\lambda \text { using } \\
\text { machine 1 }\end{array}$ & $\begin{array}{c}\lambda \text { using } \\
\text { machine 2 }\end{array}$ \\
\hline 1 & 51.0938 & 51.0165 & 50.7747 \\
\hline 2 & 5.9589 & 5.9354 & 5.85 \\
\hline 3 & 46.6306 & 46.5528 & 46.3713 \\
\hline 4 & 12.9438 & 12.9115 & 12.8651 \\
\hline 5 & 14.9108 & 14.9426 & 14.7363 \\
\hline 6 & 36.3053 & 36.2722 & 36.1804 \\
\hline
\end{tabular}

From Table 4.15 , it can be noticed that the minimum eigenvalue is located in the $2^{\text {nd }}$ mode, which is the most critical mode. The participating factors for these modes have been calculated and the result is shown in Figure 4.28. In general, the result shows that, the buses 5 and 6 have the highest 
participation factors to the critical mode, which are similar the results obtained before using the constant load model and voltage dependent loads. The largest participation factor value at bus \# 5 indicates a high contribution of this bus to the voltage collapse.

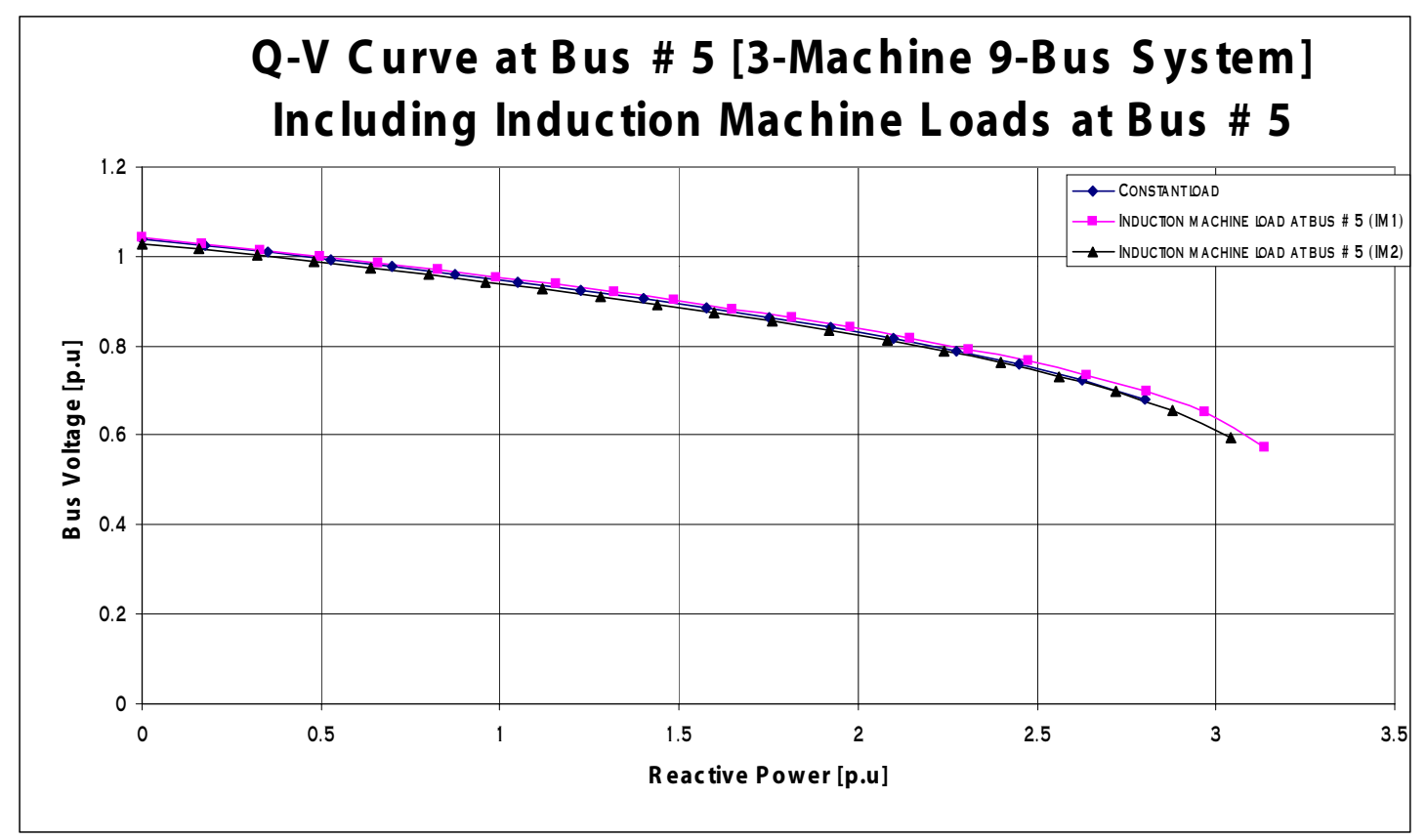

Figure 4.29 The Q-V curves at bus 5 for the WSCC 3-Machines 9-Bus system at different load models at bus\# 5.

The Q-V curves were generated for the weakest bus, bus \# 5, of the critical mode in the Western System Coordinating Council (WSCC) 3-Machines 9-Bus system as expected by the modal analysis method at different load models at bus \# 5. The curves are shown in Figure 4.29.

Table 4.16 Voltage and reactive power margins for the WSCC system from Q-V curves for bus\# 5.

\begin{tabular}{|c|c|c|c|c|c|c|c|c|c|c|c|c|c|}
\hline \multirow{2}{*}{\multicolumn{2}{|c|}{$\begin{array}{c}\text { Operating } \\
\text { Point }\end{array}$}} & \multicolumn{4}{|c|}{ Constant Load } & \multicolumn{4}{|c|}{ Induction machine 1} & \multicolumn{4}{|c|}{ Induction machine 2} \\
\hline & & \multicolumn{2}{|c|}{$\begin{array}{l}\text { Maximum } \\
\text { withstand }\end{array}$} & \multicolumn{2}{|c|}{ Margin } & \multicolumn{2}{|c|}{$\begin{array}{l}\text { Maximum } \\
\text { withstand }\end{array}$} & \multicolumn{2}{|c|}{ Margin } & \multicolumn{2}{|c|}{$\begin{array}{l}\text { Maximum } \\
\text { withstand }\end{array}$} & \multicolumn{2}{|c|}{ Margin } \\
\hline $\mathrm{V}$ & Q & $\mathrm{V}$ & $\mathrm{Q}$ & $\Delta \mathrm{V}$ & $\Delta \mathrm{Q}$ & V & $\mathrm{Q}$ & $\Delta \mathrm{V}$ & $\Delta \mathrm{Q}$ & $\mathrm{V}$ & $\mathrm{Q}$ & $\Delta \mathrm{V}$ & $\Delta \mathrm{Q}$ \\
\hline 1 & 0.5 & 0.724 & 2.625 & 0.276 & 2.125 & 0.5719 & 3.135 & 0.4281 & 2.635 & 0.5945 & 3.04 & 0.4055 & 2.54 \\
\hline
\end{tabular}

From Table 4.16, the induction machine load model affected the stability margin. However, those models didn't change the expected weakest buses for the voltage collapse and agreed with the 
constant load model. On the other hand, a slight change in the voltage level as well as in the distance to voltage collapse appeared.

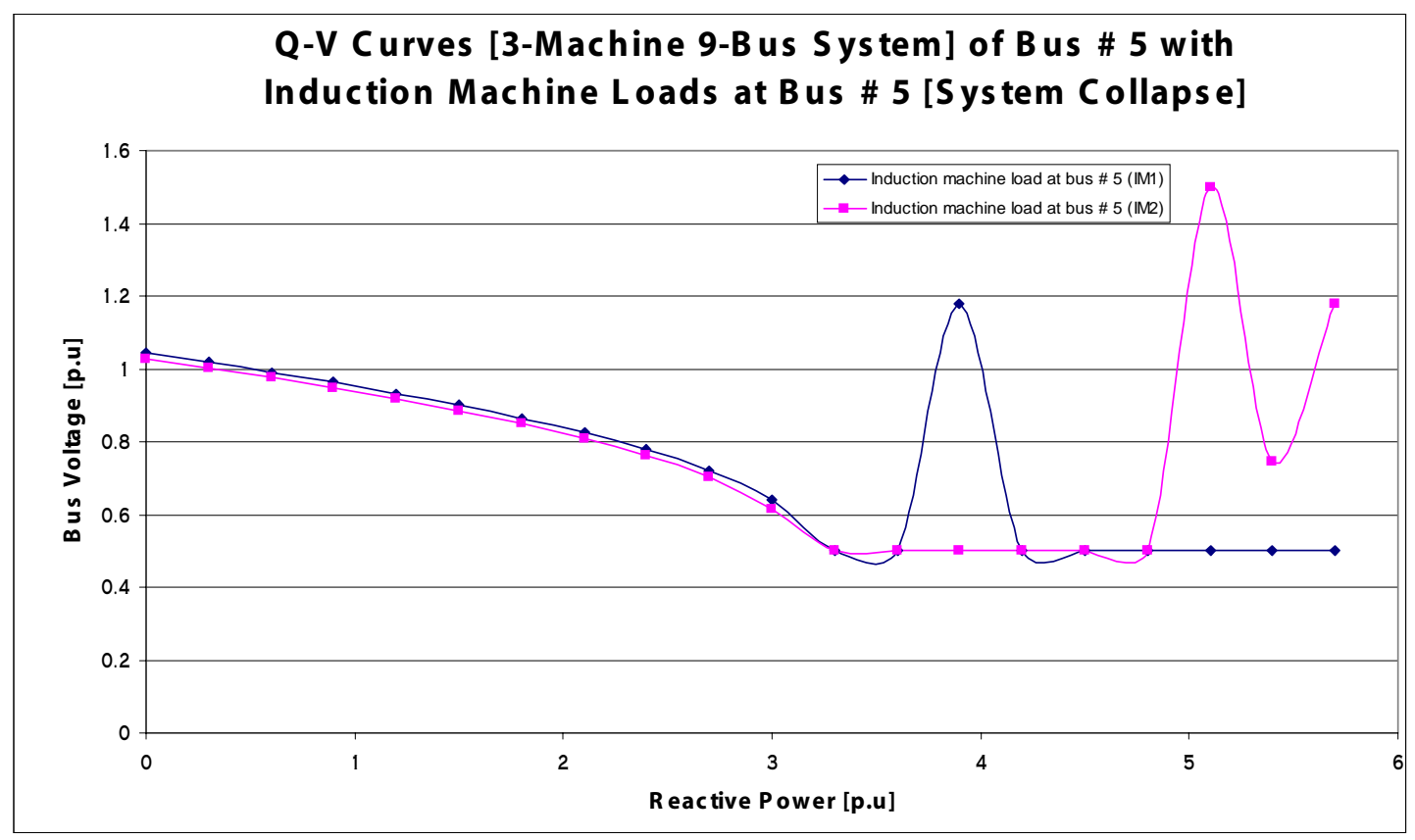

Figure 4.30 The Q-V curves of bus \# 5 for the WSCC 3-Machines 9-Bus system at different induction machine load models (Unstable system).

Figure 4.30 show the Q-V curves of bus 5 at the Western System Coordinating Council (WSCC) 3-Machines 9-Bus system considering the effect of induction machine load models while the stability margins are exceeded. The curves show unstable operation.

\subsubsection{The IEEE 14 Bus system.}

Figure 4.31 shows the voltage profiles of all buses of the IEEE 14 Bus system as obtained form the load flow including induction machine load at bus \# 14. The result shows the effect of both induction machine load and the constant load. It can be seen that all the bus voltages are within the acceptable level. In general, the lowest voltage compared to the other buses can be noticed at bus number 4 in all cases. 


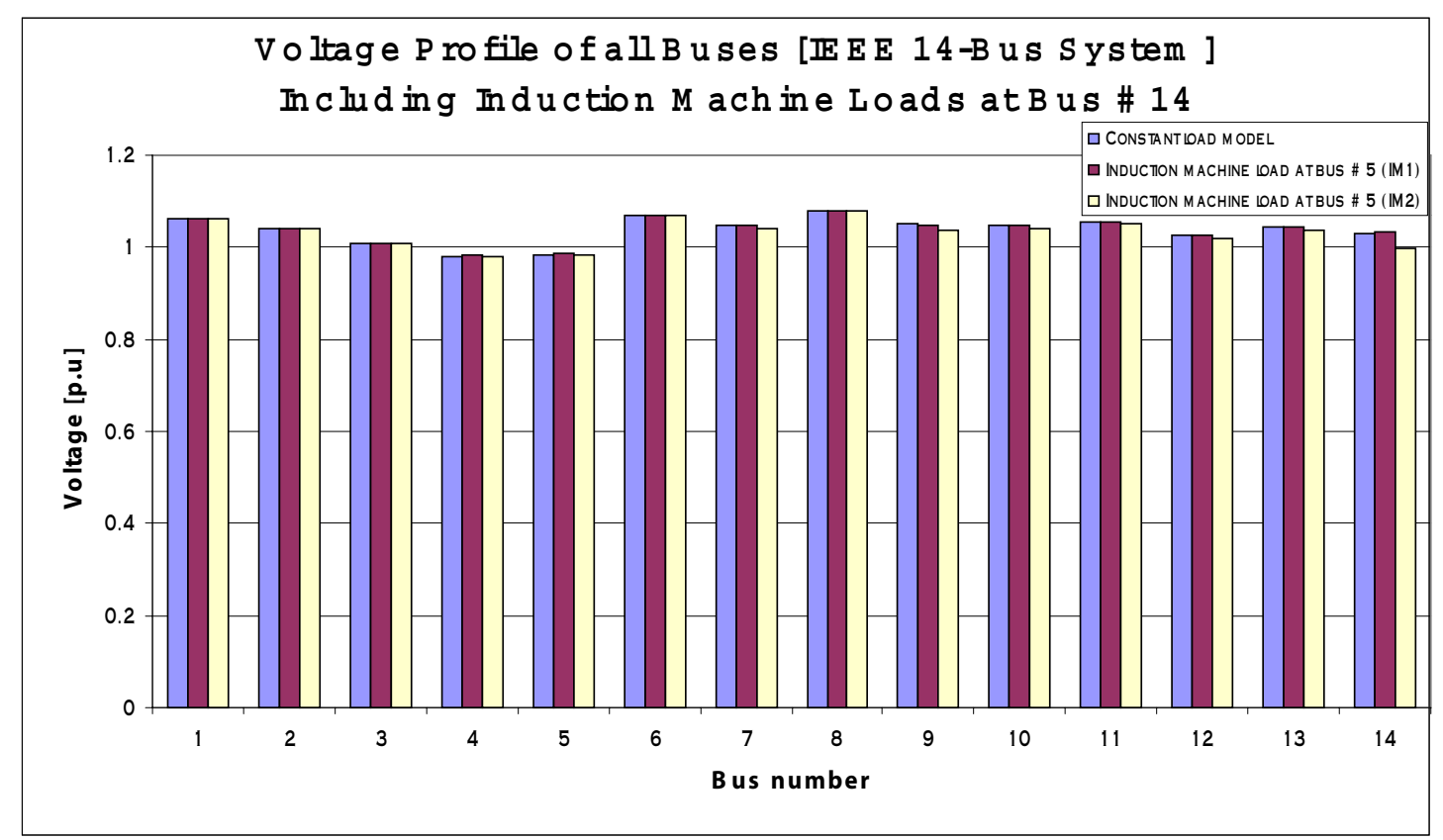

Figure 4.31 Voltage profiles of all buses of the IEEE 14 Bus system including Induction machine load at bus \# 14.

Again the total number of eigenvalues of the reduced Jacobian matrix $J_{R}$ is expected to be nine as shown in Table 4.17. The eigenvalues are listed for all the simulated load types. Note that all the eigenvalues are positive which means that the system voltage is stable.

Table 4.17 IEEE 14 Bus system eigenvalues at different loads at bus \# 14.

\begin{tabular}{|c|c|c|c|}
\hline & $\begin{array}{c}\lambda \text { at constant } \\
\text { load }\end{array}$ & $\begin{array}{c}\lambda \text { using } \\
\text { machine } 1\end{array}$ & $\begin{array}{c}\lambda \text { using } \\
\text { machine } 2\end{array}$ \\
\hline 1 & 62.5497 & 62.7199 & 62.609 \\
\hline 2 & 40.0075 & 39.9959 & 39.6377 \\
\hline 3 & 21.5587 & 21.5789 & 21.4679 \\
\hline 4 & 2.7811 & 2.7714 & 2.6679 \\
\hline 5 & 11.1479 & 11.1654 & 11.097 \\
\hline 6 & 15.7882 & 15.8279 & 15.7543 \\
\hline 7 & 5.4925 & 5.4867 & 5.3967 \\
\hline 8 & 18.7197 & 18.7337 & 18.5763 \\
\hline 9 & 7.5246 & 7.512 & 7.3341 \\
\hline
\end{tabular}

From Table 4.17, it can be noticed that the minimum eigenvalue is the $4^{\text {th }}$ mode, which is the most critical mode. The participating factors for these modes have been calculated and the result is 


\section{CHAPTER 4 RESULTS AND DISCUSSION}

shown in Figure 4.32. In general, the result shows that, the buses 14,10 and 9 have the highest participation factors to the critical mode, which are similar as obtained before using the constant load model and voltage dependent loads. The largest participation factor value at bus \# 14 indicates the highest contribution of this bus to the voltage collapse.

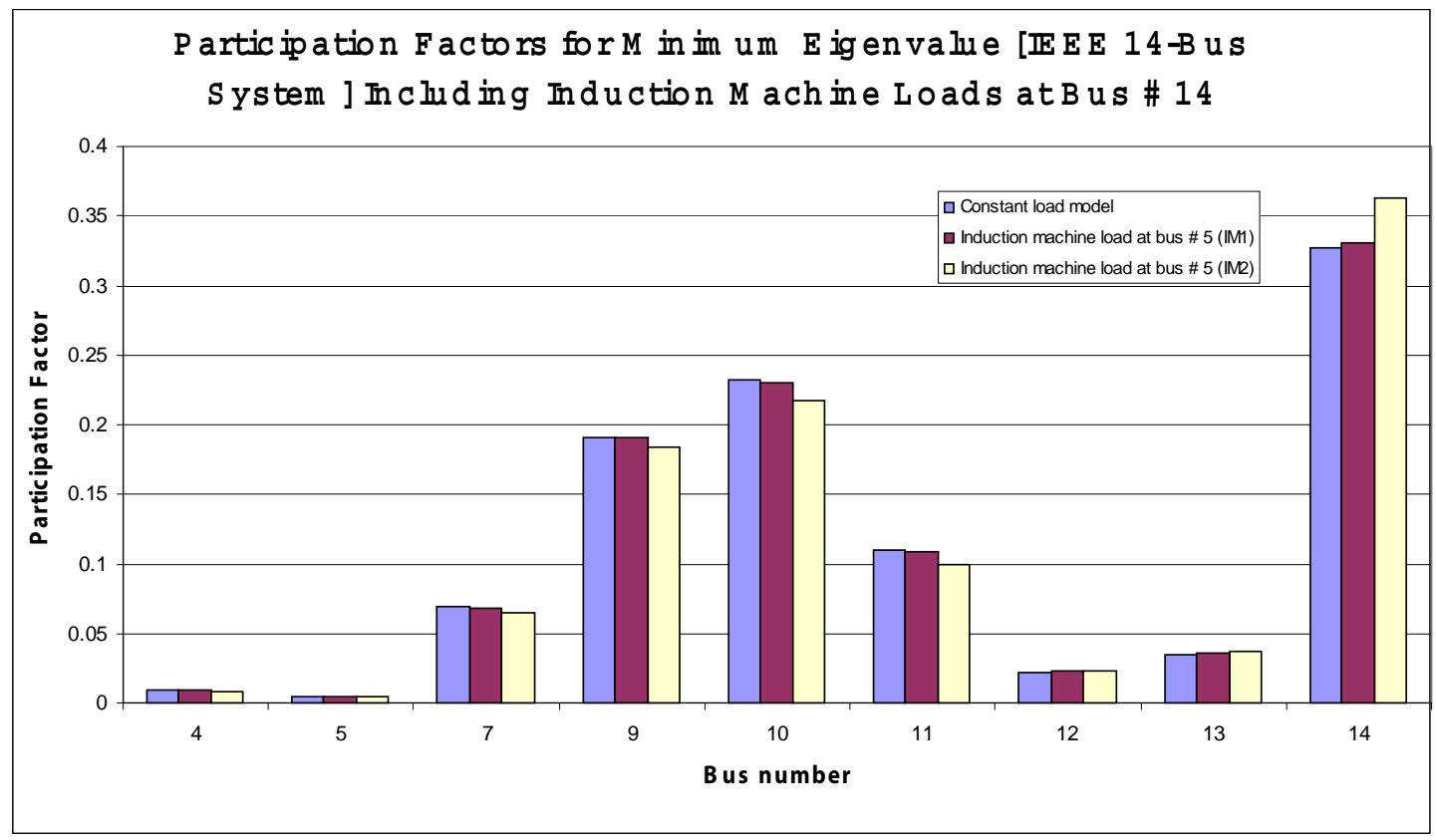

Figure 4.32 The participating factor of all buses for most critical modes for the IEEE 14 Bus System at different load's models in bus \# 14.

The Q-V curves were generated for the weakest bus, bus \# 14, in the IEEE 14-Bus system. The curves are shown in Figure 4.33.

Table 4.18 Voltage and reactive power margins for the IEEE 14 Bus system from Q-V curves for bus \# 14.

\begin{tabular}{|c|c|c|c|c|c|c|c|c|c|c|c|c|c|}
\hline \multirow{2}{*}{\multicolumn{2}{|c|}{$\begin{array}{c}\text { Operating } \\
\text { Point }\end{array}$}} & \multicolumn{4}{|c|}{ Constant Load } & \multicolumn{4}{|c|}{ Induction machine 1} & \multicolumn{4}{|c|}{ Induction machine 2} \\
\hline & & \multicolumn{2}{|c|}{$\begin{array}{l}\text { Maximum } \\
\text { withstand }\end{array}$} & \multicolumn{2}{|c|}{ Margin } & \multicolumn{2}{|c|}{$\begin{array}{l}\text { Maximum } \\
\text { withstand }\end{array}$} & \multicolumn{2}{|c|}{ Margin } & \multicolumn{2}{|c|}{$\begin{array}{l}\text { Maximum } \\
\text { withstand }\end{array}$} & \multicolumn{2}{|c|}{ Margin } \\
\hline $\mathrm{V}$ & $\mathrm{Q}$ & V & $\mathrm{Q}$ & $\Delta \mathrm{V}$ & $\Delta \mathrm{Q}$ & V & Q & $\Delta \mathrm{V}$ & $\Delta \mathrm{Q}$ & V & Q & $\Delta \mathrm{V}$ & $\Delta \mathrm{Q}$ \\
\hline 1 & 0.05 & 0.6349 & 1.17 & 0.3651 & 1.12 & 0.6373 & 1.1875 & 0.3627 & 1.1375 & 0.6532 & 1.0925 & 0.3468 & 1.0425 \\
\hline
\end{tabular}

From Table 4.18, the induction machine load model affected the stability margin. However, those models didn't change the expected weakest buses for the voltage collapse and agreed with the 


\section{CHAPTER 4 RESULTS AND DISCUSSION}

results obtained by constant load model and dependent voltage load models. On the other hand, a noticed change in the voltage level as well as in the distance to voltage collapse appeared clearly.

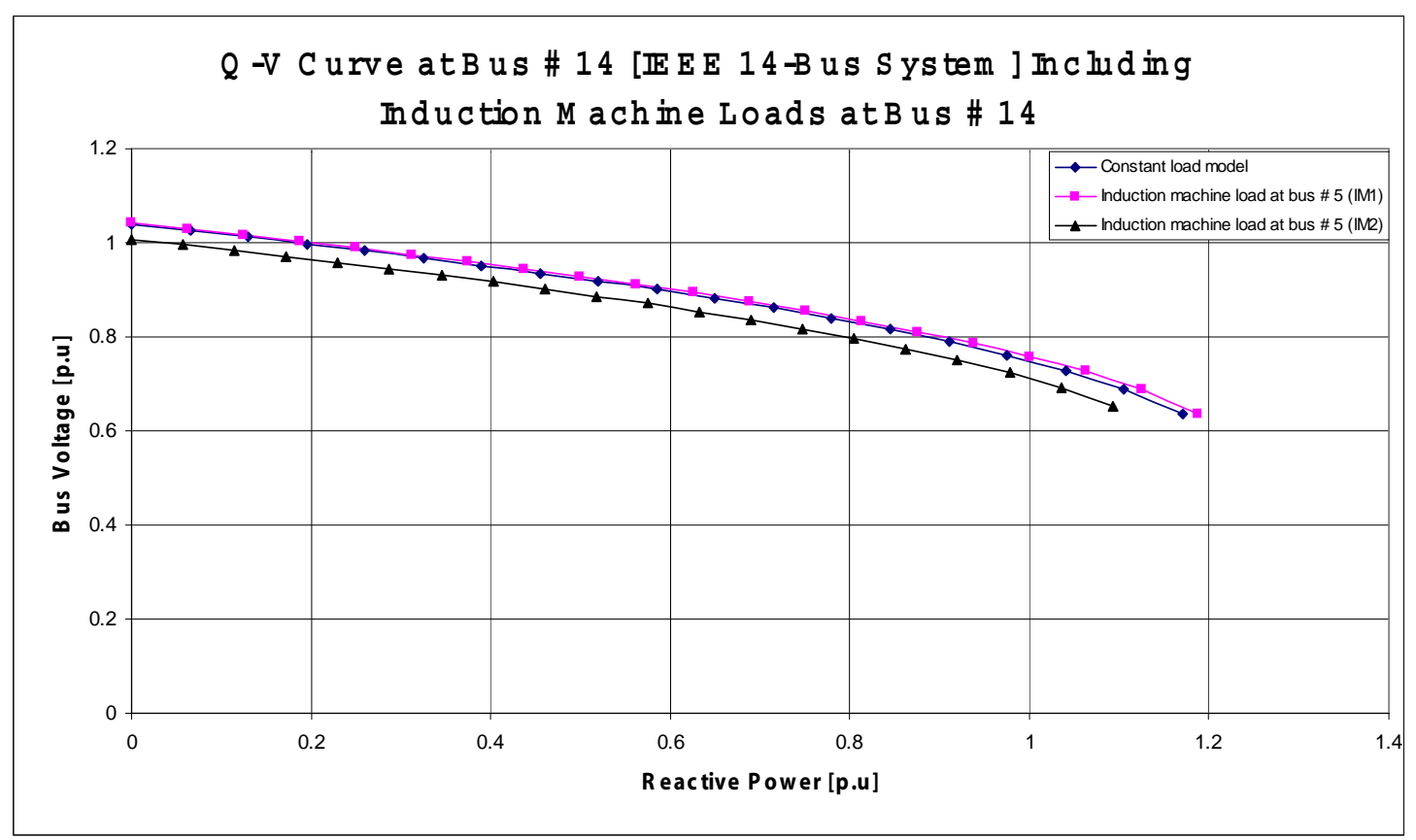

Figure 4.33 The Q-V curves at bus \# 14 for the IEEE 14 Bus System at different load's models in bus \# 14.

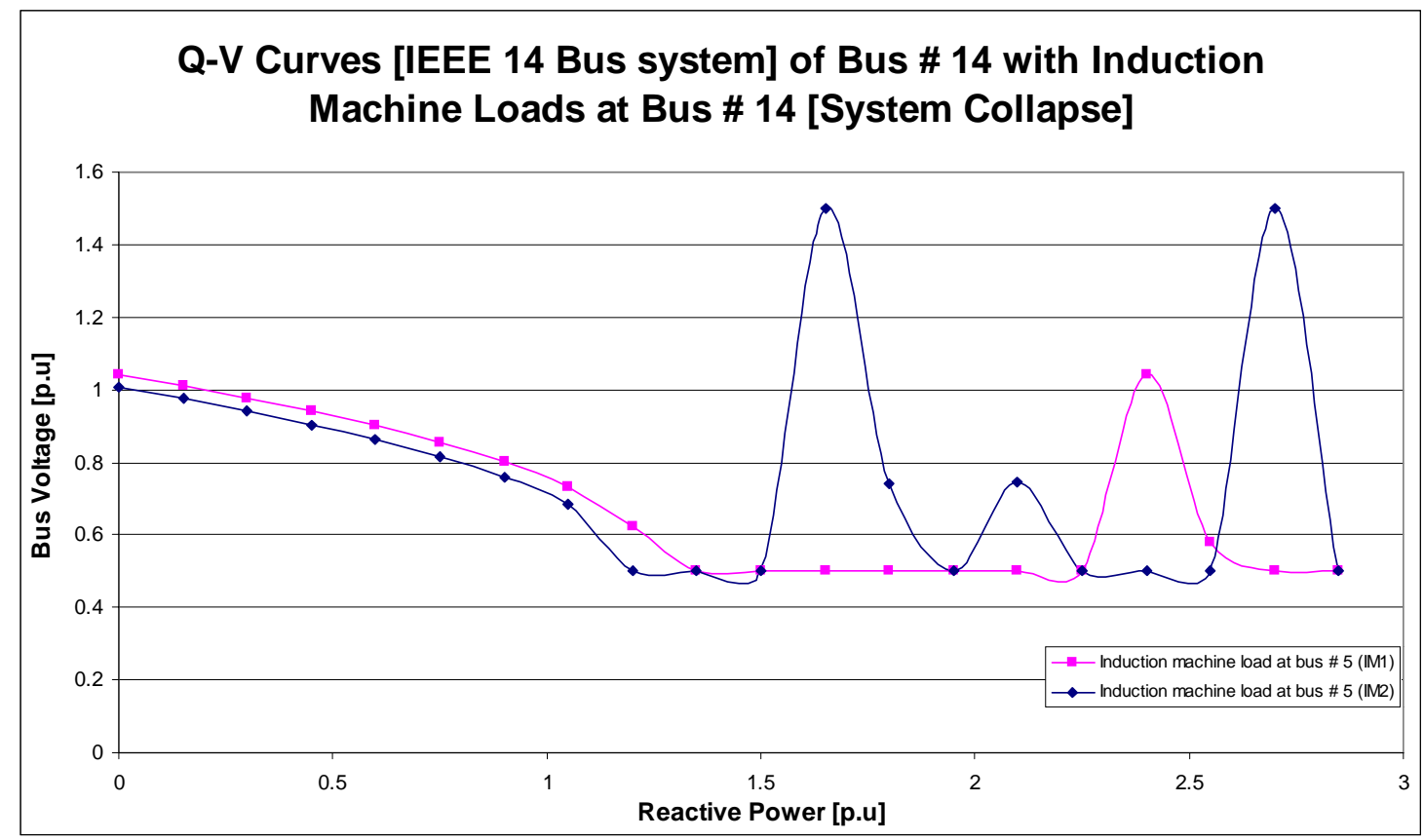

Figure 4.34 The Q-V curves of bus \# 14 for the IEEE 14 Bus system at different induction machine load's models at bus \# 14 (Unstable system). 
Figure 4.34 shows the Q-V curves of bus number 14 of the IEEE 14 Bus system considering the effect of induction machine load models at bus \# 14. While the stability margins are being exceeded, the curve demonstrates unstable operation.

\subsubsection{The IEEE 30 Bus system.}

Figure 4.35 shows the voltage profiles of all buses of the IEEE 30 Bus system as obtained form the load flow including induction machine loads at bus \# 30. The result shows the effect of both induction machines load and the constant load. It can be seen that all the bus voltages are within the acceptable level except buses 29 and 30. In general, the lowest voltage compared to the other buses can be noticed at bus number 30 in all cases.

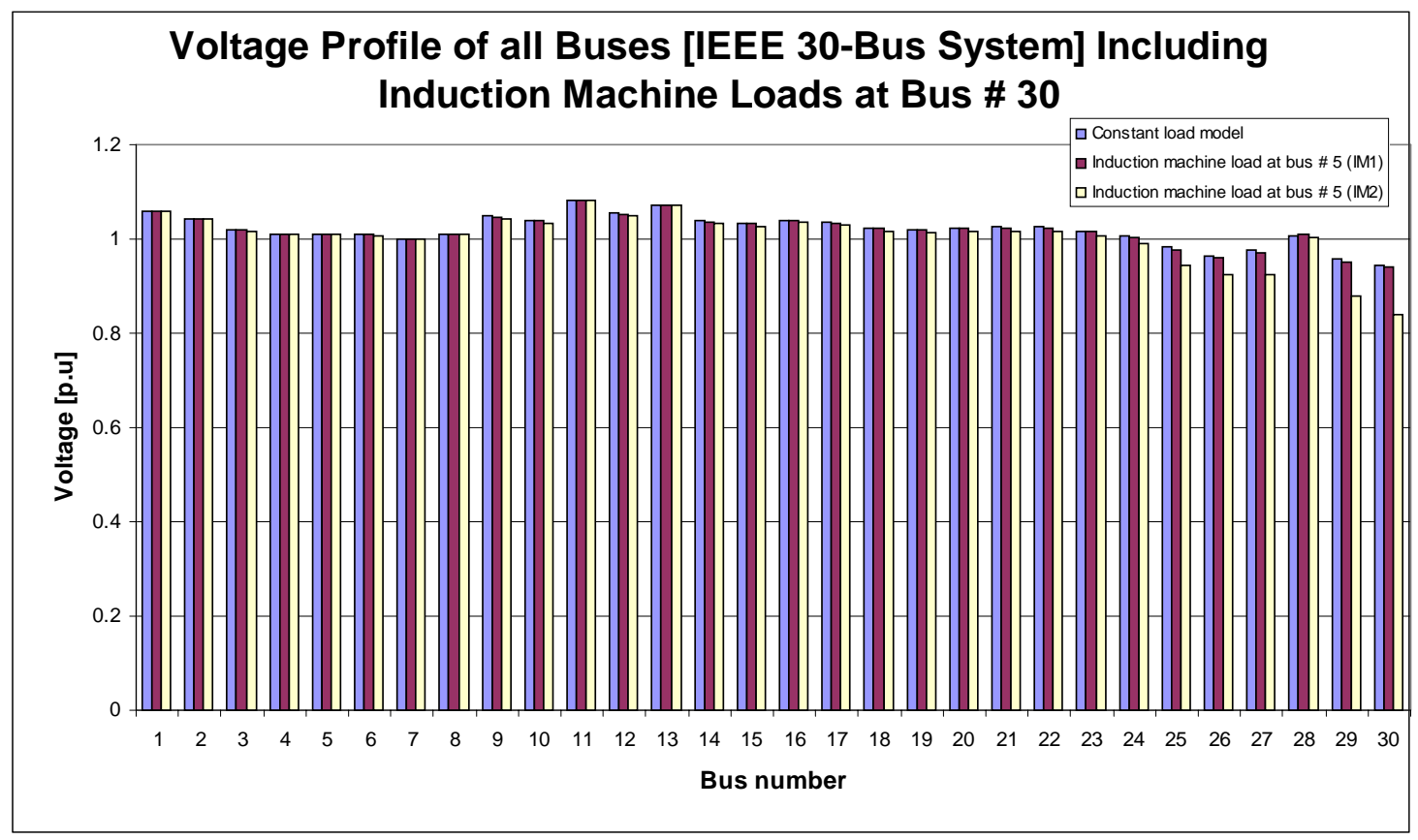

Figure 4.35 Voltage profiles of all buses of the IEEE 30 Bus system including Induction machine load at bus \# 30.

Again the total number of eigenvalues of the reduced Jacobian matrix $J_{R}$ is expected to be 24 as shown in Table 4.19. The eigenvalues are listed for all the simulated load types. Note that all the eigenvalues are positive which means that the system voltage is stable. 
Table 4.19 IEEE 30 Bus system eigenvalues at different loads at bus \# 30.

\begin{tabular}{||c||c|c|c||}
\cline { 2 - 4 } \multicolumn{1}{c||}{} & $\begin{array}{c}\lambda \text { at constant } \\
\text { load }\end{array}$ & $\begin{array}{c}\lambda \text { using } \\
\text { machine 1 }\end{array}$ & $\begin{array}{c}\lambda \text { using } \\
\text { machine 2 }\end{array}$ \\
\hline 1 & 110.2056 & 110.2649 & 110.0322 \\
\hline 2 & 100.6465 & 100.4899 & 99.775 \\
\hline 3 & 65.9541 & 65.9984 & 65.8706 \\
\hline 4 & 59.5431 & 59.4711 & 59.1563 \\
\hline 5 & 37.8188 & 35.3631 & 37.5844 \\
\hline 6 & 35.3863 & 37.7779 & 35.2388 \\
\hline 7 & 23.0739 & 23.4069 & 23.297 \\
\hline 8 & 23.4238 & 23.0806 & 22.9207 \\
\hline 9 & 19.1258 & 19.1138 & 19.0051 \\
\hline 10 & 19.7817 & 18.0663 & 19.6983 \\
\hline 11 & 18.0785 & 16.3282 & 17.9456 \\
\hline 12 & 16.3753 & 13.7015 & 15.935 \\
\hline 13 & 0.5060 & 13.6141 & 13.3871 \\
\hline 14 & 13.7279 & 0.4982 & 13.5787 \\
\hline 15 & 13.6334 & 1.0176 & 0.4293 \\
\hline 16 & 1.0238 & 11.0536 & 10.9996 \\
\hline 17 & 11.0447 & 1.7142 & 0.9713 \\
\hline 18 & 1.7267 & 8.7766 & 1.611 \\
\hline 19 & 8.7857 & 3.5755 & 8.7311 \\
\hline 20 & 3.5808 & 4.0463 & 3.545 \\
\hline 21 & 4.0507 & 7.4123 & 7.1496 \\
\hline 22 & 7.4360 & 5.4383 & 4.0233 \\
\hline 23 & 6.0207 & 5.9895 & 5.5639 \\
\hline 24 & 5.4527 & 19.7704 & 5.195 \\
\hline & & & \\
\hline
\end{tabular}

From Table 4.19, it can be noticed that the minimum eigenvalue is located in modes number 13, 14 and 15, which are the most critical modes. The participating factors for these modes have been calculated and the results are shown in Figure 4.36. In general, the result shows that, the buses 30, 29 and 26 have the highest participation factors to the critical mode, which are similar to the results obtained before using the constant load model and voltage dependent loads. The largest participation factor value at bus \# 30 indicates a high contribution of this bus to the voltage collapse. 
The Q-V curves were generated for the weakest buses, bus \# 30, of the critical mode in the IEEE 30-Bus system. The curves are shown in Figure 4.37.

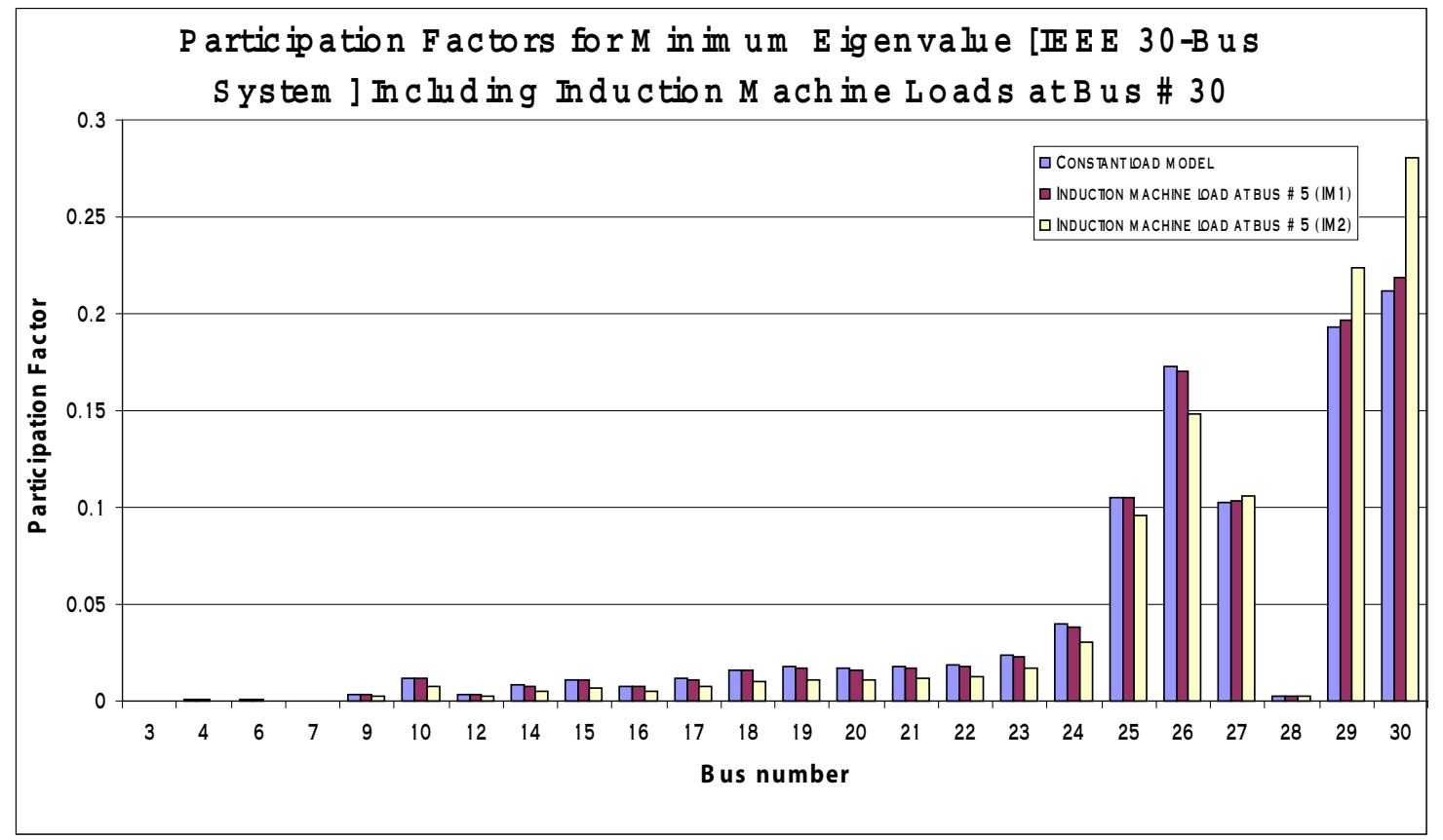

Figure 4.36 The participating factor of all buses for most critical modes for the IEEE 30 Bus System at different load models at bus \# 30.

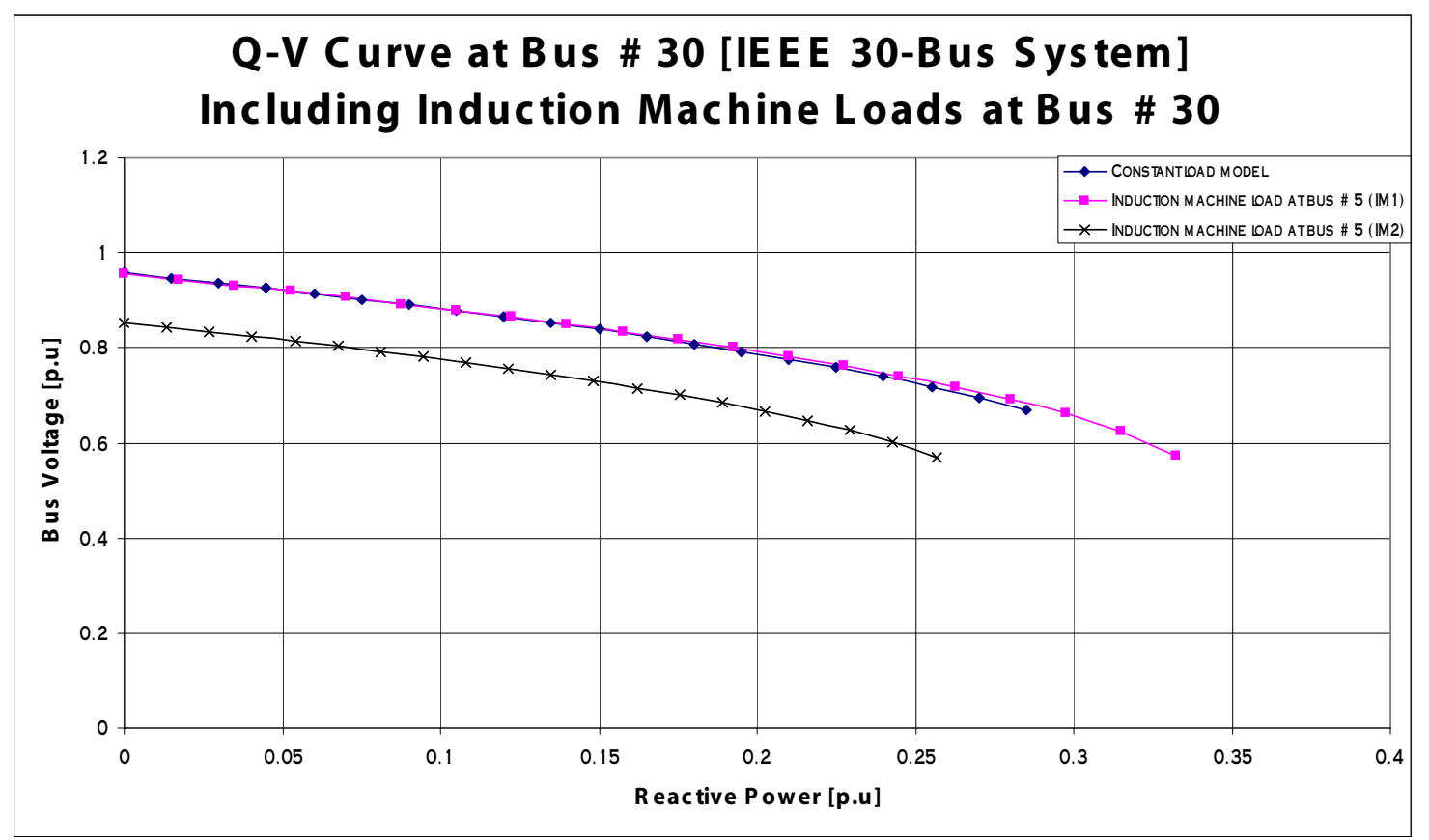

Figure 4.37 The Q-V curves at bus \# 30 for the IEEE 30 Bus System at different load's models in bus \# 30. 
CHAPTER 4 RESULTS AND DISCUSSION

Table 4.20 Voltage and reactive power margins for the IEEE 30 Bus system from Q-V curves for bus \# 30.

\begin{tabular}{|c|c|c|c|c|c|c|c|c|c|c|c|c|c|}
\hline \multirow{2}{*}{\multicolumn{2}{|c|}{$\begin{array}{c}\text { Operating } \\
\text { Point }\end{array}$}} & \multicolumn{4}{|c|}{ Constant Load } & \multicolumn{4}{|c|}{ Induction machine 1} & \multicolumn{4}{|c|}{ Induction machine 2} \\
\hline & & \multicolumn{2}{|c|}{$\begin{array}{l}\text { Maximum } \\
\text { withstand }\end{array}$} & \multicolumn{2}{|c|}{ Margin } & \multicolumn{2}{|c|}{$\begin{array}{l}\text { Maximum } \\
\text { withstand }\end{array}$} & \multicolumn{2}{|c|}{ Margin } & \multicolumn{2}{|c|}{$\begin{array}{l}\text { Maximum } \\
\text { withstand }\end{array}$} & \multicolumn{2}{|c|}{ Margin } \\
\hline $\mathrm{V}$ & $\mathrm{Q}$ & $\mathrm{V}$ & $\mathrm{Q}$ & $\Delta \mathrm{V}$ & $\Delta \mathrm{Q}$ & $\mathrm{V}$ & $\mathrm{Q}$ & $\Delta \mathrm{V}$ & $\Delta \mathrm{Q}$ & $\mathrm{V}$ & Q & $\Delta \mathrm{V}$ & $\Delta \mathrm{Q}$ \\
\hline 1 & 0.019 & 0.6688 & 0.285 & 0.3312 & 0.266 & 0.5731 & 0.3325 & 0.4269 & 0.3135 & 0.5693 & 0.2565 & 0.4307 & 0.2375 \\
\hline
\end{tabular}

From Table 4.20, the induction machine load model affected the stability margin. However, those models didn't change the expected weakest buses for the voltage collapse and agreed with the results obtained by constant load model and dependent voltage load models. On the other hand, a noticed change in the voltage level as well as in the distance to voltage collapse appeared clearly.

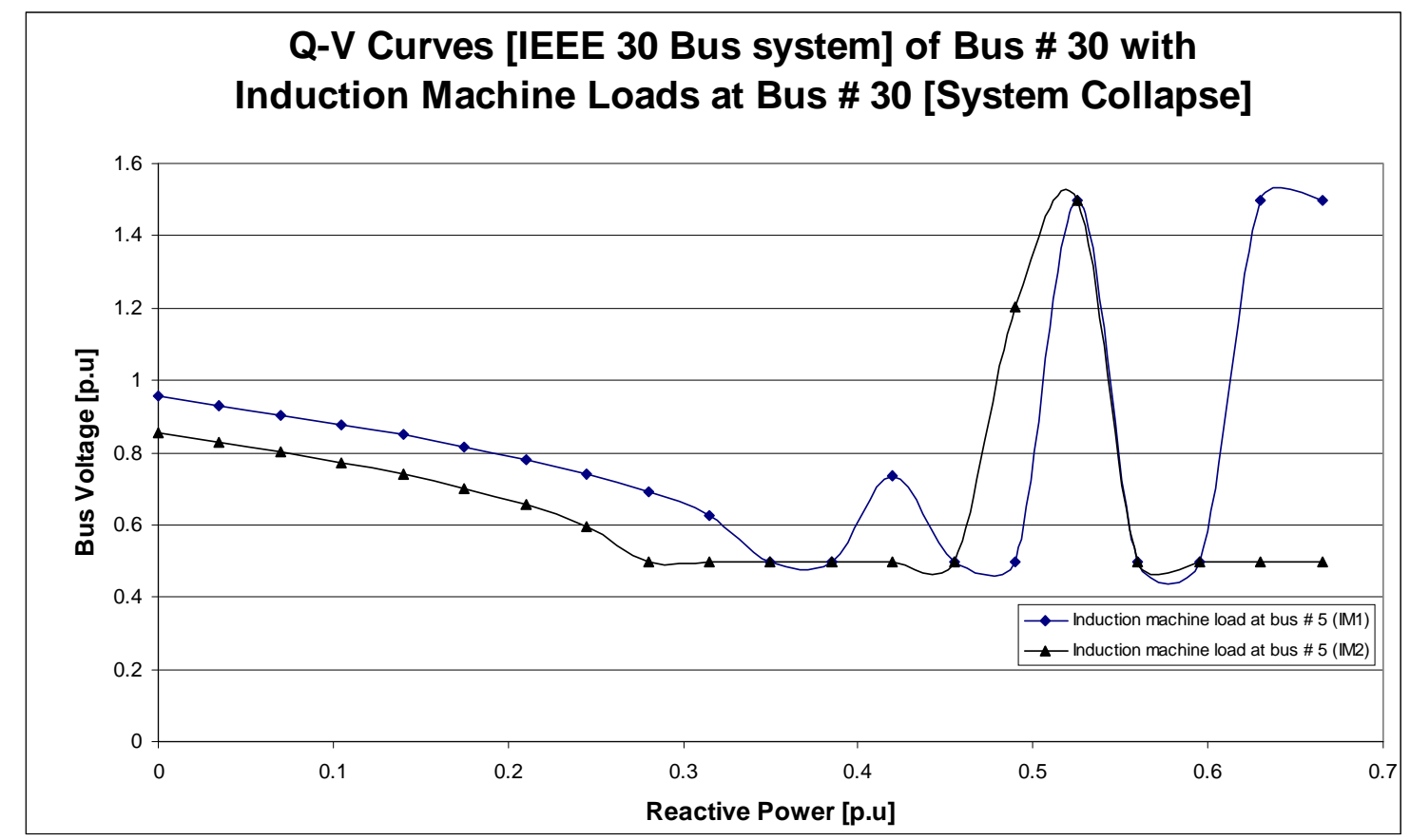

Figure 4.38 The $Q$-V curves of bus \# 30 for the IEEE 30 Bus system at different induction machine load models at bus \# 30 (Unstable system).

Figure 4.38 shows the Q-V curves of bus number 30 of the IEEE 30 Bus system. While the stability margins are exceeded, the curve indicates unstable operation. 


\section{CHAPTER 5}

\section{CONCLUSION \& RECOMMENDATIONS}

\subsection{Conclusion}

In this research, the voltage collapse problem is studied. The following can be concluded:

1. The Modal analysis technique is applied to investigate the stability of three well-known power systems. The method computes the smallest eigenvalue and the associated eigenvectors of the reduced Jacobian matrix using the steady state system model. The magnitude of the smallest eigenvalue gives us a measure of how close the system is to the voltage collapse. Then, the participating factor can be used to identify the weakest node or bus in the system associated to the minimum eigenvalue.

2. The Q-V curves are used successfully to confirm the result obtained by Model analysis technique, where the same buses are found to be the weakest and contributing to voltage collapse.

3. Using the Q-V curves, the stability margin or the distance to voltage collapse is identified based on voltage and reactive power variation. Furthermore, the result can be used to evaluate the reactive power compensation.

4. The load characteristic is considered in this study. Different voltage dependent load models are proposed and applied to the analysis.

5. The results obtained by considering the voltage dependent load models confirmed the ones obtained by using constant load model. In general, results obtained by the constant load model and the voltage dependent load models, agreed about the weakest buses that contribute to voltage instability or voltage collapse. However, using voltage dependent load 


\section{CHAPTER 5 CONCLUSION \& RECOMMENDATIONS}

models changes the stability margin and the distance to voltage collapse is improved. In addition, using the voltage dependent load models maintains much better voltage level.

6. The induction machine load model is considered in this study. The model is represented by active and reactive powers consumed by the induction motor, where both of them are function of the machine slip, bus voltage and bus angle. Induction machines with two different ratings are simulated for the analysis.

7. The results obtained by considering the induction machine load model confirmed the results previously obtained by using constant load model and voltage dependent load models. In general, the obtained results agreed about the weakest buses that contribute to voltage instability or voltage collapse. However, considering induction machine load model changes the stability margin.

\subsection{Recommendations for the Future Research.}

This research work leads to various promising topics for future investigations. The following recommendations are made for the future research:

1. Modeling of the other power system devices such as generators and static var compensators.

2. Consideration of suitable solutions for the voltage collapse problem in the analyzed system. 


\section{REFERENCES}

\section{REFERENCES}

[1] C. W. Taylor, "Power System Voltage Stability." New York: MaHraw-Hill, 1994.

[2] Sauer, Peter W. and Pai, M. A. "Power System Dynamics and Stability" New Jersey Prenitice Hall, 1998.

[3] Machowski, Bialek and Bumby "Power System Dynamics and Stability" John Wiley \& Sons Ltd, 1997.

[4] Sirisuth, Piya "Voltage Instability analysis using the Sensitivity of Minimum Singular Value of Load Flow Jacobian" 1993.

[5] Ajjarapu, V. and Lee, B. "Bibliography on Voltage Stability" IEEE Trans. on Power Systems, vol. 13, pp. 115-125, 1998.

[6] C. Counan, M. Trotignon, E. Corride, G. Bortoni, M. Stubbe, and J. Deuse, "Major incidents on the French electric system- Potentiality and curative measures," IEEE Trans. on Power Systems, vol. 8, pp. 879-886, Aug. 1993.

[7] R. DÕAquila, N. W. Miller, K. M. Jimma, M. T. Shehan, and G. L. Comegys, "Voltage stability of the Puget Sound System under Abnormally Cold Weather Conditions," IEEE Trans. on Power Systems, vol. 8, pp. 1133-1142, Aug. 1993.

[8] F. D. Galiana and Z. C. Zeng, "Analysis of the Load Behavior near Jacobian Singularity," IEEE Trans. on Power Systems, vol. 7, pp. 1529-1542, Nov. 1992.

[9] P. Kessel and H. Glavitsch, "Estimating the Voltage Stability of a Power System," IEEE Trans. on Power Delivery, vol. 1, pp. 346-353, July 1986.

[10] Y. Tamura, H. Mori, and S. Iwamoto, "Relationship between Voltage Stability and Multiple Load Flow Solutions in Electric Systems," IEEE Trans. on Power Apparatus and Systems, vol. PAS-102, pp. 11151123, May 1983.

[11] P. A. Lof, T. Smed, C. Anderson, and D. J. Hill, "Fast Calculation of a Voltage Stability Index," IEEE Trans. on Power Systems, vol. 7, pp. -64, Feb. 1992.

[12] V. A. Venikov, V. A. Stroev, V. I. Idelchick, and V. I. Trasov, "Estimation of Electric Power System SteadyState Stability in Load Flow Calculation," IEEE Trans. on Power Apparatus and Systems, vol. PAS-94, pp. 1034-1041, May/June 1975.

[13] H. G. Kwanti, A. K. Pasrija, and L. Y. Bahar, "Static Bifurcations in Electric Power Networks: Loss of Steady-State Stability and Voltage Collapse," IEEE Trans. on Circuits and Systems, vol. CAS-33, pp. 981991, Oct. 1986.

[14] M. M. Begovic and A. G. Phadke, "Voltage Stability Assessment through measurement of a reduced state vector," IEEE Trans. on Power Systems, vol. 5, pp. 198-203, Feb. 1990.

[15] P. Pal, "Voltage Stability Conditions Considering Load Characteristics", IEEE Trans. on Power Systems, Vol. 7, No. 2, pp. 243-249, Feb. 1992.

[16] M. Suzuki, S. Wada, T. Asano, and K. Kudo, "Newly Developed Voltage Security Monitoring System", IEEE Trans. On Power System, Vol. 7, No. 3, pp. 965-972, August 1992.

[17] Y. Mansour, W. Xu, F. Alverado, and C. Rinzin, "SVC Placement Using Critical Modes of Voltage Instability", IEEE Trans. On Power Systems, Vol. 9, No. 2, pp. 757-763, May 1994.

[18] E. Vaahedi et al., "Voltage Stability Contingency Screening and Ranking", IEEE Trans. On Power Systems Vol. 14, No. 1, pp. 256-265 Feb. 1999.

[19] R. Schlueter, "A Voltage Stability Security Assessment Method", IEEE Trans. On Power Systems, Vol. 13, No. 4, pp. 1423-1438, Nov. 1998.

[20] B. Gao, G. Morison, and P. Kundur, "Voltage Stability Evaluation Using Modal Analysis", IEEE Trans. on Power Systems, Vol. 7, No. 4, pp. 1423-1543, Nov 1992.

[21] G. Morison, B. Gao and P. Kundur, "Voltage Stability Analysis Using Static and Dynamic Approaches", IEEE Trans. on Power Systems, Vol. 8, No. 3, pp. 1159-1171, Aug. 1993.

[22] P. A. Lof, G. Anderson, and D. J. Hill, "Voltage Stability Indices For Stressed Power System," IEEE Trans. on Power Systems, vol. 8, pp. 326-335, Feb. 1993.

[23] N. Flatabo and H. Dommel, "Voltage Stability Condition in a Power Transmission System calculated by Sensitivity Methods", EEE Trans. on Power Systems, vol. 5, pp. 1286-1293, Nov. 1990.

[24] T. Overbye and C. DeMarco, "Improved Power System stability Assessment Using Energy Method", IEEE Trans. On Power System, Vol. 6, No. 4, pp. 1890-1896, Nov. 1995.

[25] C. DeMarco and T. Overbye, "An Energy based security Measure for Assessing Vulnerability To Voltage Collapse", IEEE Trans. On Power System, Vol. 5, No. 2, pp. 419-427, May 1990. 


\section{REFERENCES}

[26] A. El-Keib and X. Ma, "Application of Artificial Neural Networks In Voltage Stability Assessment", IEEE Trans. On Power System, Vol. 10, No. 4, pp. 1890-1896, Nov. 1995.

[27] C. Liu, C. Chang, and M. Su, "Neuro-Fuzzy Networks for Voltage Security Monitoring based On Synchronous Pharos Measurements", IEEE Trans.On Power System,Vol. 13, No. 2, May 1998.

[28] Conoordia, C. and Ihara, S., "Load Representation in Power System Stability Studies", IEEE Trans. On Power Apparatus and Systems Vol. PAS-101, No. 4, pp. 969-976, April. 1982.

[29] Price, William W., Wirgau, Kim A., Murdoch, Alexander, Mitsche, James V., Vaahedi, Ebrahim and ElKady, Moe A., "Load Modeling for Power Flow and Transient Stability Computer Studies", IEEE Trans. On Power Systems Vol. 3, No. No. 1, pp. 180-187, Feb. 1988.

[30] T. Cutsem, "A Method to Compute Reactive Power margins with respect to Voltage", IEEE Trans. On Power Systems, Vol. PWRS-6, No. 2, pp. 145-156, Feb. 1991

[31] G. Verghes, I. Perez-Arriaga and F. Schewwppe, "Selective Modal Analysis With Application To Electric Power systems", Part II IEEE trans, I. On Power APP. And System, Vol. PAS 101, No. 9, pp. 31173134, 1982.

[32] E. Vaahedi, Y. Mansour and D. Sun, "Large Scale Voltage Stability Constrained Optimal Planning and Voltage Stability Applications Using Existing OPF/Optimal Var Planning Tools", IEEE Trans. On Power Systems Vol. 14, No. 1, Feb.1999.

[33] H. D. Chiang, I. Dobson, R. J. Thomas, J. S. Thorp, and L. Fekih-Ahmed, "On voltage collapse in electric power systems" IEEE Trans. on Power Systems, vol. 5, pp. 601-611, May 1990.

[34] J. C. Chow, R. Fischl, and H. Yan," on the evaluation of voltage collapse criteria" IEEE Trans. On Power Systems, vol. 5, pp. 612-620, May 1990.

[35] C. Barbier and J. P. Barret, "Analysis of Phenomena of Voltage Collapse on a Transmission system," Review Generale de IÕelectricite, vol. 89, pp. 672-690, Oct. 1980.

[36] R. J. Thomas and A. Tiranuchit, "Voltage Instabilities in Electric Power Networks," Proc. Eighteenth Southeast Symposium on Systems Theory, pp. 359-363, 1986. 


\section{APPENDIX A}

\section{A.1 Test Systems Load Flow Data.}

\section{A.1.1 WSCC system Load Flow Data.}

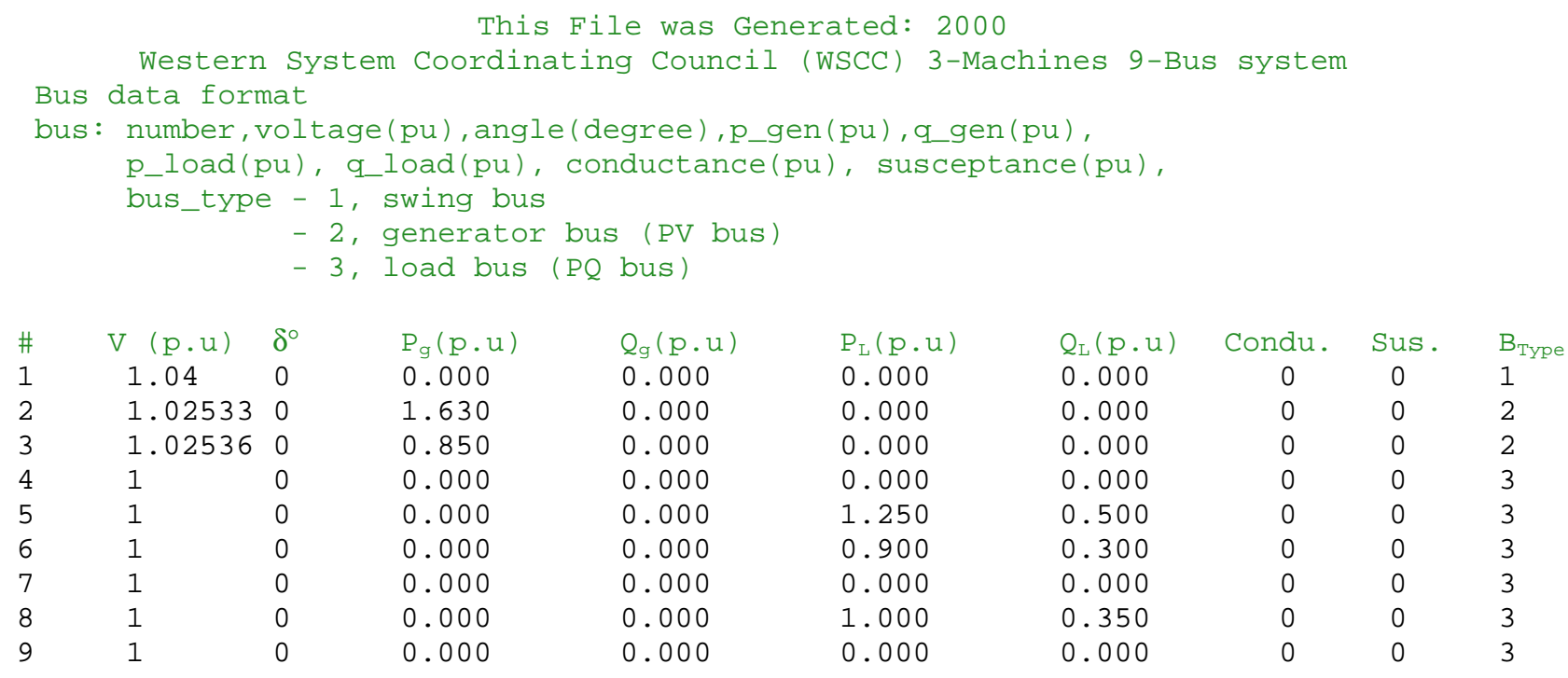

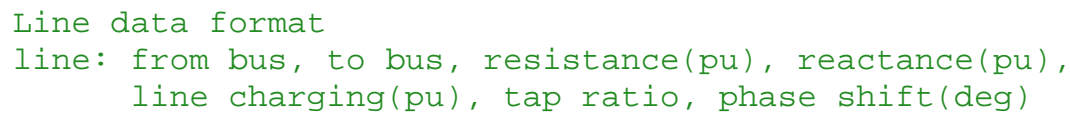

$\begin{array}{ll}\text { From } & \text { To } \\ 2 & 7 \\ 7 & 8 \\ 7 & 5 \\ 5 & 4 \\ 4 & 1 \\ 4 & 6 \\ 6 & 9 \\ 9 & 3 \\ 9 & 8\end{array}$

$\begin{array}{ll}R(p . u) & X(p . u) \\ 0.0000 & 0.0625 \\ 0.0085 & 0.0720 \\ 0.0320 & 0.1610 \\ 0.0100 & 0.0850 \\ 0.0000 & 0.0576 \\ 0.0170 & 0.0920 \\ 0.0390 & 0.1700 \\ 0.0000 & 0.0586 \\ 0.0119 & 0.1008\end{array}$

Line Cha.

0.0000

Tap

1.00

$0.0745 * 2$

1.00

$0.1530 * 2 \quad 1.00$

1.00

$0.0880 * 2$

0.0000

1.00

$0.0790 * 2 \quad 1.00$

$0.1790 * 2 \quad 1.00$

1.00

0.0000

1.00

Phase

0.00

0.00

0.00

0.00

0.00

0.00

$0.1045 * 2$

0.00

0.00

0.00

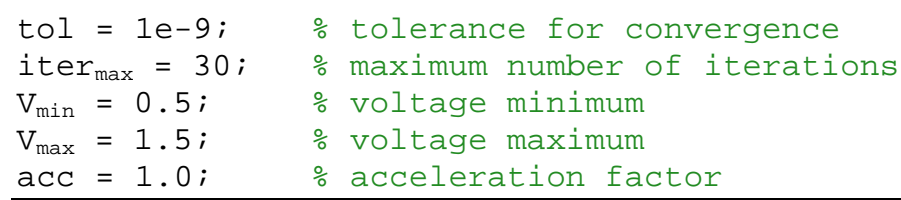




\section{APPENDIX A}

\section{A.1.2 IEEE 14 Bus System Load Flow Data.}

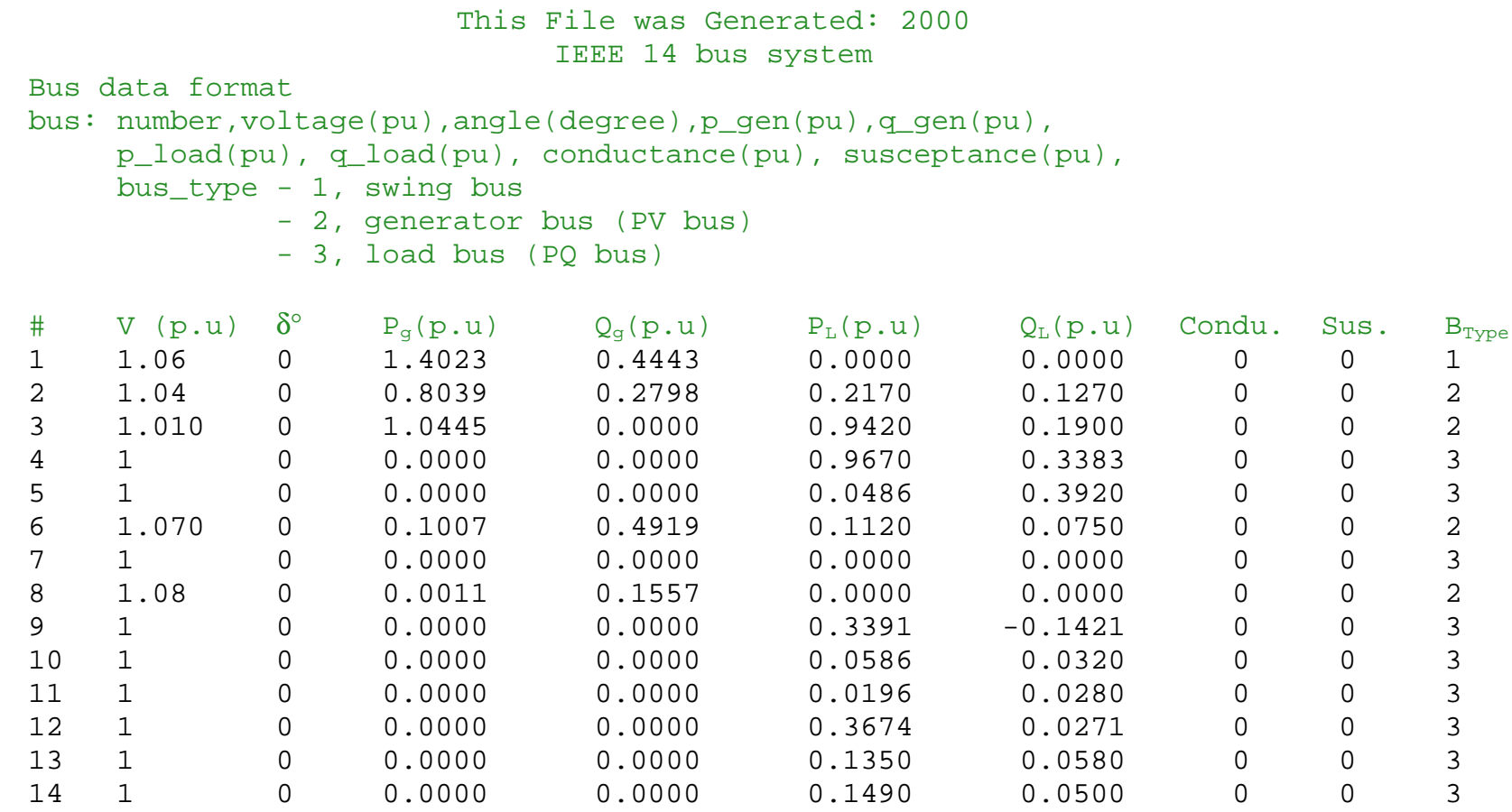

Line data format

line: from bus, to bus, resistance(pu), reactance(pu), line charging(pu), tap ratio, phase shift(deg)

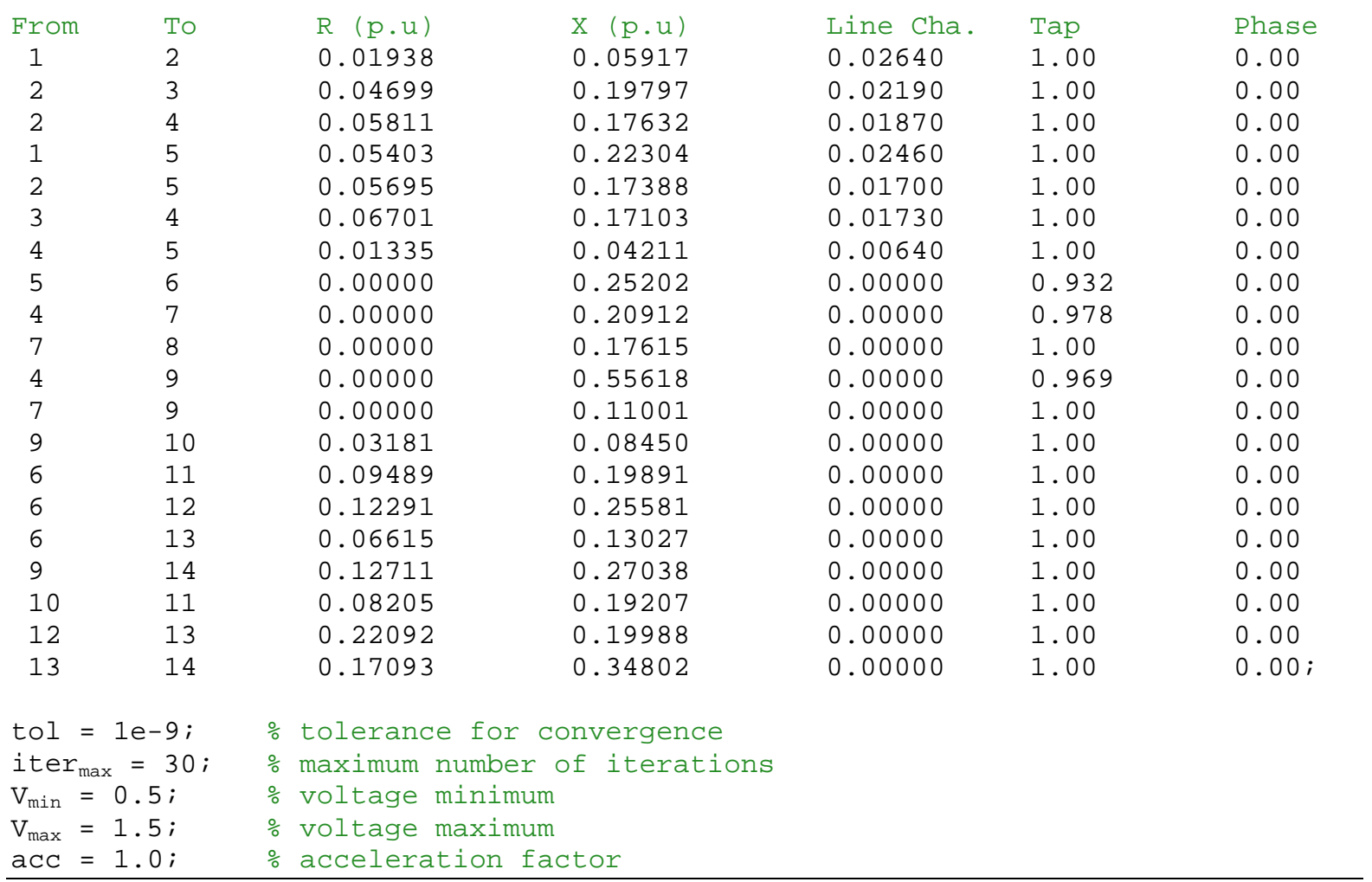




\section{APPENDIX A}

\section{A.1.3 IEEE 30 Bus System Load Flow Data.}

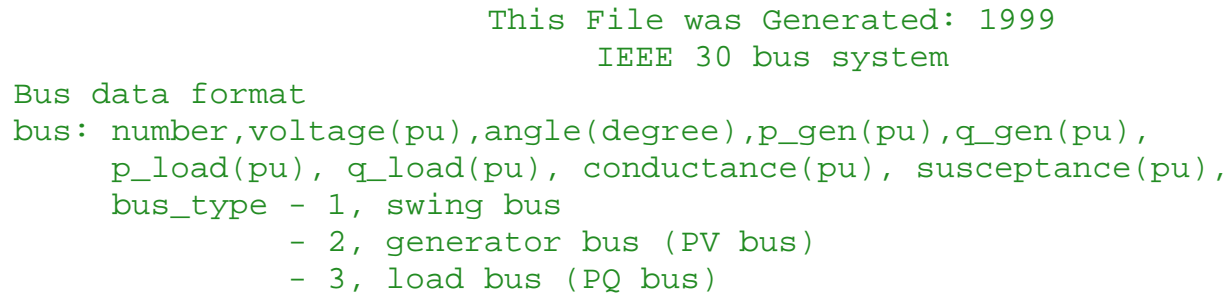

$\begin{array}{ll}\# & V(p \cdot u) \\ 1 & 1.06 \\ 2 & 1.043 \\ 3 & 1 \\ 4 & 1 \\ 5 & 1.01 \\ 6 & 1 \\ 7 & 1 \\ 8 & 1.01 \\ 9 & 1 \\ 10 & 1 \\ 11 & 1.082 \\ 12 & 1 \\ 13 & 1.071 \\ 14 & 1 \\ 15 & 1 \\ 16 & 1 \\ 17 & 1 \\ 18 & 1 \\ 19 & 1 \\ 20 & 1 \\ 21 & 1 \\ 22 & 1 \\ 23 & 1 \\ 24 & 1 \\ 25 & 1 \\ 26 & 1 \\ 27 & 1 \\ 28 & 1 \\ 29 & 1 \\ 30 & 1 \\ & \end{array}$

\begin{tabular}{|c|c|}
\hline$\delta^{\circ}$ & $P_{g}(p \cdot u)$ \\
\hline 0 & 0 \\
\hline 0 & 0.4 \\
\hline 0 & 0 \\
\hline 0 & 0 \\
\hline 0 & 0 \\
\hline 0 & 0 \\
\hline 0 & 0 \\
\hline 0 & 0 \\
\hline 0 & 0 \\
\hline 0 & 0 \\
\hline 0 & 0 \\
\hline 0 & 0 \\
\hline 0 & 0 \\
\hline 0 & 0 \\
\hline 0 & 0 \\
\hline 0 & 0 \\
\hline 0 & 0 \\
\hline 0 & 0 \\
\hline 0 & 0 \\
\hline 0 & 0 \\
\hline 0 & 0 \\
\hline 0 & 0 \\
\hline 0 & 0 \\
\hline 0 & 0 \\
\hline 0 & 0 \\
\hline 0 & 0 \\
\hline 0 & 0 \\
\hline 0 & 0 \\
\hline 0 & 0 \\
\hline 0 & 0 \\
\hline
\end{tabular}

$Q_{g}(p \cdot u)$
0
0
0
0
0
0
0
0
0
0
0
0
0
0
0
0
0
0
0
0
0
0
0
0
0
0
0
0
0
0

0
0
0
0
0
0
0
0
0
0
0
0
0

$P_{\mathrm{L}}(\mathrm{p} . u)$
0.000
0.217
0.024
0.076
0.942
0.000
0.228
0.300
0.000
0.058
0.000
0.112
0.000
0.062
0.082
0.035
0.090
0.032
0.095
0.022
0.175
0.000
0.032
0.087
0.000
0.035
0.000
0.000
0.024
0.106

$\mathrm{Q}_{\mathrm{L}}(\mathrm{p} \cdot \mathrm{u})$ Condu. Sus.

0.000

0.127

0.012

0.016

0.190

0.000

0.109

0.300

0.000

0.020

0.000

0.075

0.000

0.016

0.025

0.018

0.058

0.009

0.034

0.007

0.112

0.000

0.016

0.067

0.000

0.023

0.000

0.000

0.009

0.019

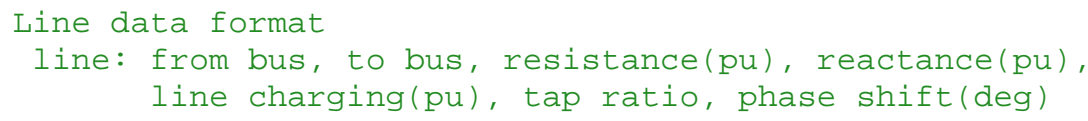

$\begin{array}{lllllll}\text { From } & \text { To } & \mathrm{R}(\mathrm{p} . \mathrm{u}) & \mathrm{X}(\mathrm{p} . \mathrm{u}) & \text { Line Cha. } & \text { Tap } & \text { Phase } \\ 1 & 2 & 0.019200 & 0.057500 & 0.026400 & 1.00 & 0.00 \\ 1 & 3 & 0.045200 & 0.185200 & 0.020400 & 1.00 & 0.00 \\ 2 & 4 & 0.013200 & 0.037900 & 0.004200 & 1.00 & 0.00 \\ 2 & 5 & 0.047200 & 0.198300 & 0.020900 & 1.00 & 0.00 \\ 2 & 6 & 0.058100 & 0.176300 & 0.018700 & 1.00 & 0.00 \\ 4 & 6 & 0.011900 & 0.041400 & 0.004500 & 1.00 & 0.00\end{array}$




\section{APPENDIX A}

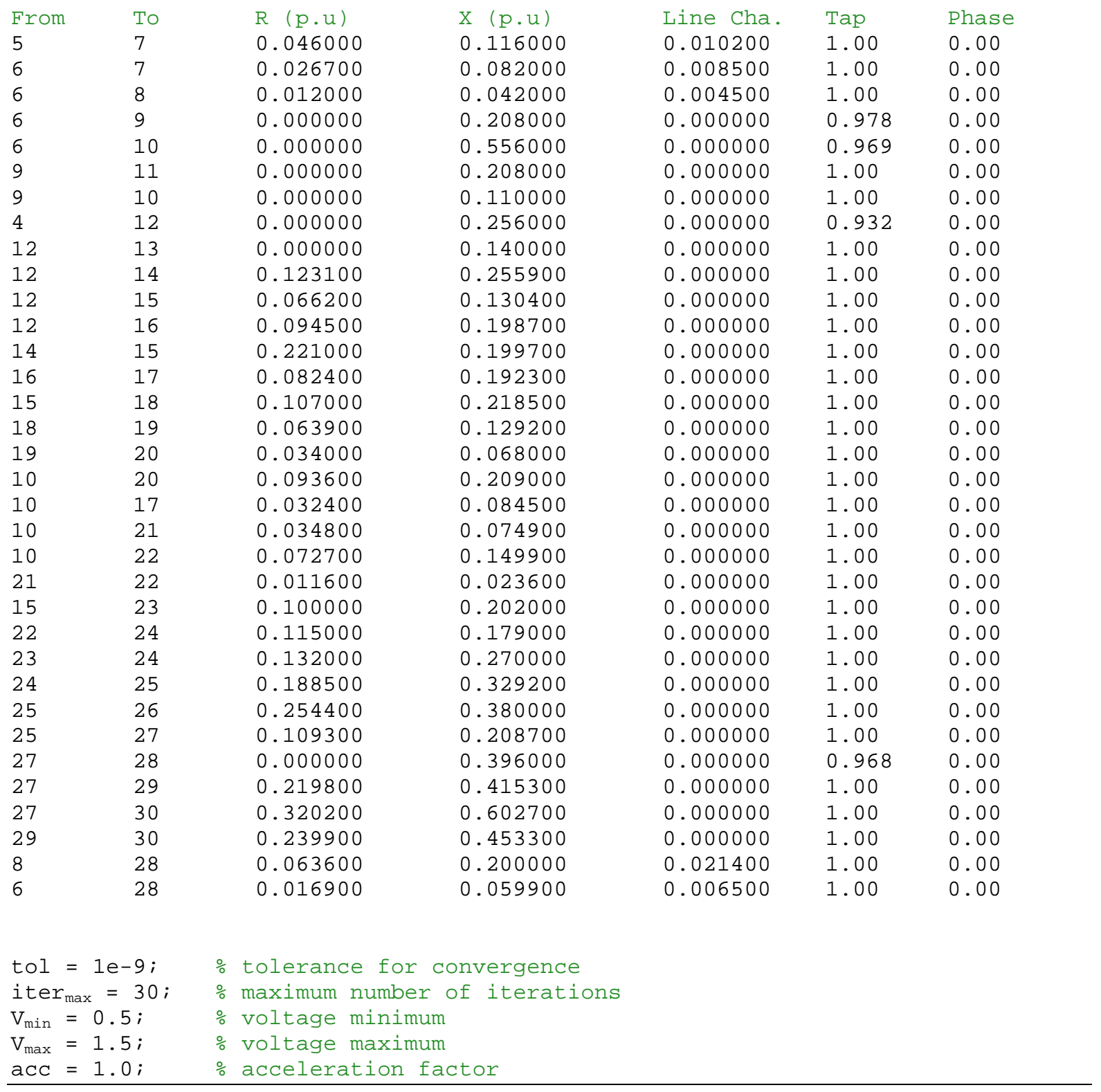




\title{
A.2 Load Flow Solution.
}

\section{A.2.1 WSCC system Load Flow Solution with Constant Load Model.}

\author{
LOAD-FLOW STUDY \\ REPORT OF POWER FLOW CALCULATIONS \\ 07-Sep-2000
}

\begin{tabular}{|c|c|c|c|c|c|c|c|}
\hline \multicolumn{4}{|c|}{ SWING BUS } & \multicolumn{4}{|l|}{ : BUS 1} \\
\hline \multicolumn{4}{|c|}{ NUMBER OF ITERATIONS } & \multicolumn{4}{|l|}{$: 5$} \\
\hline \multicolumn{4}{|c|}{ SOLUTION TIME } & \multicolumn{4}{|c|}{$: 0.16 \mathrm{sec}$} \\
\hline \multicolumn{4}{|c|}{ TOTAL TIME } & \multicolumn{4}{|c|}{$: 0.381$ sec. } \\
\hline \multirow{3}{*}{ TOTAL } & \multicolumn{3}{|c|}{ REAL POWER LOSSES } & \multicolumn{2}{|c|}{$: 0.0463789$. } & & \\
\hline & \multicolumn{3}{|c|}{ REACTIVE POWER LOSSES } & \multicolumn{4}{|c|}{-0.922664} \\
\hline & \multirow{2}{*}{\multicolumn{2}{|c|}{ VOLTS }} & & \multicolumn{2}{|c|}{ GENERATION } & \multicolumn{2}{|c|}{ LOAD } \\
\hline BUS & & & ANGLE & REAL & REACTIVE & REAL & REACTIVE \\
\hline 1 & & .040 & 0.000 & 0.716 & 0.268 & 0.000 & 0.000 \\
\hline 2 & & .025 & 9.272 & 1.630 & 0.067 & 0.000 & 0.000 \\
\hline 3 & & .025 & 4.659 & 0.850 & -0.108 & 0.000 & 0.000 \\
\hline 4 & & .026 & -2.216 & 0.000 & 0.000 & 0.000 & 0.000 \\
\hline 5 & & .996 & -3.988 & 0.000 & 0.000 & 1.250 & 0.500 \\
\hline 6 & & .013 & -3.687 & 0.000 & 0.000 & 0.900 & 0.300 \\
\hline 7 & & .026 & 3.715 & 0.000 & 0.000 & -0.000 & -0.000 \\
\hline 8 & & .016 & 0.724 & 0.000 & 0.000 & 1.000 & 0.350 \\
\hline \multirow[t]{2}{*}{9} & & .033 & 1.962 & 0.000 & 0.000 & -0.000 & -0.000 \\
\hline & & LINE & FLOWS & & & & \\
\hline LINE & FROM & BUS & TO BUS & REAL & REACTIVE & & \\
\hline 1 & & 2 & 7 & 1.630 & 0.067 & & \\
\hline 1 & & 7 & 2 & -1.630 & 0.091 & & \\
\hline 2 & & 7 & 8 & 0.764 & -0.008 & & \\
\hline 2 & & 8 & 7 & -0.759 & -0.107 & & \\
\hline 3 & & 7 & 5 & 0.866 & -0.083 & & \\
\hline 3 & & 5 & 7 & -0.843 & -0.114 & & \\
\hline 4 & & 5 & 4 & -0.407 & -0.386 & & \\
\hline 4 & & 4 & 5 & 0.409 & 0.228 & & \\
\hline 5 & & 4 & 1 & -0.716 & -0.237 & & \\
\hline 5 & & 1 & 4 & 0.716 & 0.268 & & \\
\hline 6 & & 4 & 6 & 0.307 & 0.009 & & \\
\hline 6 & & 6 & 4 & -0.305 & -0.165 & & \\
\hline 7 & & 6 & 9 & -0.595 & -0.135 & & \\
\hline 7 & & 9 & 6 & 0.608 & -0.180 & & \\
\hline 8 & & 9 & 3 & -0.850 & 0.149 & & \\
\hline 8 & & 3 & 9 & 0.850 & -0.108 & & \\
\hline 9 & & 9 & 8 & 0.242 & 0.031 & & \\
\hline 9 & & 8 & 9 & -0.241 & -0.243 & & \\
\hline
\end{tabular}




\title{
APPENDIX A
}

\section{A.2.2 IEEE 14 Bus System Load Flow Solution with Constant Load Model.}

\author{
LOAD-FLOW STUDY \\ REPORT OF POWER FLOW CALCULATIONS \\ 07-Sep-2000
}

\begin{tabular}{|c|c|}
\hline SWING BUS & : BUS 1 \\
\hline NUMBER OF ITERATIONS & $: 5$ \\
\hline SOLUTION TIME & $: 0.13$ sec. \\
\hline TOTAL TIME & $: 0.401$ sec. \\
\hline TOTAL REAL POWER LOSSES & $: 0.111425$ \\
\hline
\end{tabular}

\begin{tabular}{cccccrr} 
& & & \multicolumn{2}{c}{ GENERATION } & \multicolumn{2}{c}{ LOAD } \\
BUS & VOLTS & ANGLE & REAL & REACTIVE & REAL & REACTIVE \\
1 & 1.060 & 0.000 & 1.517 & 0.308 & 0.000 & 0.000 \\
2 & 1.040 & -2.592 & 0.804 & 0.488 & 0.217 & 0.127 \\
3 & 1.010 & -5.150 & 1.045 & 0.133 & 0.942 & 0.190 \\
4 & 0.979 & -8.522 & 0.000 & 0.000 & 0.967 & 0.338 \\
5 & 0.983 & -7.188 & 0.000 & 0.000 & 0.049 & 0.392 \\
6 & 1.070 & -14.551 & 0.101 & 0.388 & 0.112 & 0.075 \\
7 & 1.046 & -12.332 & 0.000 & 0.000 & -0.000 & -0.000 \\
8 & 1.080 & -12.322 & 0.001 & 0.209 & 0.000 & 0.000 \\
9 & 1.050 & -14.249 & 0.000 & 0.000 & 0.339 & -0.142 \\
10 & 1.049 & -14.473 & 0.000 & 0.000 & 0.059 & 0.032 \\
11 & 1.056 & -14.534 & 0.000 & 0.000 & 0.020 & 0.028 \\
12 & 1.024 & -17.614 & 0.000 & 0.000 & 0.367 & 0.027 \\
13 & 1.044 & -16.094 & 0.000 & 0.000 & 0.135 & 0.058 \\
14 & 1.029 & -16.062 & 0.000 & 0.000 & 0.149 & 0.050
\end{tabular}

\begin{tabular}{rrrrr}
\multicolumn{5}{c}{ LINE FLOWS } \\
LINE & FROM BUS & TO BUS & REAL & REACTIVE \\
1 & 1 & 2 & 0.872 & 0.077 \\
1 & 2 & 1 & -0.859 & -0.065 \\
2 & 2 & 3 & 0.261 & 0.089 \\
2 & 3 & 2 & -0.257 & -0.098 \\
3 & 2 & 4 & 0.654 & 0.163 \\
3 & 4 & 2 & -0.629 & -0.108 \\
4 & 1 & 5 & 0.644 & 0.231 \\
4 & 5 & 1 & -0.621 & -0.162 \\
5 & 2 & 5 & 0.531 & 0.174 \\
5 & 5 & 2 & -0.515 & -0.141 \\
6 & 3 & 4 & 0.360 & 0.041 \\
6 & 4 & 3 & -0.351 & -0.036 \\
7 & 4 & 5 & -0.510 & 0.069 \\
7 & 5 & 4 & 0.513 & -0.064 \\
8 & 5 & 6 & 0.574 & -0.025 \\
8 & 6 & 5 & -0.574 & 0.100 \\
9 & 4 & 7 & 0.333 & -0.202 \\
9 & 7 & 4 & -0.333 & 0.234 \\
10 & 7 & 8 & -0.001 & -0.202 \\
10 & 8 & 7 & 0.001 & 0.209 \\
11 & 4 & 9 & 0.190 & -0.062 \\
11 & 9 & 4 & -0.190 & 0.083
\end{tabular}




\title{
APPENDIX A
}

\begin{tabular}{rrrrr}
12 & 7 & 9 & 0.334 & -0.031 \\
12 & 9 & 7 & -0.334 & 0.043 \\
13 & 9 & 10 & 0.050 & -0.003 \\
13 & 10 & 9 & -0.050 & 0.003 \\
14 & 6 & 11 & 0.029 & 0.064 \\
14 & 11 & 6 & -0.028 & -0.063 \\
15 & 6 & 12 & 0.263 & 0.070 \\
15 & 12 & 6 & -0.255 & -0.054 \\
16 & 6 & 13 & 0.271 & 0.079 \\
16 & 13 & 6 & -0.267 & -0.070 \\
17 & 9 & 14 & 0.135 & 0.019 \\
17 & 14 & 9 & -0.133 & -0.014 \\
18 & 10 & 11 & -0.009 & -0.035 \\
18 & 11 & 10 & 0.009 & 0.035 \\
19 & 12 & 13 & -0.113 & 0.027 \\
19 & 13 & 12 & 0.115 & -0.024 \\
20 & 13 & 14 & 0.016 & 0.036 \\
20 & 14 & 13 & -0.016 & -0.036 \\
\hline
\end{tabular}

A.2.3 IEEE 30 Bus System Load Flow Solution with Constant Load Model.

\author{
LOAD-FLOW STUDY \\ REPORT OF POWER FLOW CALCULATIONS \\ 07-Sep-2000
}

\begin{tabular}{|c|c|c|c|c|c|c|}
\hline \multicolumn{3}{|c|}{ SWING BUS } & \multicolumn{4}{|l|}{ : BUS 1} \\
\hline \multicolumn{3}{|c|}{ NUMBER OF ITERATIONS } & \multicolumn{4}{|l|}{ : 5} \\
\hline \multicolumn{3}{|c|}{ SOLUTION TIME } & \multicolumn{4}{|c|}{$: 0.17$ sec } \\
\hline \multicolumn{3}{|c|}{ TOTAL TIME } & \multicolumn{4}{|c|}{$: 0.33$ sec. } \\
\hline \multicolumn{3}{|c|}{ TOTAL REAL POWER LOSSES } & \multicolumn{4}{|c|}{ : 0.179697 . } \\
\hline \multirow[t]{2}{*}{ TOTAL } & REACTIVE & POWER LOSSES & \multicolumn{4}{|c|}{$: 0.527394$} \\
\hline & & & \multicolumn{2}{|c|}{ GENERATION } & \multicolumn{2}{|l|}{ LOAD } \\
\hline BUS & VOLTS & ANGLE & REAL & REACTIVE & REAL & REACTIVE \\
\hline 1 & 1.060 & 0.000 & 2.614 & -0.130 & 0.000 & 0.000 \\
\hline 2 & 1.043 & -5.509 & 0.400 & 0.568 & 0.217 & 0.127 \\
\hline 3 & 1.019 & -7.987 & 0.000 & 0.000 & 0.024 & 0.012 \\
\hline 4 & 1.010 & -9.651 & 0.000 & 0.000 & 0.076 & 0.016 \\
\hline 5 & 1.010 & -14.414 & 0.000 & 0.394 & 0.942 & 0.190 \\
\hline 6 & 1.009 & -11.378 & 0.000 & 0.000 & 0.000 & -0.000 \\
\hline 7 & 1.001 & -13.144 & 0.000 & 0.000 & 0.228 & 0.109 \\
\hline 8 & 1.010 & -12.135 & 0.000 & 0.404 & 0.300 & 0.300 \\
\hline 9 & 1.048 & -14.522 & 0.000 & 0.000 & -0.000 & -0.000 \\
\hline 10 & 1.040 & -16.172 & 0.000 & 0.000 & 0.058 & 0.020 \\
\hline 11 & 1.082 & -14.522 & -0.000 & 0.177 & 0.000 & 0.000 \\
\hline 12 & 1.054 & -15.438 & 0.000 & 0.000 & 0.112 & 0.075 \\
\hline 13 & 1.071 & -15.438 & -0.000 & 0.127 & 0.000 & 0.000 \\
\hline 14 & 1.038 & -16.337 & 0.000 & 0.000 & 0.062 & 0.016 \\
\hline 15 & 1.033 & -16.406 & 0.000 & 0.000 & 0.082 & 0.025 \\
\hline 16 & 1.041 & -16.022 & 0.000 & 0.000 & 0.035 & 0.018 \\
\hline 17 & 1.035 & -16.336 & 0.000 & 0.000 & 0.090 & 0.058 \\
\hline 18 & 1.023 & -17.025 & 0.000 & 0.000 & 0.032 & 0.009 \\
\hline
\end{tabular}




\section{APPENDIX A}

\begin{tabular}{|c|c|c|c|c|c|c|}
\hline 19 & 1.020 & -17.200 & 0.000 & 0.000 & 0.095 & 0.034 \\
\hline 20 & 1.024 & -17.001 & 0.000 & 0.000 & 0.022 & 0.007 \\
\hline 21 & 1.025 & -16.616 & 0.000 & 0.000 & 0.175 & 0.112 \\
\hline 22 & 1.025 & -16.600 & 0.000 & 0.000 & -0.000 & -0.000 \\
\hline 23 & 1.018 & -16.767 & 0.000 & 0.000 & 0.032 & 0.016 \\
\hline 24 & 1.006 & -16.901 & 0.000 & 0.000 & 0.087 & 0.067 \\
\hline 25 & 0.983 & -16.279 & 0.000 & 0.000 & 0.000 & -0.000 \\
\hline 26 & 0.964 & -16.729 & 0.000 & 0.000 & 0.035 & 0.023 \\
\hline 27 & 0.977 & -15.626 & 0.000 & 0.000 & -0.000 & 0.000 \\
\hline 28 & 1.008 & -11.984 & 0.000 & 0.000 & -0.000 & -0.000 \\
\hline 29 & 0.956 & -16.978 & 0.000 & 0.000 & 0.024 & 0.009 \\
\hline \multirow[t]{2}{*}{30} & 0.944 & -17.951 & 0.000 & 0.000 & 0.106 & 0.019 \\
\hline & LINE & FLOWS & & & & \\
\hline LINE & FROM BUS & TO BUS & REAL & REACTIVE & & \\
\hline 1 & 1 & 2 & 1.782 & -0.208 & & \\
\hline 1 & 2 & 1 & -1.727 & 0.343 & & \\
\hline 2 & 1 & 3 & 0.832 & 0.078 & & \\
\hline 2 & 3 & 1 & -0.804 & 0.016 & & \\
\hline 3 & 2 & 4 & 0.459 & 0.053 & & \\
\hline 3 & 4 & 2 & -0.448 & -0.038 & & \\
\hline 4 & 3 & 4 & 0.780 & -0.028 & & \\
\hline 4 & 4 & 3 & -0.772 & 0.045 & & \\
\hline 5 & 2 & 5 & 0.832 & 0.028 & & \\
\hline 5 & 5 & 2 & -0.802 & 0.076 & & \\
\hline 6 & 2 & 6 & 0.619 & 0.017 & & \\
\hline 6 & 6 & 2 & -0.599 & 0.026 & & \\
\hline 7 & 4 & 6 & 0.694 & -0.171 & & \\
\hline 7 & 6 & 4 & -0.688 & 0.187 & & \\
\hline 8 & 5 & 7 & -0.140 & 0.128 & & \\
\hline 8 & 7 & 5 & 0.142 & -0.134 & & \\
\hline 9 & 6 & 7 & 0.374 & -0.023 & & \\
\hline 9 & 7 & 6 & -0.370 & 0.025 & & \\
\hline 10 & 6 & 8 & 0.292 & -0.102 & & \\
\hline 10 & 8 & 6 & -0.291 & 0.101 & & \\
\hline 11 & 6 & 9 & 0.285 & -0.071 & & \\
\hline 11 & 9 & 6 & -0.285 & 0.088 & & \\
\hline 12 & 6 & 10 & 0.163 & 0.011 & & \\
\hline 12 & 10 & 6 & -0.163 & 0.003 & & \\
\hline 13 & 9 & 11 & 0.000 & -0.172 & & \\
\hline 13 & 11 & 9 & -0.000 & 0.177 & & \\
\hline 14 & 9 & 10 & 0.285 & 0.084 & & \\
\hline 14 & 10 & 9 & -0.285 & -0.075 & & \\
\hline 15 & 4 & 12 & 0.450 & 0.147 & & \\
\hline 15 & 12 & 4 & -0.450 & -0.098 & & \\
\hline 16 & 12 & 13 & 0.000 & -0.125 & & \\
\hline 16 & 13 & 12 & -0.000 & 0.127 & & \\
\hline 17 & 12 & 14 & 0.081 & 0.028 & & \\
\hline 17 & 14 & 12 & -0.080 & -0.026 & & \\
\hline 18 & 12 & 15 & 0.184 & 0.084 & & \\
\hline 18 & 15 & 12 & -0.181 & -0.079 & & \\
\hline 19 & 12 & 16 & 0.074 & 0.037 & & \\
\hline 19 & 16 & 12 & -0.073 & -0.036 & & \\
\hline 20 & 14 & 15 & 0.018 & 0.010 & & \\
\hline 20 & 15 & 14 & -0.018 & -0.010 & & \\
\hline 21 & 16 & 17 & 0.038 & 0.018 & & \\
\hline 21 & 17 & 16 & -0.038 & -0.017 & & \\
\hline 22 & 15 & 18 & 0.060 & 0.017 & & \\
\hline
\end{tabular}




\section{APPENDIX A}

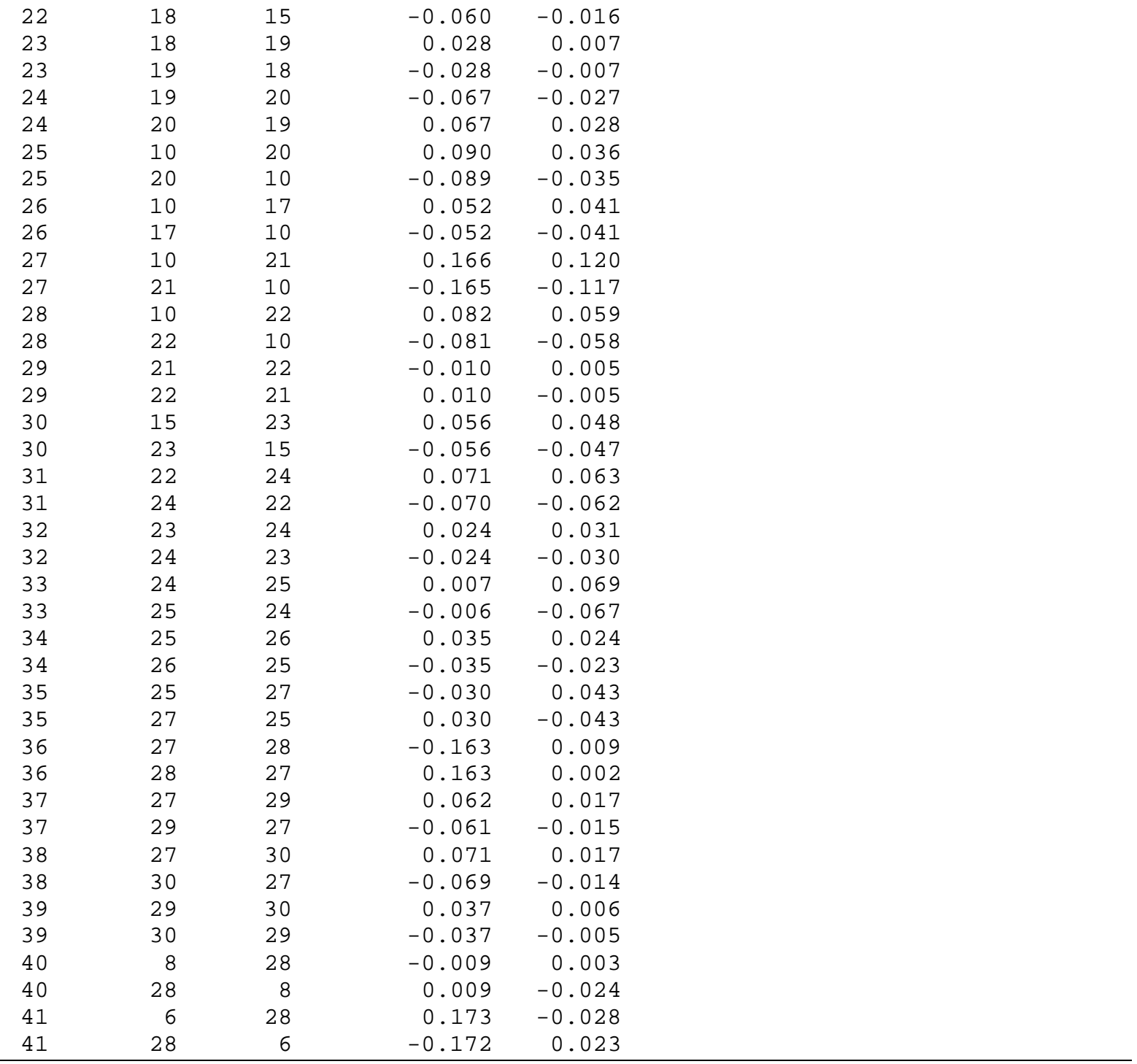




\section{APPENDIX B}

\section{B.1 Analysis Program.}

In this research a load flow program using Matlab is developed to carry out the analysis. The following m-files are built to:

1. Calculate load flow solution and plot out the voltage profile of the test system.

2. Generates the Q-V curves for a selected bus in the system.

3. Calculates of eigenvalues, eigenvectors and participation factor matrix.

4. Include the effect of voltage dependent load models and induction machine load model.

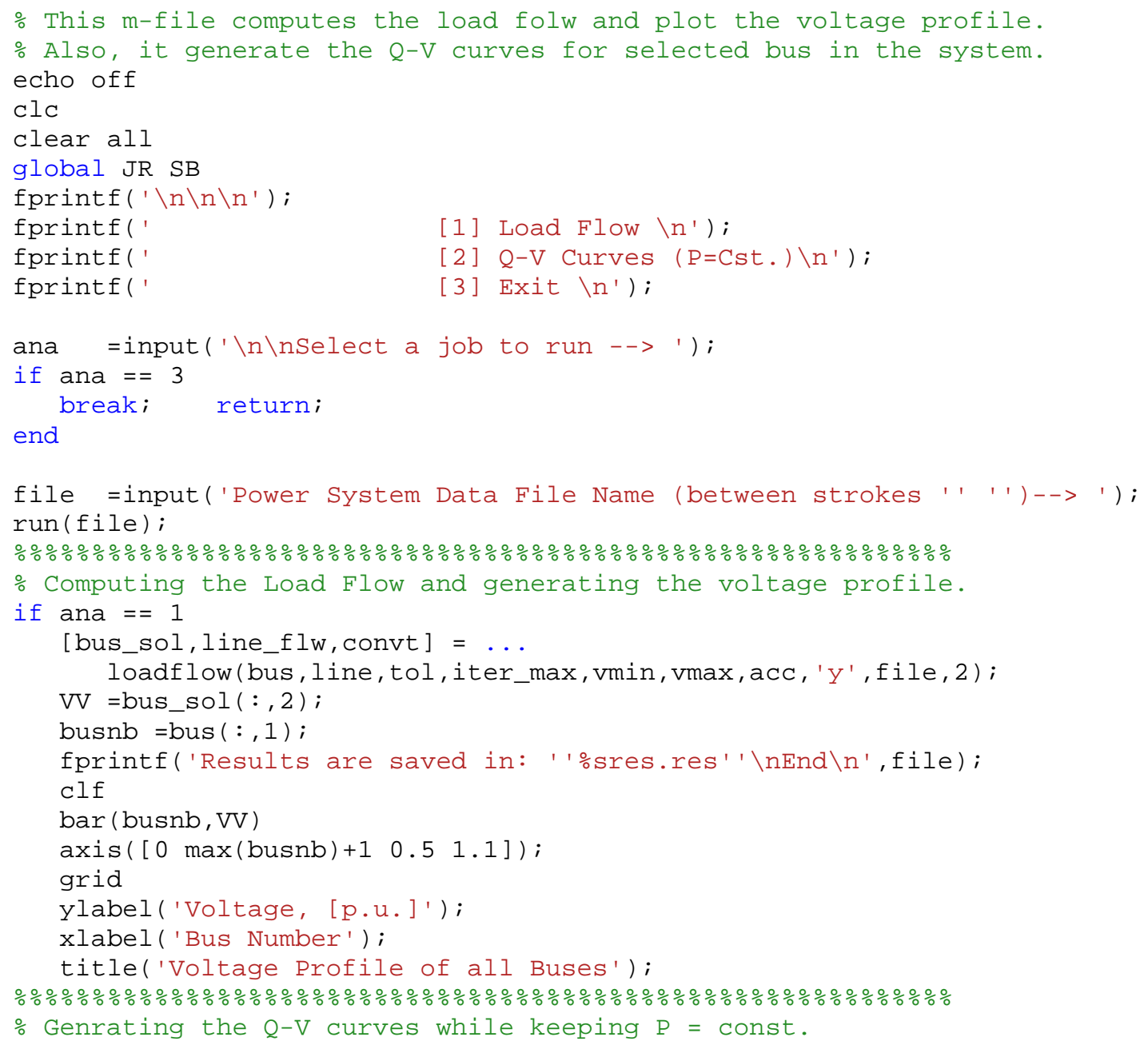




\section{APPENDIX B}

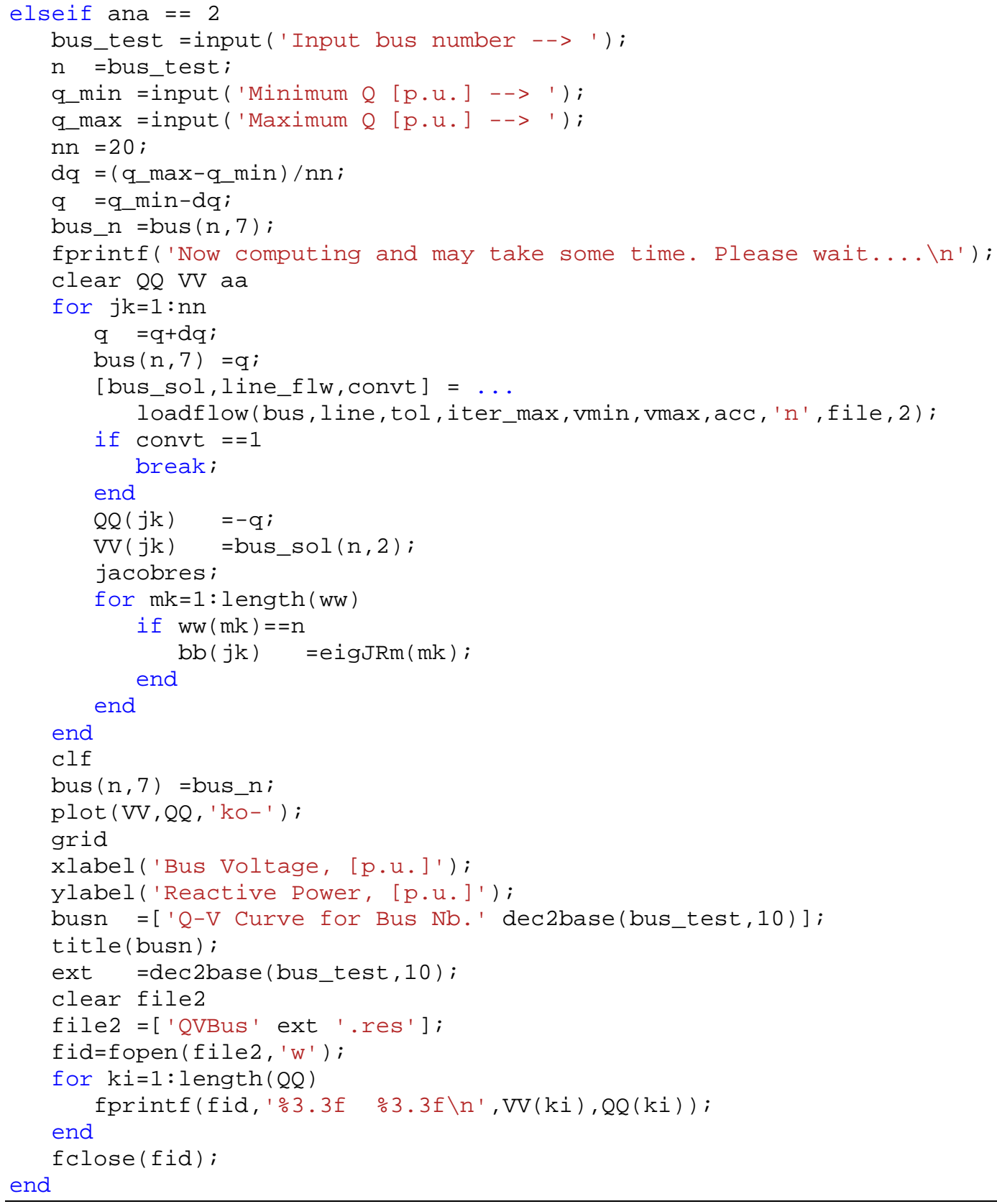




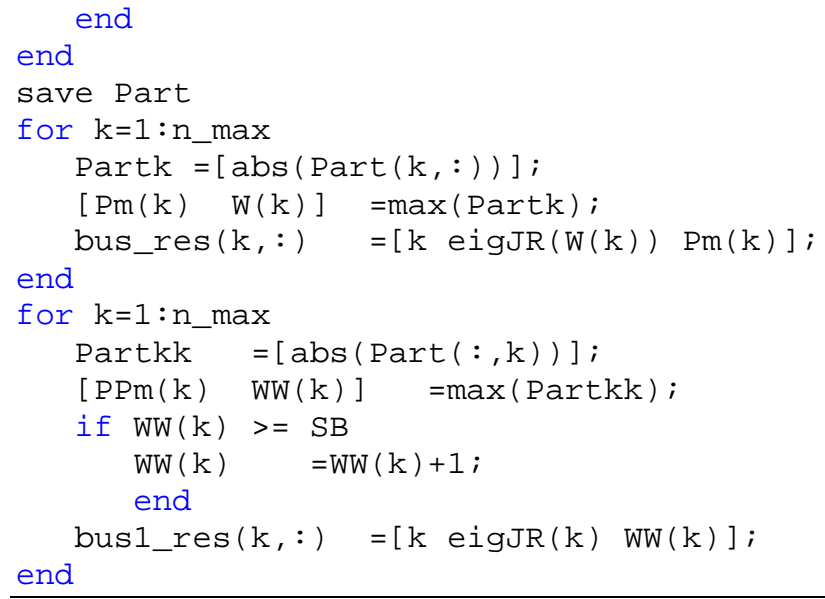




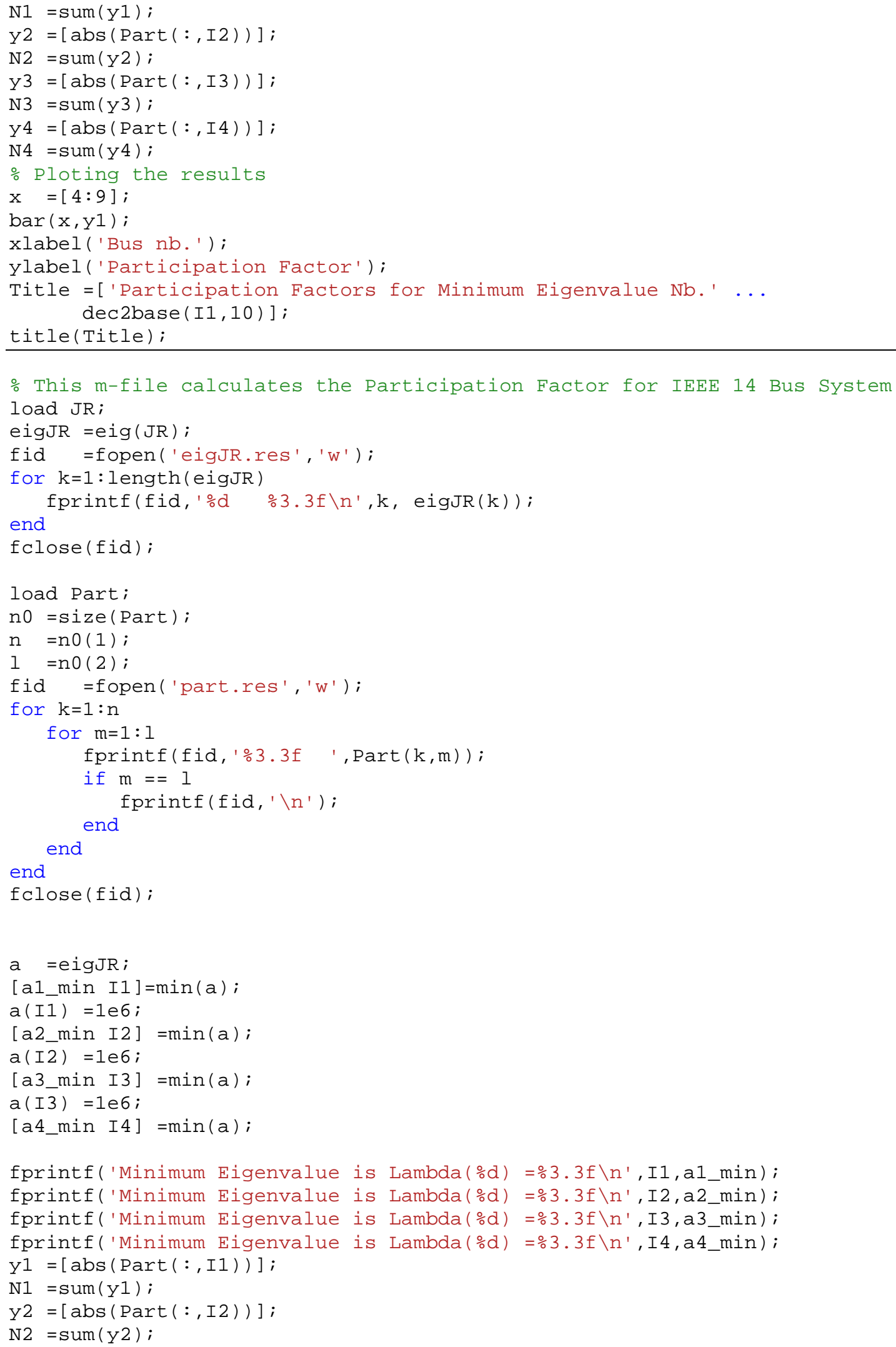




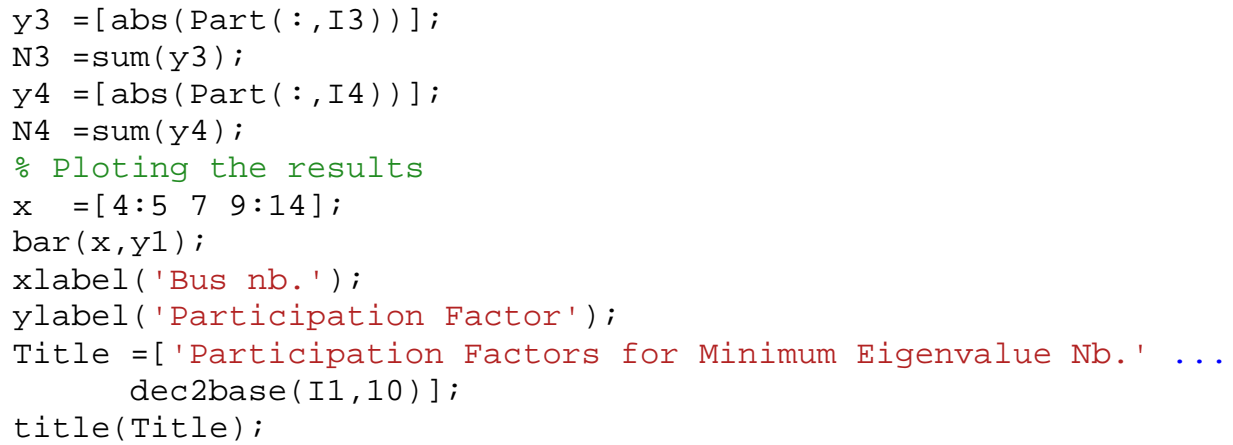




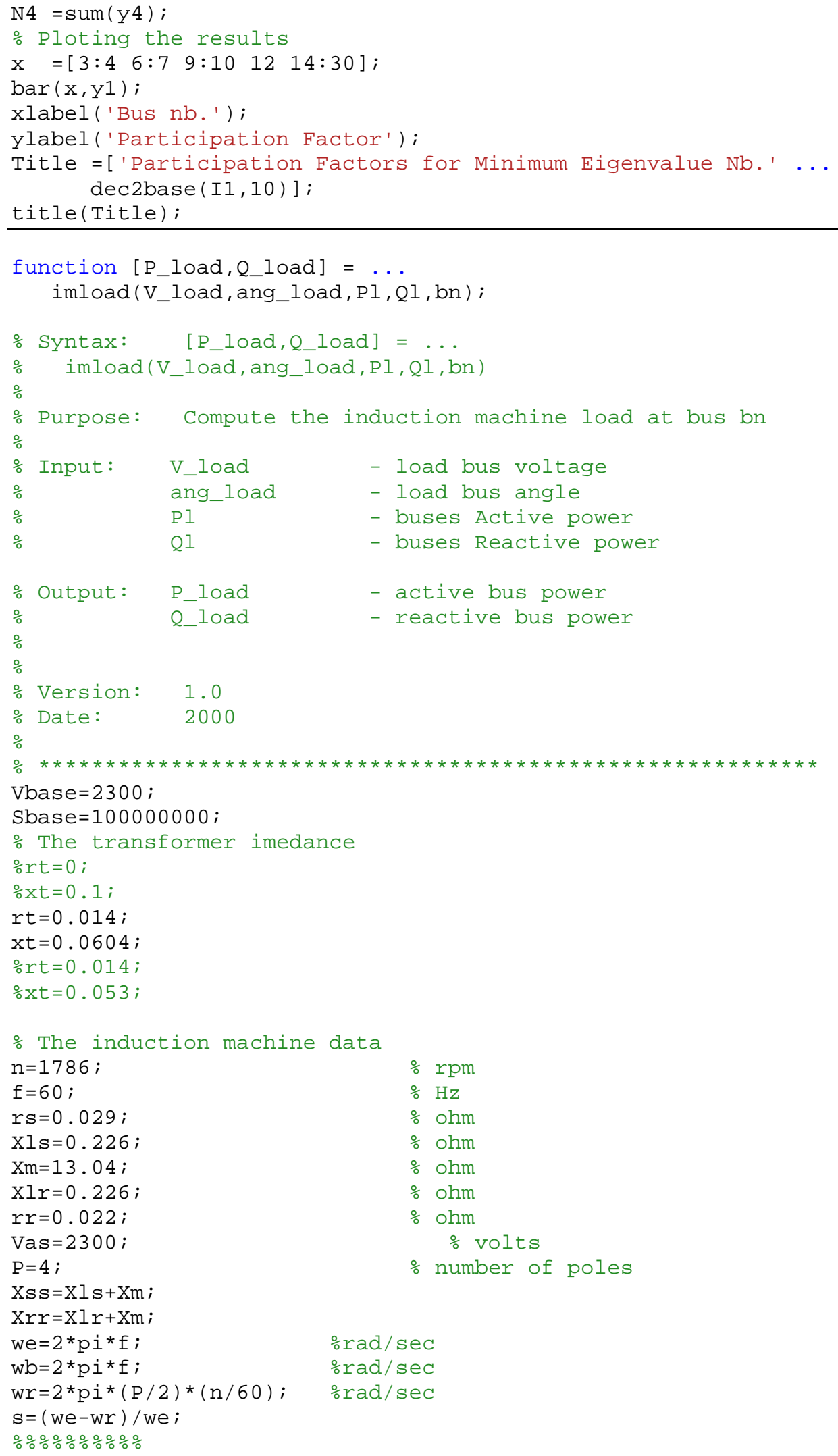




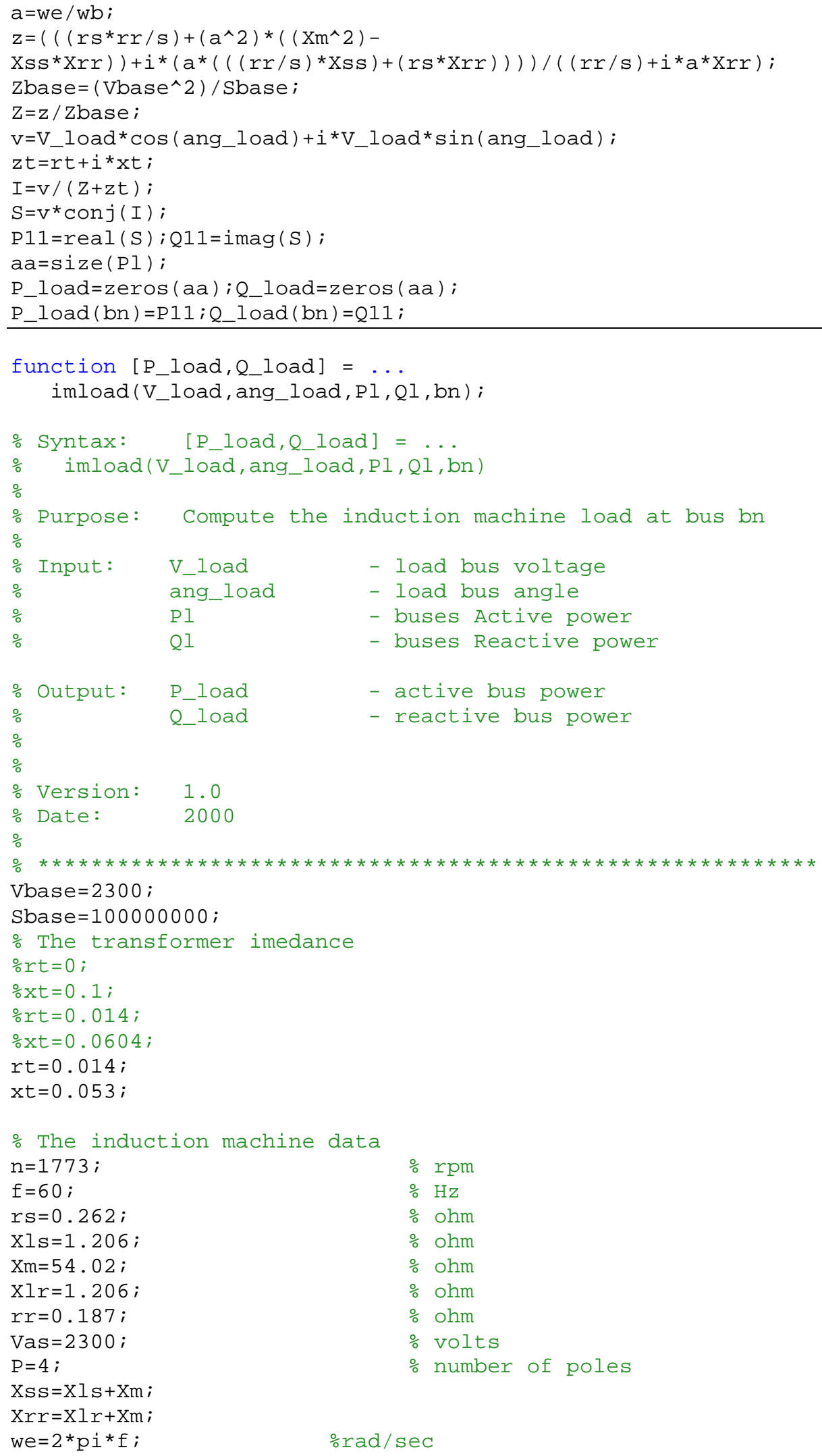




\section{APPENDIX B}

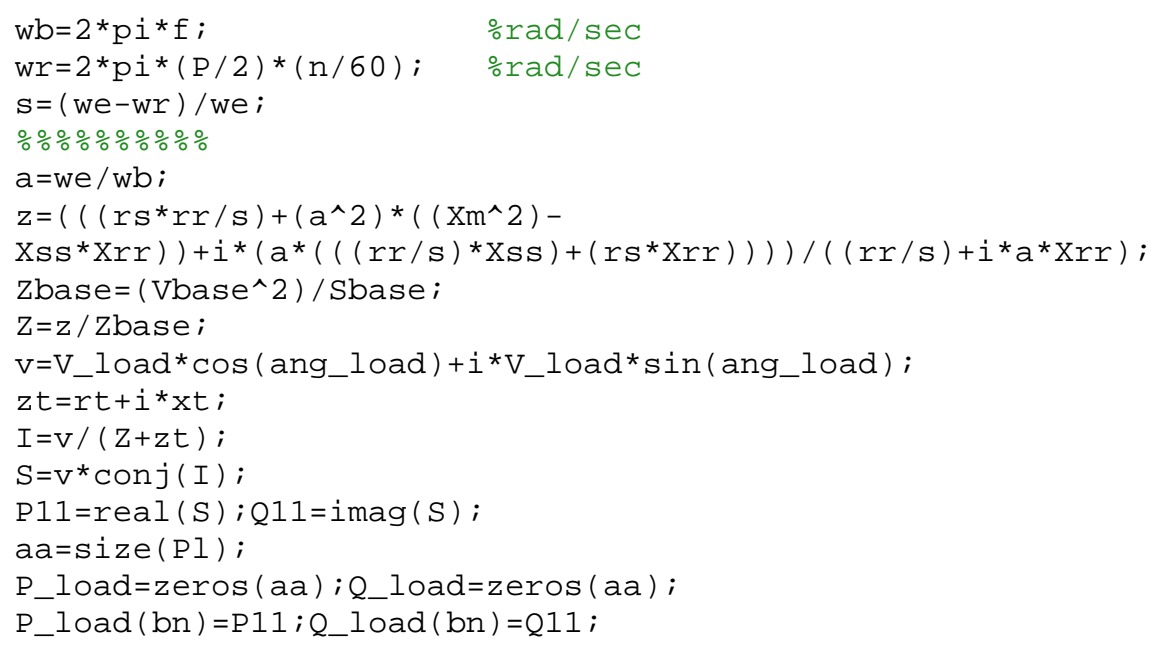




\section{B.2 Load Flow Program}

The load follow program used in the analysis, was found by Kwok W. Cheung, Joe H. Chow in

1991. This program calls the following m-file:

1. loadflow.m

\section{Ybus.m}

3. calc.m

4. form_jac.m

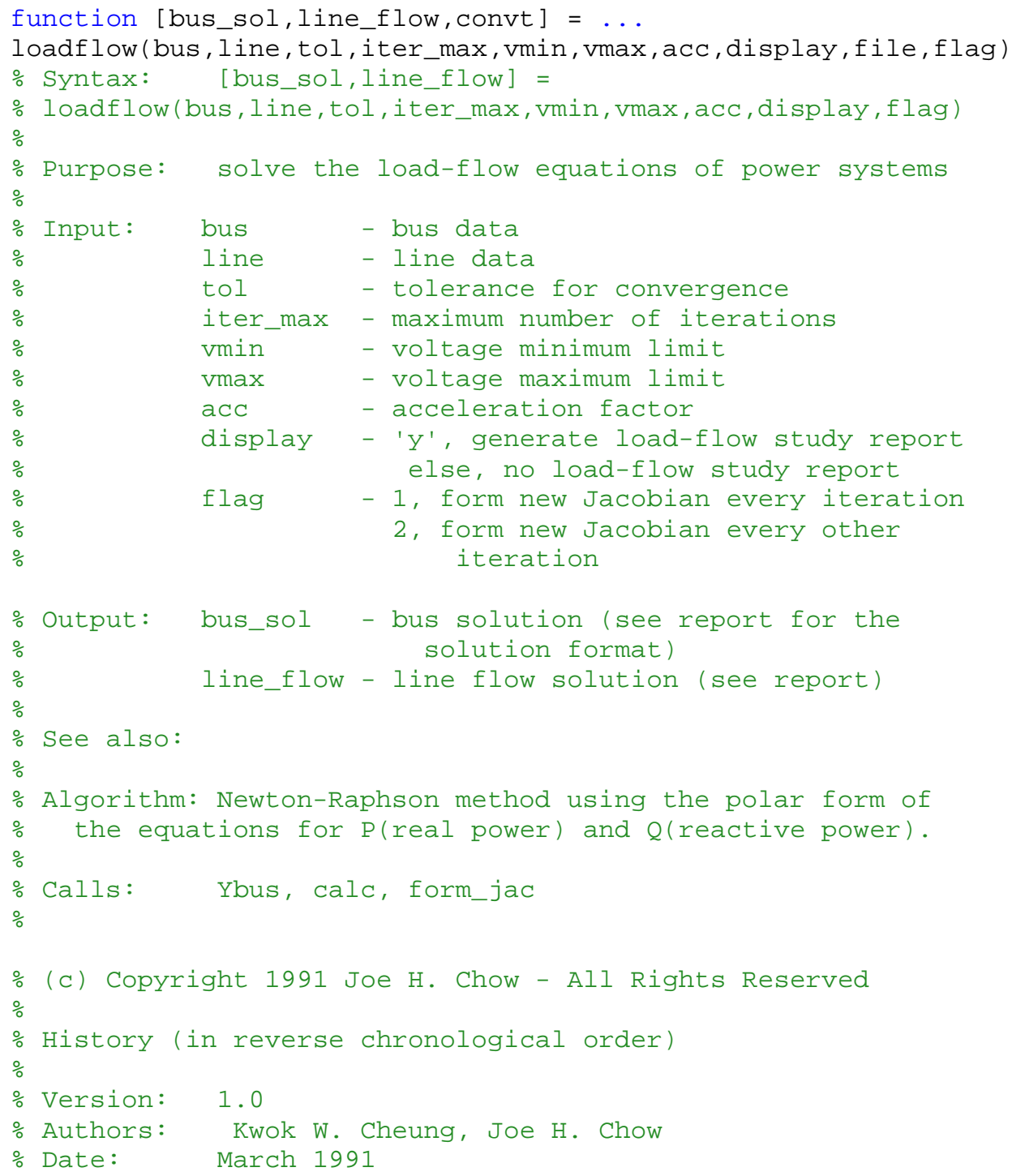




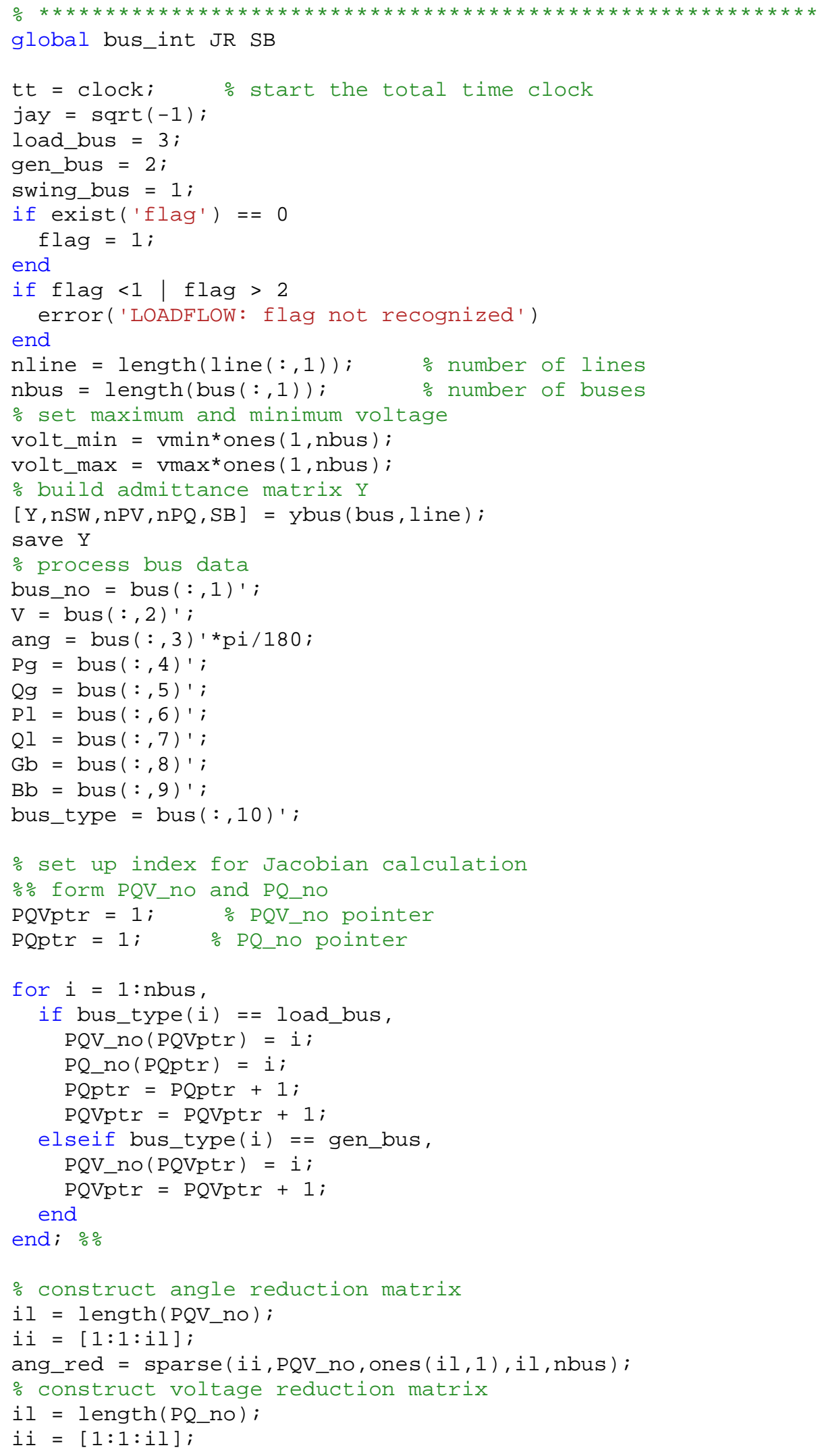




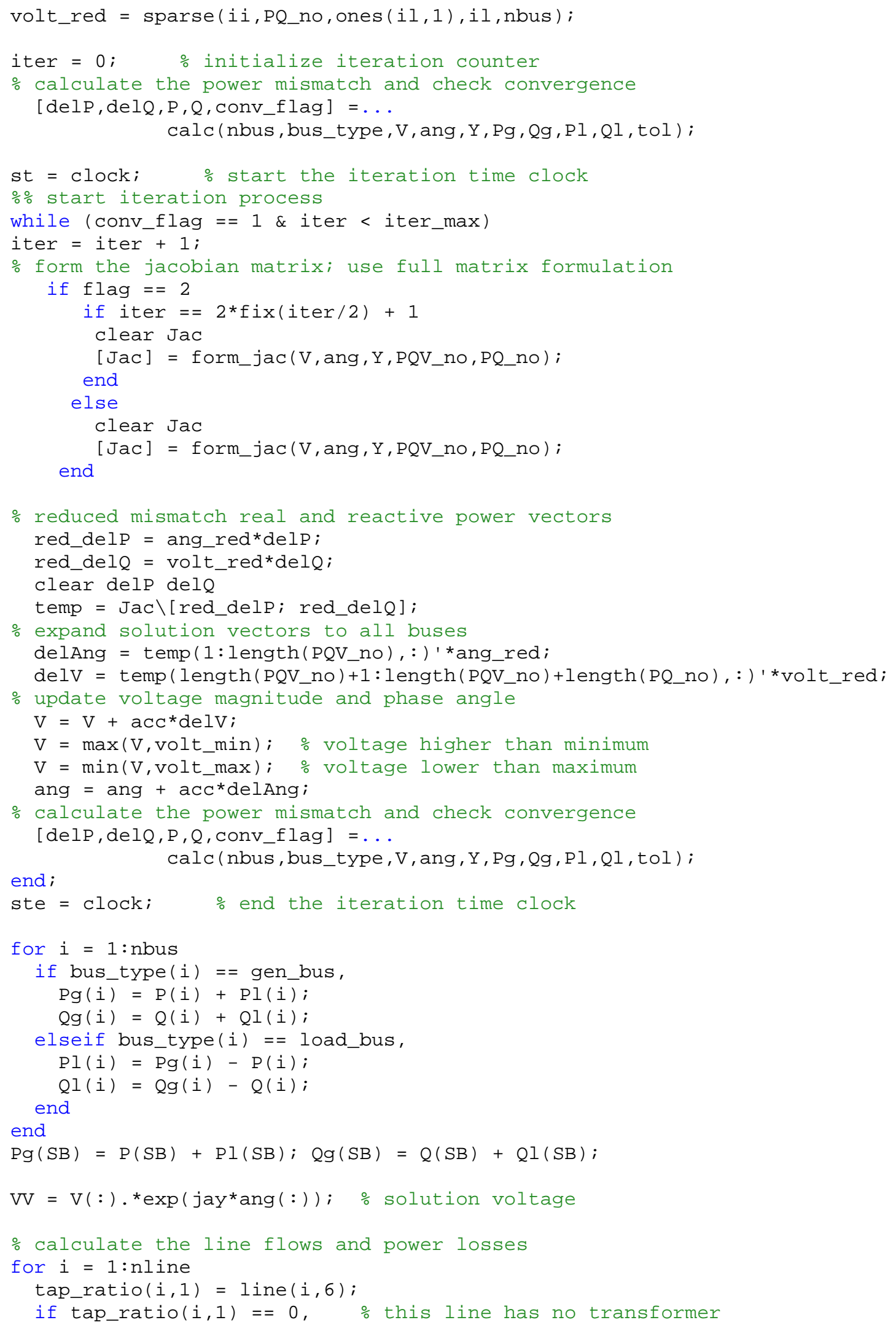




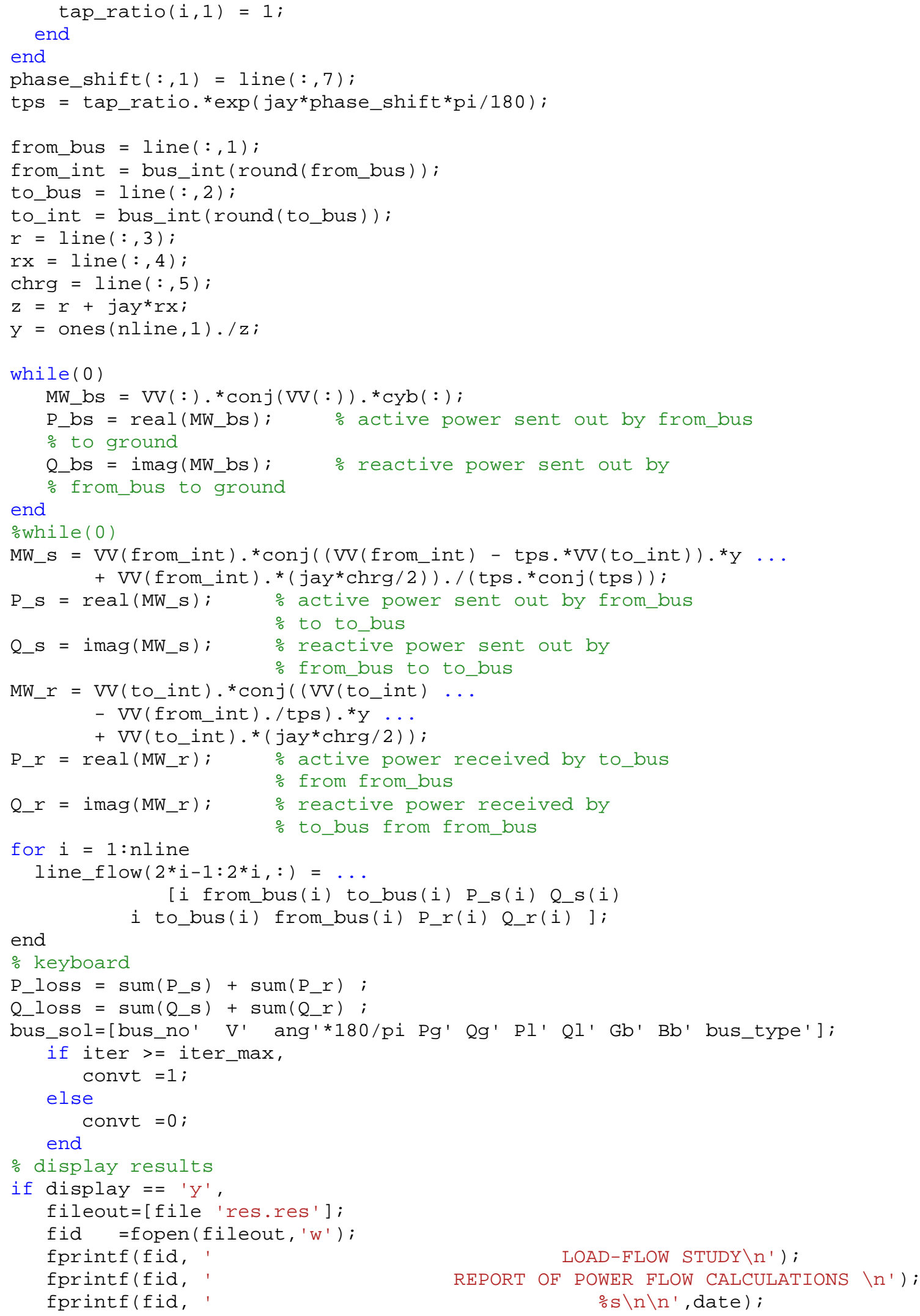



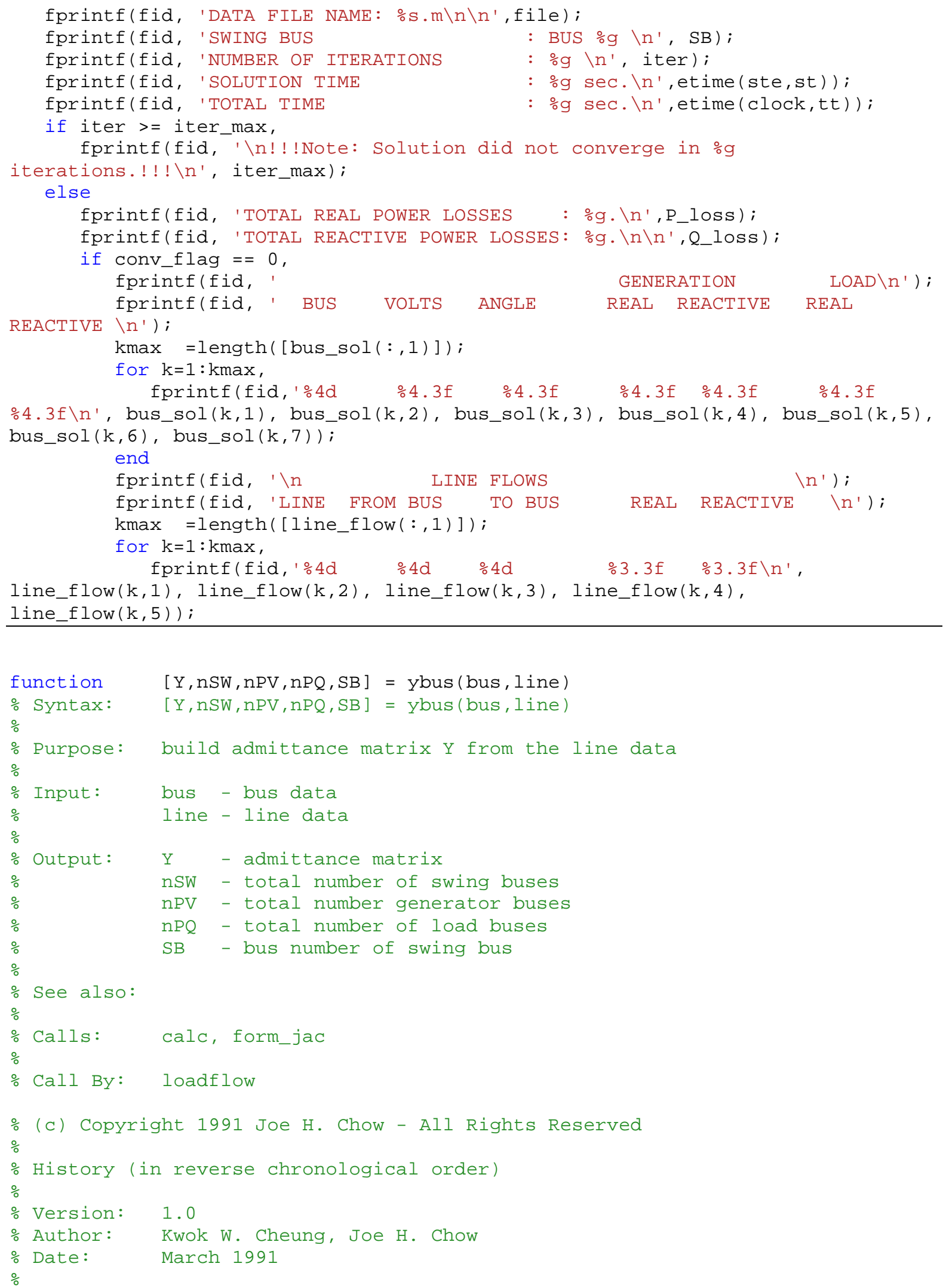


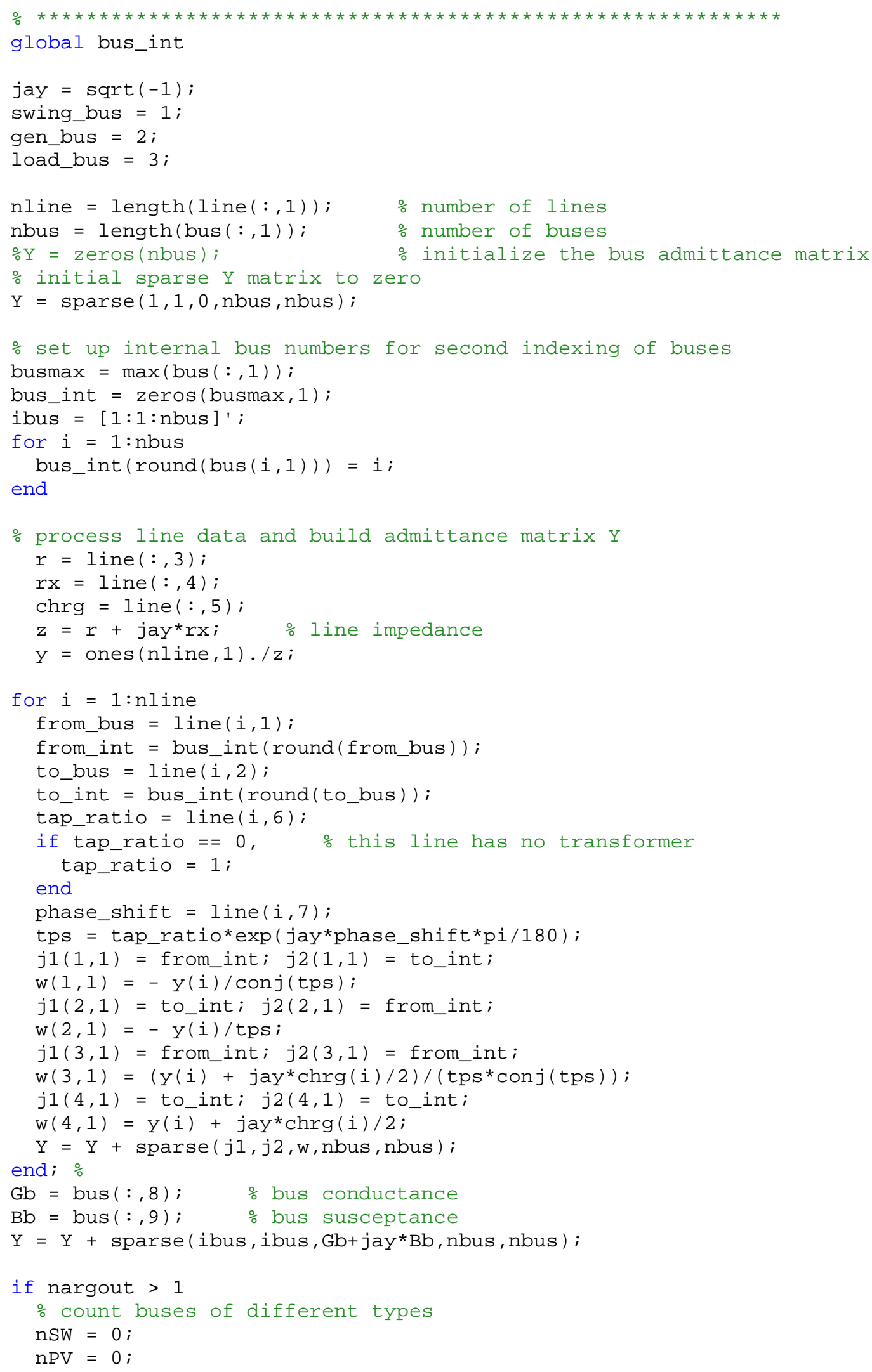




\section{APPENDIX B}

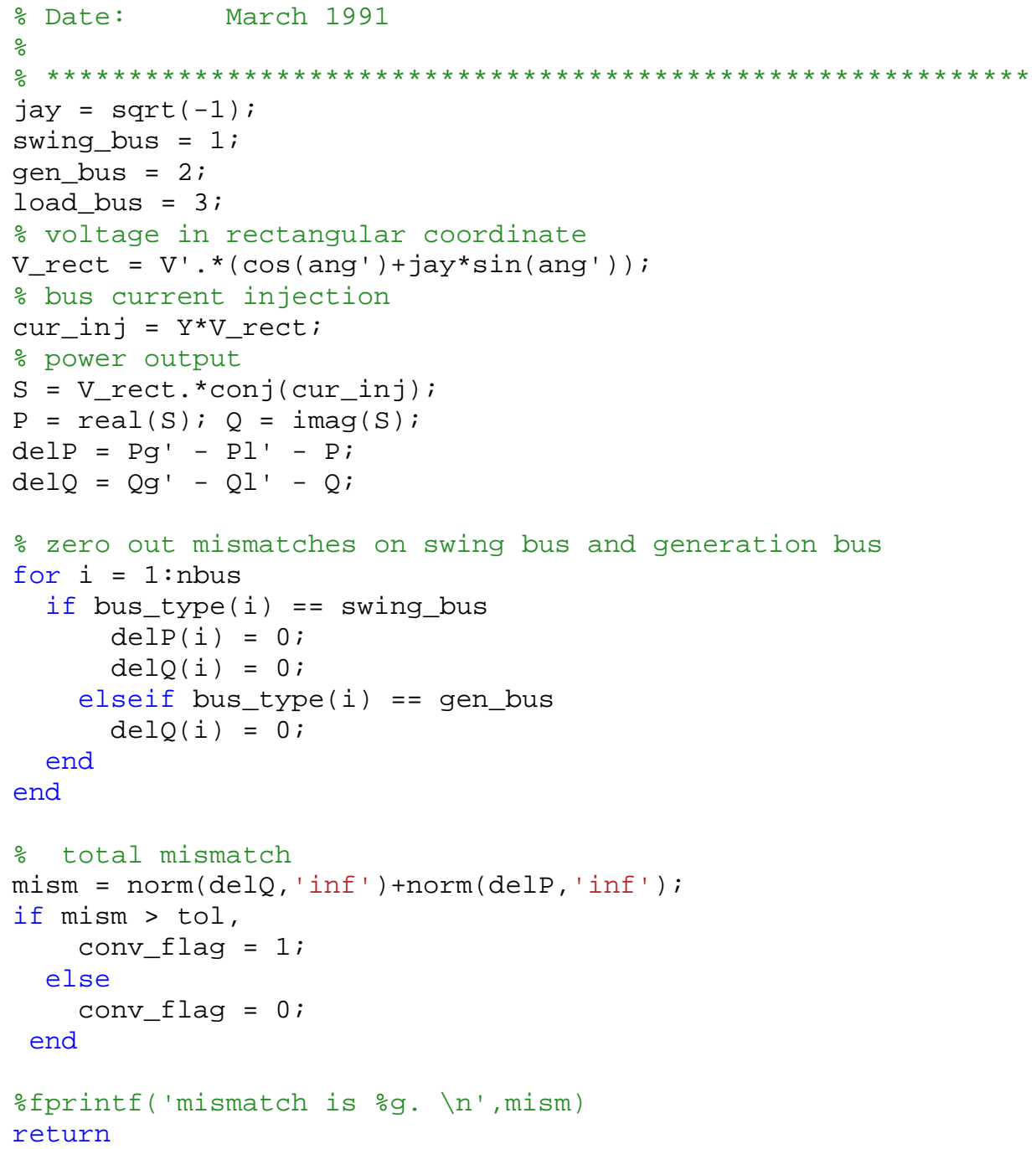




\section{APPENDIX B}

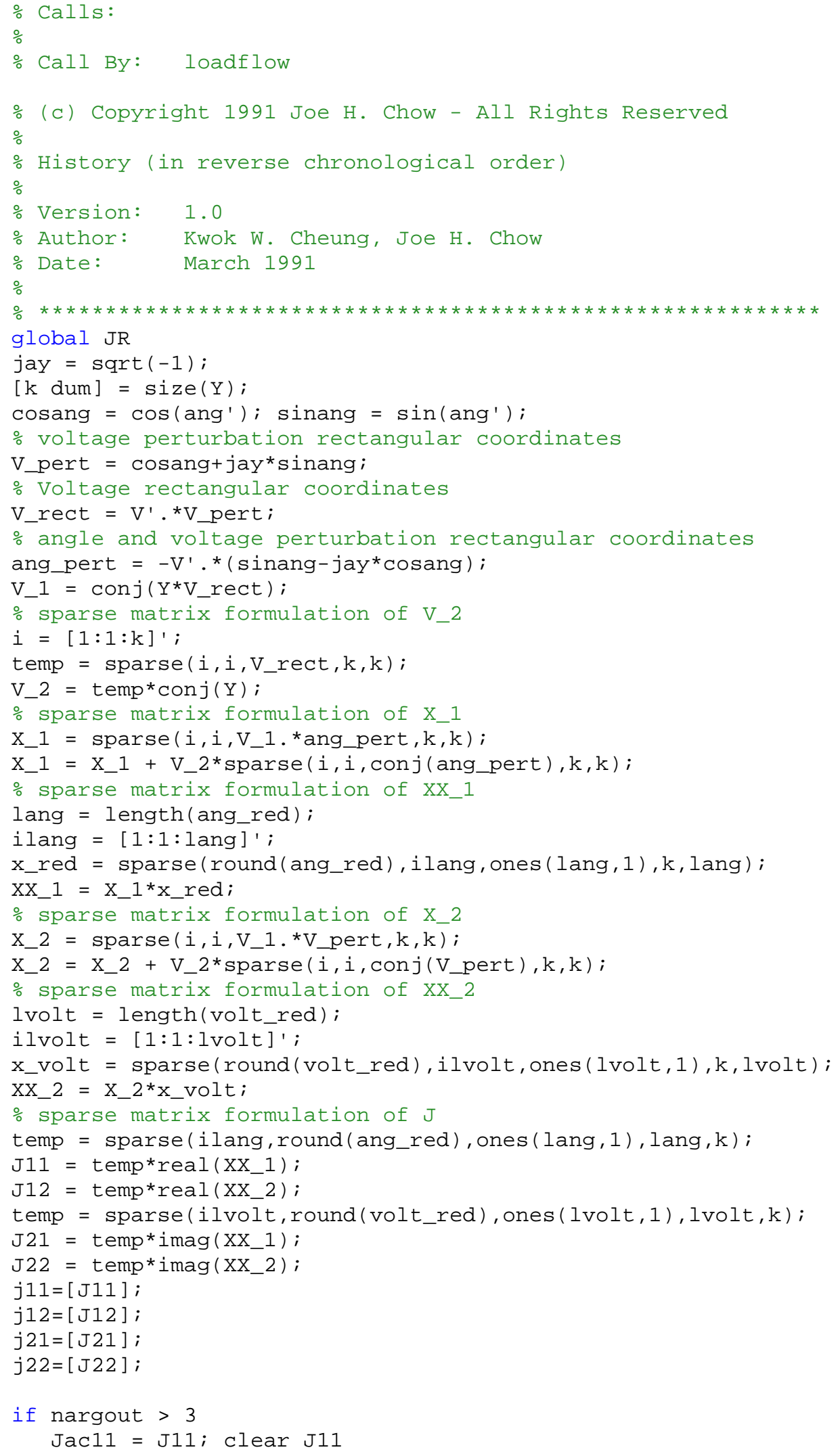




\section{APPENDIX B}

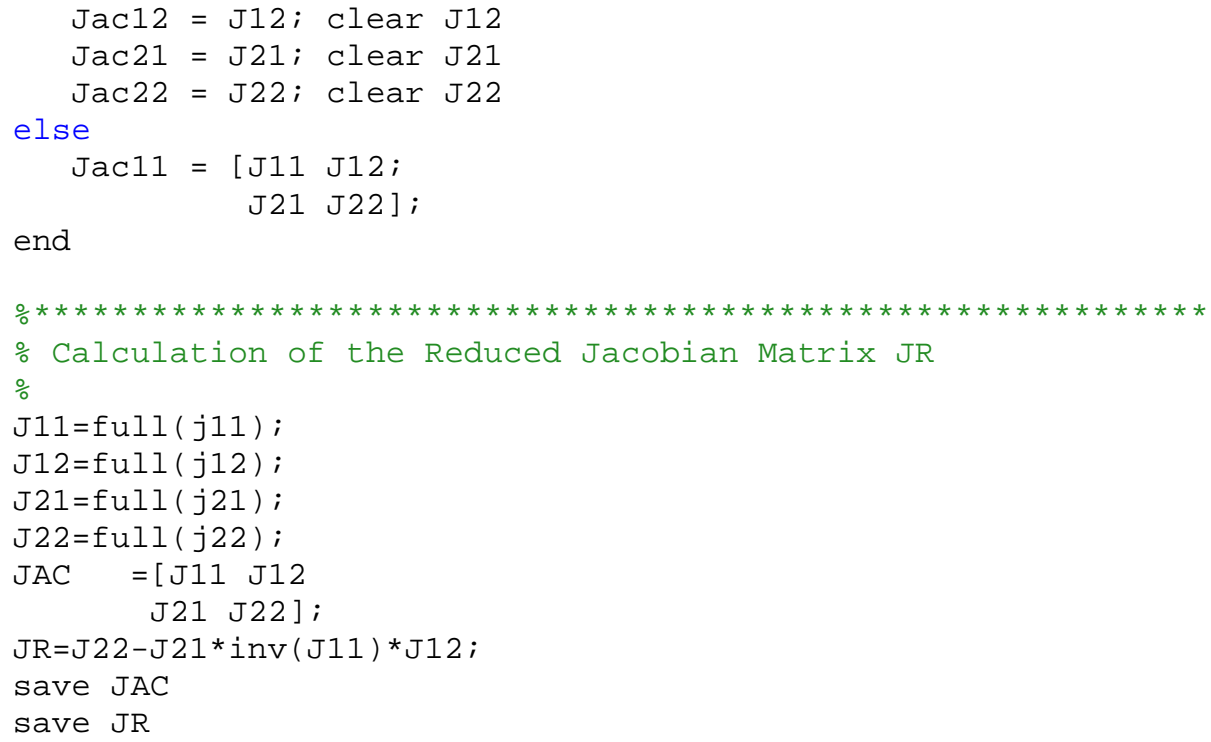

